\title{
Accounting Conservatism
}

\author{
By
}

(Richard) Zhe Wang

A thesis submitted to the Victoria University of Wellington in fulfilment of the requirements for the degree of Doctor of Philosophy in Accounting

Victoria University of Wellington 


\section{Abstract}

This thesis provides an in-depth examination of accounting conservatism, which is one of the oldest and most important principles of accounting (Sterling, 1967; Watts, 2003a). Two main questions relating to accounting conservatism are extensively studied in this thesis: (1) How to measure accounting conservatism? (2) Why do firms adopt accounting conservatism?

This thesis consists of three main chapters that answer these two questions from three different perspectives. The first chapter studies the existing empirical measures of accounting conservatism from a construct validity perspective and concludes that construct validity of the existing measures is mixed to low.

The second chapter examines the validity and bias in the Basu (1997) measure of accounting conservatism - one of the most widely used measure of conservatism in the accounting literature. The second chapter shows, analytically and empirically, that the Basu (1997) measure is biased upwards by the default risk of a firm, and proposes a new measure of conservatism that is free from this bias. This new measure of conservatism is called the "Default-Adjusted-Basu" measure.

The third chapter investigates the economic rationale for accounting conservatism, and proposes a signalling theory for accounting conservatism. In a debt market characterized by information asymmetry, a borrower firm's degree of conservatism can serve as a credible signal about that borrower firm's level of operating risk to the lenders in the debt market. Thus, one potential benefit of accounting conservatism is that it can reduce the degree of information asymmetry in the debt market. 


\section{Acknowledgment}

I am greatly indebted to my supervisors, Professor Tony van Zijl and Professor Ciarán Ó hÓgartaigh, for their invaluable guidance and support. They have played a role in my academic career far beyond that of merely supervising my thesis - they have helped me to become not only a better researcher, but a better person.

Studying at the School of Accounting \& Commercial Law (SACL) of Victoria University of Wellington has been an extremely stimulating and rewarding experience for me. SACL has a tradition of critical thinking and thinking "outside the box", which has a profound influence on the way I conduct my own research. I therefore thank all of the staff and faculty members in SACL, for creating such a stimulating environment of scholarship. I also wish to express my gratitude to SACL for providing me with the SACL PhD scholarship. Special thanks goes to Professor Keitha Dunstan, the former Head of School, who has supported my professional development in many ways.

I am grateful to my fellow PhD students for their friendship, intellectual discussions, and enjoyable BBQs outings. I am especially fortunate to have shared an office with Rahmadi Murwanto, a fellow PhD student, over the last three years. Many interesting discussions with Rahmadi have uplifted my spirit at the most difficult times of my $\mathrm{PhD}$.

Last, but not least, I would like to thank my parents for their endless support throughout my $\mathrm{PhD}$. Without their love, I simply could not have completed this $\mathrm{PhD}$. 


\section{Contents}

$\begin{array}{ll}\text { Abstract } & 1\end{array}$

$\begin{array}{lr}\text { Acknowledgement } & 2\end{array}$

List of Figures

$\begin{array}{ll}\text { List of Tables } & 7\end{array}$

$\begin{array}{lr}\text { General Introduction } & 8\end{array}$

0.1 Background and motivation . . . . . . . . . . 8

0.2 Overview of the chapters . . . . . . . . . . . . . 17

0.3 Contributions of the thesis . . . . . . . . . . 22

1 Measures of Accounting Conservatism: A Construct Validity Perspec$\begin{array}{ll}\text { tive } & 25\end{array}$

1.1 Introduction . . . . . . . . . . . . . 25

1.2 Existing measures of conservatism . . . . . . . . . . . . . . 29

1.3 Construct validity \& the existing measures of conservatism . . . . . 54

1.4 Discussion ........................... 68

1.5 Conclusions . . . . . . . . . . . . . . . . 77

1.6 Appendix ........................ 79 
2 The Impact of Default Risk on the Basu Measure of Accounting Con$\begin{array}{lr}\text { servatism } & \mathbf{8 0}\end{array}$

2.1 Introduction $\ldots \ldots \ldots \ldots$. . . . . . . . . . 80

2.2 The link between the Basu asymmetric timeliness coefficient and default-risk .................... 84

2.3 A new measure of conservatism _. . . . . . . . . . . 93

2.4 Proxies and data . . . . . . . . . . . . . . . 95

2.5 Main empirical results . . . . . . . . . . . . . . . 102

2.6 Robustness tests . . . . . . . . . . . . . . . . 110

2.7 Conclusions . . . . . . . . . . . . . . . . . 118

2.8 Appendix . . . . . . . . . . . . . . . . . 120

3 The Signalling Role of Accounting Conservatism in the Debt Market with Asymmetric Information 126

3.1 Introduction and background literature . . . . . . . . . 126

3.2 Four basic properties of conservatism . . . . . . . . . . 133

3.3 Model set-up . . . . . . . . . . . . . . . . . . . . . . . 148

3.4 Signalling equilibria . . . . . . . . . . . . . . . 154

3.5 Implications . . . . . . . . . . . . . . . 163

3.6 Conclusions . . . . . . . . . . . . . . . 166

3.7 Appendix A - proofs . . . . . . . . . . . . . 168

3.8 Appendix B - an empirical test of the signalling theory . . . . . 173

$\begin{array}{lr}\text { Conclusions and Implications for Future Research } & 180\end{array}$

$\begin{array}{lr}\text { Bibliography } & 184\end{array}$ 


\section{List of Figures}

2.1 Box-plot of distance-to-default (DD) - "normal firm-years" vs. "out-

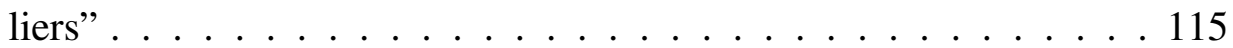

3.1 Basu earnings function (with discontinuity) . . . . . . . . . 136

3.2 Basu earnings function (without discontinuity) . . . . . . . . . . 137

3.3 Earnings as a function of conservatism . . . . . . . . . . . 142

3.4 Debt value as a function of conservatism (Single-crossing property) 147

3.5 Equity value as a function of conservatism (Single-crossing property) 147

3.6 Timeline of the conservatism-signalling game . . . . . . . . . . . 149

3.7 Separating Equilibrium . . . . . . . . . . . . . . . 157 


\section{List of Tables}

1.1 A summary of the empirical literature on conservatism . . . . . . 30

1.2 Statistics on the measures of conservatism in the paper survey . . . 40

1.3 Validation Criteria (sub-validities) . . . . . . . . . . . 55

1.4 Evidence of convergent validity $\ldots \ldots$. . . . . . . . . . 60

1.5 Descriptive statistics . . . . . . . . . . . . . . 79

2.1 Descriptive statistics . . . . . . . . . . . . . . . . . 99

2.2 Correlation Table . . . . . . . . . . . . . . . . 100

2.3 The association between the Basu measure of conservatism and distance-to-default (DD) . . . . . . . . . . . . . . . . 104

2.4 The association between the Default-Adjusted-Basu (DAB) measure and distance-to-default (DD) . . . . . . . . . . . . 105

2.5 A simpler (and naive) version of the Default-Adjusted-Basu (DAB) measure ........................... 109

2.6 Robustness Test - Ball \& Shivakumar's (2005) AACF measure of conservatism and Distance-to-Default (DD) . . . . . . . 113

2.7 Robustness test - An alternative specification of Net Income Before Interest ("NIBI2") in the DAB measure $\ldots \ldots \ldots . . \ldots 117$

3.1 Numerical example of Lemma 3.1 and $3.2 \ldots \ldots$. . . . . . . . 143 
3.2 Basu AT \& AACF regressions augmented by Asset Volatility (VOL) 178

3.3 Default-Adjusted-Basu measure and Asset Volatility (VOL) . . . . . 179 


\section{General Introduction}

The accountant transcends the conservatism of the proverb, 'Do not count your chicken before they are hatched,' saying, 'Here are a lot of chickens already safely hatched, but for the love of Mike, use discretion and don't count them all, for perhaps some will die.'

— Henry R. Hatfield (1927, p. 256)

\subsection{Background and motivation}

The subject of this thesis is accounting conservatism, which is one of the oldest and most important principles of accounting (Sterling, 1967; Watts, 2003a). Broadly speaking, conservatism is a tendency that accountants, when encountering uncertainties in economic transactions, choose to report lower estimates for the values of assets and revenues, but higher estimates for the values of liabilities and expenses. Conservatism in accounting ensures that costs are not understated in the accounts and revenues are not overstated. Conservatism appears to be closely related to the concept of realisation, as conservatism implies that a profit should not be recognized before it is realized. Sterling (1967) suggests that conservatism may in fact be the root of the realisation principle.

Conservatism, as viewed by modern researchers and accounting standard setters, 
is a principle under which accountants exercise a reasonable degree of prudence in recognizing transactions subject to genuine economic uncertainties. The modern view of accounting conservatism does not seem to include, or permit, any deliberate manipulations of the accounts by understating income in one period and overstating income in a latter period, if there is no or little economic uncertainty surrounding the transactions. The latter behaviour is often called "big bath" accounting, which creates hidden reserves, and is inconsistent with the principle of accounting conservatism. The view of accounting standard setters towards conservatism and hidden reserves is clearly evident in FASB's conceptual framework:

Conservatism in financial reporting should no longer connote deliberate, consistent understatement of net assets and profits. (FASB, 1980, para. 93)

Then in paragraph 95, the FASB conceptual framework indicates that:

Conservatism no longer requires deferring recognition of income beyond the time that adequate evidence of its existence becomes available or justifies recognizing losses before there is adequate evidence that they have been incurred. (FASB, 1980, para. 95)

Therefore, while conservatism and the creation of hidden reserves are superficially similar, there is however a clear line that separates these two types of behaviours. Conservatism is a genuine, prudent response to uncertainty, whereas big bath accounting is a deliberate attempt to mislead the users of financial statements when there is in fact no uncertainty. As W. A. Paton so clearly pointed out, "sheer understatement where it is possible to ascertain the actual facts is not conservatism but concealment." (Paton and Stevenson, 1916, p. 237) 
Modern accounting researchers recognise that conservatism has the effect of accelerating the recognition of economic losses and deferring the recognition of economic gains (e.g. Basu, 1997; Watts, 2003a). Therefore, economic losses are reflected in earnings faster than economic gains, under conservatism. This property of conservatism is described by Basu (1997) as the asymmetric timeliness of earnings, which has become the anchor for a number of empirical and theoretical works on accounting conservatism in recent years (see Watts, 2003b; Ryan, 2006, for literature reviews).

The asymmetric timeliness of earnings property of accounting conservatism, as described above, highlights the intertemporal nature of accounting conservatism: the recognition of unverifiable or unrealised economic gains in earnings are delayed until they subsequently become verifiable or realised in later periods. Thus, in a typical life cycle of a firm, earnings tend to lag economic income by several accounting periods. In the early stages of the life of the firm where investment outlays tend to be high and revenues low, earnings tend to be lower than the economic income of the firm; but in the mature stage of the firm, where revenues are larger and more stable, earnings tend to catch up with the economic income or even exceed it (Monahan, 2005; Zhang, 2005). However, one should not argue that accounting conservatism is not always "conservative" simply because it may lead to lower earnings in one period and higher earnings in another. To make that argument would be to entirely miss the main purpose of accounting conservatism, which is to create a higher standard of verification for recognition of good news, as a mechanism for coping with economic uncertainties. Thus, the intertemporal properties of earnings are merely a consequence of that main purpose of accounting conservatism, rather than the cause of it.

The most common example of conservatism is the "lower of cost and market" 
rule of inventory valuation. This well-known rule states that inventory values should not be written up when the market value of inventory exceeds its cost, but should immediately be written down when the market value falls below the cost. According to a renowned accounting historian, R. H. Parker (1969), the lower of cost and market rule was firmly established somewhere in the 19th century. George O. May reportedly said that by the time he entered the accounting profession in England in 1892, the rule had already been well established (Parker, 1969). This suggests that conservatism probably has been around since the 19th century at the latest, while some researchers argue that the time is even longer. ${ }^{1}$

Sivakumar and Waymire (2003) conducted a historical study into the accounting of U.S. railroads at the beginning of the 20th century, using modern empirical methods. Their study shows that railroad companies in the US around the turn of the 20th century were not only conservative in their accounting methods and policies, but also gradually increased their levels of accounting conservatism, in response to changing regulations and other factors. This study provides some of the most convincing empirical evidence that accounting conservatism has existed for a long period of time, resonating the similar conclusion reached by accounting historians based on other (mostly non-empirical) methods.

Conservatism's influence on modern accounting standards is pervasive, and examples of accounting conservatism can be found in many modern accounting standards. Apart from the lower of cost and market rule, which still remains in the US and international accounting standards today, many other rules and standards exist that are examples of accounting conservatism. They include the impairment of fixed-assets, the expensing of the majority of the research and development costs,

\footnotetext{
${ }^{1}$ Basu (1997) argues that accounting conservatism has been established for at least 500 years in Europe. Basu's claim is supported by the historical evidence that traces the lower of cost and market rule back to Italy in the 15th century, and to France in the 17th century (Littleton, 1941).
} 
provisions, and contingent assets and liabilities, among many others. All these rules or standards demonstrate the basic characteristic of conservatism, which is that accountants must exercise a degree of prudence in recognizing uncertain economic gains.

Empirical studies into accounting conservatism in the second half of the 20th century have provided ample evidence that accounting conservatism is a fundamental characteristic of financial reporting in virtually all the developed countries in the world, and also in many developing countries (See Watts, 2003b; Ball et al., 2000; Bushman and Piotroski, 2006; Basu, 1997; Ball et al., 2003). This is an active area of research and more studies in this area are currently being undertaken.

The phenomenon of accounting conservatism has intrigued many accounting researchers since the very early stages of the development of accounting theory. However, there have been an eclectic and divided range of opinion about accounting conservatism, and much of the argument has still to be resolved even today. Beginning in the late 1930s, and until the 1980s, conservatism had been criticised by a number of prominent accounting scholars, including Gilman, Hatfield, May and Paton (Chatfield, 1996). According to Chatfield (1996), some of the most frequently used arguments against conservatism are: (1) accounting conservatism is not consistent in that it produces lower income in one period and leads to higher income in another period; (2) accounting conservatism is arbitrary and gives managers too much discretionary power over reporting, among other problems.

However, as Watts (2003a; 2003b) has noted, despite the criticisms of conservatism, not only has accounting conservatism survived numerous accounting reforms, regulations and economic crises in the past century, but also the average degree of accounting conservatism, in the US at least, has even increased slightly during the past 30 years or so. And this claim has been substantiated by many em- 
pirical studies based on large samples of data from the US and worldwide. It seems that conservatism is extremely resilient in the modern economy.

For example, in regard to the lower of cost and market rule, Parker observes:

"The astonishing thing about the lower of cost and market rule is its ability to survive attack. G. O. May was probably right in suggesting that most accountants are 'content to regard the demonstrated practical wisdom of the rule as outweighing any supposed illogicality'." (Parker, 1969, p. 257)

But why do accountants want to conform with the "practical wisdom" of conservatism despite its criticisms? After all, is there any logic, if any, hidden behind the seeming illogicality of conservatism? In fact, finding that logic to support conservatism has become the main occupation of many positive accounting researchers over the last decade.

The main interest of contemporary accounting researchers in conservatism is to find the rationale, if any, behind conservatism, and thus to explain why conservatism is so resilient in the modern economy. While the search for rational explanations of conservatism is still ongoing, it has already paid big dividends. A large part of the recent advancements in the conservatism literature can be summarised in the following five rational explanations of accounting conservatism: (1) the litigation risk explanation, (2) the debt-contracting explanation, (3) the managerial-contracting explanation, (4) the political cost explanation, and (5) the tax-incentive explanation (See Watts, 2003a, for a review of these explantions). These explanations have made conservatism, once unjustifiable in the eyes of Paton and Hatfield, significantly more justifiable.

The theoretical developments in the area of accounting conservatism appear to 
be fueled by an additional factor - the movement against conservatism by accounting standard setters, especially the FASB and the IASB. These accounting standard setting bodies have been attempting to abandon the conservatism principle in favour of the "neutrality principle" (IASB, 2006; FASB, 2006). It is claimed that if the neutrality principle is followed, there should be no downward bias in the reported net profit, even though there is some uncertainty as to the amount and the realisation of the profit. The chief justification for this view is that the conservatism principle appears inconsistent with the qualitative characteristic of representational faithfulness due to the bias it introduces. In contrast, neutrality is argued to lead to unbiased representations of the underlying economic performance and condition of the firm, thereby providing more reliable and relevant information to users of financial statements.

For example, in the discussion paper issued by the IASB in 2006 in a joint project with the FASB to review and revise the conceptual framework of accounting, the boards comment that:

However, the boards concluded that describing prudence or conservatism as a desirable quality or response to uncertainty would conflict with the quality of neutrality. Even with the proscriptions of deliberate misstatement that appear in the existing frameworks, an admonition to be prudent is likely to lead to a bias in reported financial position and financial performance. Moreover, understating assets (or overstating liabilities) in one period frequently leads to overstating financial performance in later periods - a result that cannot be described as prudent. Neither result is consistent with the desirable quality of neutrality, which encompasses freedom from bias. Accordingly, the proposed framework does not include prudence or conservatism as de- 
sirable qualities of financial reporting information. (IASB, 2006, para. $\mathrm{BC} 2.22)$

However, the above view taken by accounting standard setters is not shared by all accounting academics and practitioners. Many, including Watts (2003a; 2003b; 2006), disagree with the standard setter's movement away from conservatism in the accounting conceptual frameworks and accounting standards. The dissenters argue that accounting conservatism is not as illogical as it may initially appear; conservatism is, in fact, driven by some fundamental economic forces, and is an efficient reporting mechanism in response to the economic, legal and political environment in which firms operate. The dissenting opinion is primarily based on the five rational explanations of conservatism mentioned above and the results of recent empirical studies on accounting conservatism. Therefore, the proponents of conservatism argue that if conservatism is compulsorily replaced by neutrality, firms will likely adopt sub-optimal accounting techniques that will damage their economic efficiency, in particular their contracting efficiency.

A controversy therefore arises between the supporters and the opponents of accounting conservatism, which may have in part stimulated the academic research into accounting conservatism in the past decade or so. ${ }^{2}$ It is hoped that the research into conservatism will provide academics, standard setters, and policy makers with a deeper and richer understanding of the likely impacts of the policy of replacing the conservatism principle with the neutrality principle in the conceptual framework and in accounting standards.

Against this backdrop, this $\mathrm{PhD}$ thesis is the author's own research efforts to attempt to understand the important and interesting phenomenon of accounting con-

\footnotetext{
${ }^{2} \mathrm{~A}$ good starting point for seeing the arguments in this debate is a pair of articles published by each side of the debate in Journal of Accounting Economics (2001): Holthausen and Watts (2001) and Barth et al. (2001). And more recently, the view of the proponents of accounting conservatism is re-expressed by Kothari et al. (2009)
} 
servatism. The main thrust of this thesis is to contribute to answering the following two questions:

\section{Research Question (1): How can we empirically measure the degree of ac- counting conservatism?}

Arguably, the first step towards understanding the causes and effects of the phenomenon of accounting conservatism is to be able to accurately observe and measure it in empirical studies. That is not just true of accounting research, but true of science in general. The history of science is in some respect a history of observations and measurements, careful and ingenious ones, of course. If Galileo had not constructed a superior and sharper telescope in the early 17th century, it would have taken astronomers much longer to realize that the earth goes around the sun, instead of the other way around. If Rutherford had not meticulously taken his observations about the trajectories of alpha particles being shot through a very thin paper of gold, physicists would probably have taken years longer, if ever, to discover the internal structure of atoms. For researchers of accounting conservatism and for any financial analysts interested in understanding the causes and effects of accounting conservatism, it is just as essential to first observe and measure the degree of accounting conservatism in financial reporting as it was for Galileo to first make better telescopes before peeking into the sky. Chapter $1 \&$ Chapter 2 of this thesis are devoted to the task of measuring accounting conservatism.

\section{Research Question (2): Why does conservatism exist in accounting, and why is the degree of conservatism higher in some firms than others?}

After all, conservatism in financial reporting decreases the earnings and net book values of a firm, and in doing so, it could be claimed that conservatism distorts the information content of the firm's financial reports. But why, under economic 
uncertainty, does the accountant tend to report a lower and more conservative figure as the net profit out of all possible net profits? Is not the mean value, or even the median, of all possible net profits the best number to summarise the distribution of all possible net profits? If we look at the classical example of conservatism - the lower of cost and the market rule, why did the early accounting pioneers choose to report the the lower of cost and market value? Why not the higher of cost and market value, or perhaps the average of these two? So is there any rational explanations behind the tendency to report a low and more conservative net profit? As already noted, researchers have proposed several theories to explain accounting conservatism (see the literature review by Watts, 2003a). But these explanations are still far from being conclusive, and ongoing research is being conducted. Chapter 3 of this thesis contributes to this fledgling literature by proposing a new economic explanation for why accounting conservatism exists and why empiricists find that some firms are more conservative than others.

I now provide a brief overview of each of the three main chapters of the thesis (Chapters 1 to 3 ) as follows.

\subsection{Overview of the chapters}

\section{Chapter 1: Measures of accounting conservatism: a construct va- lidity perspective ${ }^{3}$}

Chapter 1 provides a survey of the literature on accounting conservatism, with a focus on assessing the construct validity of existing measures of conservatism. Accounting conservatism has been the subject of intensive empirical research in the

\footnotetext{
${ }^{3}$ A paper based on Chapter 1 is forthcoming in Journal of Accounting Literature (2009).
} 
past decade. It is essential for empiricists to develop a valid, accurate and reliable measure of accounting conservatism. To date, five key measures of conservatism have emerged in the literature: (1) Basu's(1997) asymmetric timeliness of earnings measure (“AT”), (2) Ball and Shivakumar's (2005) asymmetric-accruals-to-cashflow measure ("AACF"), (3) the commonly suggested Market-to-Book ratio measure (“MTB”), (4) Penman and Zhang's (2002) Hidden Reserves Measure (“HR”), and (5) Givoly and Hayn's (2000) Negative Accruals Measure (“NA"). However, few studies have examined, directly or tangentially, whether the applications of these measures produce facts or artefacts. Chapter 1 examines this issue from the perspective of construct validity and focuses on the the following aspects:

1. The main features of each of the five measures of accounting conservatism;

2. The construct validity of the five measures of conservatism;

3. Inconsistencies between the results of different measures of conservatism;

4. Biases in these measures of conservatism.

Chapter 1 first describes each of the five measures. Then, it considers these measures against four of the sub-validities of construct validity, within the constraints imposed by the limited and mixed relevant evidence, and guided by construct validity theory. While the available evidence is insufficient to reach a definite conclusion on the construct validity of the existing five measures of conservatism, the analysis of this chapter nevertheless suggests that the construct validity of these measures is weak. Chapter 1 then explores the challenges of measuring conservatism facing accounting researchers, and concludes with suggestions for future research. 


\section{Chapter 2: The impact of default risk on the Basu measure of accounting conservatism ${ }^{4}$}

Chapter 2 continues the previous chapter's theme of examining the measures of accounting conservatism. But instead of surveying several measures in general, the chapter investigates the validity of one particular measure of conservatism - the Basu (1997) asymmetric timeliness measure (“AT”) - in great depth. Chapter 2 focuses on the Basu measure, because it is currently the most frequently employed measure of accounting conservatism in the accounting literature and has had the greatest impact on the literature.

Chapter 2 has two closely related objectives: (1) to analytically and empirically examine the impact of default risk on the Basu (1997) measure of conservatism; and (2) to design and test a new measure of accounting conservatism - the DefaultAdjusted-Basu Measure, or the "DAB” measure.

In regards to the first objective, Chapter 2 first analytically shows that the Basu asymmetric timeliness coefficient is biased upward by the existence of default risk in a firm, and that the bias tends to increase with the level of default risk. The analytical model is primarily based on Merton's (1974) classic call-option model of equity. The empirical evidence reported in Chapter 3 is consistent with this analytical proposition.

In regards to the second objective, Chapter 2 argues that the Default-AdjustedBasu measure is likely to be more robust to the bias caused by default risk than the original Basu measure. The empirical tests reported in Chapter 2 indicates that the DAB measure is indeed free from the default-risk-bias.

The main proxy for default risk used in Chapter 2 is the distance-to-default, de-

\footnotetext{
${ }^{4}$ A paper based on Chapter 2 is currently under second review at Journal of Accounting \& Economics.
} 
veloped by Merton (1974) and estimated by Vassalou and Xing's (2004) iterative method. Vassalou and Xing's (2004) iterative method enables the author to obtain a relatively accurate estimate for the distance-to-default for each firm-year. Furthermore, the Vassalou and Xing (2004) method also yields the estimates for several essential inputs to the DAB measure.

\section{Chapter 3: The signalling role of accounting conservatism in the debt market with asymmetric information}

Having examined the measures of conservatism in Chapters 1 and 2, Chapter 3 shifts the focus to the economic theories of conservatism. In particular, Chapter 3 investigates the signalling role of accounting conservatism in a debt market characterized by information asymmetry. Chapter 3 constructs a signalling game model in order to analyse firms' decisions on their optimal degrees of conservatism under information asymmetry in the lending market. The market has asymmetric information because the borrower firms have private information about their true operating risk levels (proxied by asset volatility) that the lenders do not.

Based on this simple model, I show that the borrower firms' decision on their optimal levels of accounting conservatism depend on their own operating risk. Under mild regularity conditions, the signalling game exhibits a "stable" separating equilibrium, in which the high risk firms adopt a low degree of conservatism and vice versa. By simply observing the degree of conservatism adopted by each borrower firm, the lenders in the debt market can correctly figure out the true level of operating risk in each borrower firm. As a result, conservatism becomes a credible signalling device for the borrower firms to reveal their private information about their true risk levels to the lenders in the debt market. 
Chapter 3 also derives 4 basic properties of accounting conservative, which are stated as 4 lemmas. These basic properties mainly deal with the joint impacts of accounting conservatism and risk on firms' earnings, thereby providing a direct link between conservatism, risk and earnings. While most of these basic properties are already well known in the accounting literature, the contribution of my analysis is to show that, using Basu's (1997) definition of accounting conservatism, they can be rigorously proved with very few additional assumptions.

Appendix $B$ to Chapter 3 offers some preliminary empirical evidence on what I call the signalling theory of accounting conservatism developed in the chapter. The results of the tests of whether firms with a lower degree of asset volatility (i.e., fundamental operating risk) adopt a higher degree of accounting conservatism, and vice versa, are consistent with the signalling theory of conservatism. Low-volatility firms indeed tend to have a higher degree of conservatism, and high-volatility firms indeed tend to have a lower degree of conservatism.

It should be noted that the risk addressed in Chapter 3 is of a very different kind from that addressed in Chapter 2. Chapter 2 deals with default risk, which is chiefly concerned with downward movements in the value of the firm, subject to a degree of leverage. In contrast, Chapter 3 deals with the operating risk of the firm, as defined by asset volatility, which encompasses two-sided movements in the value of the firm, regardless of the degree of leverage. There are two key differences between these two types of risk: (1) default risk is one-sided, while asset volatility is doublesided, and (2) default risk is contingent upon the degree of leverage, while assets volatility is independent of leverage. 


\subsection{Contributions of the thesis}

This thesis contributes to the accounting literature in the following six main areas:

First, this thesis is the first in the literature that systematically examines the construct validity of existing measures of accounting conservatism. Other researchers, like Watts (2003b) and Ryan (2006), have surveyed the empirical measures of accounting conservatism, and (in the case of Ryan, 2006) the Basu measure in particular. This thesis contributes to the literature by examining the construct validity of the existing measures in a systematic way. The result of my examination shows that the existing measures may suffer from low construct validity and further research is much needed in this area.

Second, this thesis contributes to the literature by identifying and testing a new kind of bias in the well-known Basu (1997) measure of accounting conservatism. The Basu measure is currently the most widely applied measure of accounting conservatism (Ryan, 2006, and Chapter 1), and its validity has recently been questioned by Dietrich et al. (2007) and Givoly et al. (2007). This thesis examines the validity of the Basu measure from the perspective of the default risk of a firm. This thesis finds that an upward bias in the Basu measure of conservatism is induced by the existence of default risk in a firm. The greater the degree of default risk there is, the greater this bias in the Basu measure of conservatism.

Third, this thesis further contributes to the literature by constructing a new measure of accounting conservatism - the Default-Adjusted-Basu (or "DAB") measure - which is based on the original Basu (1997) measure but is free from the effects of default risk. Empirical testing of the DAB measure shows that it is very effective at removing the bias caused by default risk in the data. Therefore, the DAB measure is likely a more accurate and less-biased measure of accounting conservatism than 
is the original Basu (1997) measure.

The fourth contribution of this thesis is that it proposes a new signalling theory of accounting conservatism. The model developed in Chapter 3 is currently the only signalling model of accounting conservatism in debt markets. In contrast, all but one of the existing analytical models that examine accounting conservatism, such as Givoly et al. (2007), Chen et al. (2007), and Kwon et al. (2001), are primarily moral hazard games, which focus on the role of accounting conservatism in an agency setting either between equity- and debt-holders, or between equity-holders and managers, ex post (i.e., after the signing of the lending contract or the compensation contract). In comparison, the proposed model is ex ante and focuses on the behaviour of borrowers and lenders prior to the signing of the lending contract.

The only existing published study that examines accounting conservatism in the information asymmetry (and signalling) framework is Bagnoli and Watts (2005). Bagnoli and Watts (2005) show that a high degree of conservatism sends out a signal to the equity market that the managers of the firm expect good profits in the future, and conversely a low degree of conservatism signals that the managers expect low profits in the future. However, Bagnoli and Watts' (2005) study focuses on the signalling role of conservatism in the equity market, whereas Chapter 3 of this thesis focuses on signalling role of conservatism in the debt market.

One of the original contributions of the proposed signalling model is that it shows that low-risk borrower firms tend to adopt higher degrees of conservatism, while high-risk borrower firms tend to adopt lower degrees of conservatism. This conclusion somewhat contradicts the prevailing view on the debt-contracting role of conservatism, which typically asserts that high risk firms would adopt a higher degree of conservatism (e.g. Watts, 2003a,b; Lara et al., 2009b). The empirical evidence reported in Appendix B of Chapter 3 lends direct support to the signalling 
theory by showing that high-risk firms actually adopt a lower degree of accounting conservatism than do low-risk firms.

Fifth, Chapter 3 of the thesis further contributes to the conservatism literature by analytically deriving four basic properties of accounting conservatism. While most of these properties are already well-known in the accounting literature, this thesis is the first study that rigorously and analytically derives these properties assuming little more than Basu's (1997) definition of accounting conservatism as the asymmetric timeliness of earnings.

Finally, this thesis is the first study in the accounting literature to apply Vassalou and Xing's (2004) iterative method of estimating default risk. Vassalou and Xing's (2004) method is a relatively modern technique of calculating default risk and has shown considerable power in predicting firms' default probabilities. In accounting research, Bushman and Williams (2009) have recently employed a simpler, but noniterative, approach to measure the default risk in banks, first used by Ronn and Verma (1986). However, whilst simpler to implement, the non-iterative approach is not as accurate as the iterative approach used by Vassalou and Xing (2004), because the actual market leverage moves too fast for the non-iterative approach to reliably estimate firms' asset volatility (Crosbie and Bohn, 2003, pp. 16-17). Therefore, the use of the Vassalou and Xing (2004) method in this chapter is an innovation in the accounting literature. 


\section{Chapter 1}

\section{Measures of Accounting}

\section{Conservatism: A Construct Validity}

\section{Perspective}

\subsection{Introduction ${ }^{1}$}

Over the last decade, accounting conservatism has become the subject of an active field of empirical research in accounting. An interesting feature of the conservatism literature is the variety of existing measures of conservatism, and the apparent lack of consistency among these measures. From my review of the accounting conservatism literature, I have identified five key measures of accounting conservatism: (1) Basu's(1997) asymmetric timeliness of earnings measure (“AT"), (2) Ball and

\footnotetext{
${ }^{1} \mathrm{~A}$ paper based on this chapter co-authored with my thesis supervisors is forthcoming in the Journal of Accounting Literature (2009). I would like to thank the editor, Bipin Ajinkya, and the anonymous referee of Journal of Accounting Literature for their valuable suggestions and constructive criticisms. I would also like to thank Stephen L. Taylor for his comments on an earlier version of this chapter during his tenure as the Don Trow Visiting Fellow at Victoria University of Wellington, as well the conference participants at the European Accounting Association 2008 Annual Meeting in Rotterdam, the Netherlands, for helpful comments.
} 
Shivakumar's (2005) asymmetric-accruals-to-cash-flow measure (“AACF”), (3) the commonly suggested Market-to-Book ratio measure ("MTB”), (4) Penman and Zhang's (2002) Hidden Reserves Measure (“HR”), and (5) Givoly and Hayn's (2000) Negative Accruals Measure ("NA"). While there are several other approaches to measurement of conservatism, these five measures are the most widely applied and have had the most significant impact on the empirical literature on conservatism.

To the extent that these measures are used in empirical studies to test theories and hypotheses concerning accounting conservatism, the empirical results obtained may differ with the choice of measure used and therefore leave uncertainty about the validity and significance of the results obtained from any particular measure. Therefore, it is important that accounting researchers consider the validity of these measures of accounting conservatism. In this chapter, I attempt to address the question of the validity of the measures of accounting conservatism and focus on the following specific questions:

1. What are the main features of each of the five measures of accounting conservatism?

2. Could application of different measures of conservatism produce the same result?

3. How should the differences, if any, resulting from the use of different measures of conservatism be interpreted?

4. Are there any biases in these measures of conservatism?

The above four questions set the key issues that are relevant to empirical researchers studying accounting conservatism. I address these questions by conducting a survey of the accounting conservatism literature using the methodological framework of 
construct validity theory, as set out in Messick (1989), Cook and Campbell (1979) and others. Broadly speaking, construct validity addresses the question "are the measures representing what they are supposed to represent?" Construct validity provides a scientific framework for assessing this overall question and the subsidiary questions set out above. The concept of construct validity has been in existence for more than 50 years and has been applied in many branches of the social sciences, including psychology, education, sociology, organizational behavior and marketing. In this chapter, I apply this well-established framework to analyze the issues surrounding the validity of the existing measures of accounting conservatism.

While the primary method of investigation in Chapter 1 is one of reviewing and analyzing the existing empirical literature on accounting conservatism, I also conduct some supplementary empirical tests in Section 1.3.1, because the existing empirical evidence is incomplete in regard to convergent validity. These simple empirical tests in Section 1.3.1 allow me to get a complete view of convergent validity among all five measures of conservatism. Apart from Section 1.3.1, all other sections of Chapter 1 are based on the empirical evidence provided by the existing literature, and no further empirical tests are conducted.

The precise meaning of the construct of accounting conservatism has not been universally agreed upon by accounting researchers. A general interpretation of "conservatism" in accounting is articulated by the IASB, which states that conservatism is "a degree of caution in the exercise of the judgments needed in making the estimates required under conditions of uncertainty, such that assets or incomes are not overstated and liabilities or expenses are not understated" IASB (1989, p. 37). Nevertheless, compared to many other constructs or subject areas of accounting, the construct of conservatism does not have a well-articulated and as yet commonly agreed upon interpretation. Regardless of the meaning of conservatism, it is a the- 
oretical construct that belongs to the world of ideas and, as such, can be linked to other constructs by analytical reasoning. On the other hand, the measures of conservatism are operationalizations of the construct and application of the measures results in facts that simply reflect the relevant operationalizations. A fact observed regarding conservatism from applying any measure has no independent reference in any circumstance. In order for such facts to have significance they should obviously bear close correspondence to the underling theoretical construct.

The framework of construct validity provides a basis for discriminating between the different measures and thus it provides a useful approach to frame a review of the developing literature on conservatism. Although this chapter is mainly based on the existing evidence from the empirical literature, its contribution is to put the existing evidence into a new perspective - the perspective of construct validity.

The present survey reviews papers which adopt measures of conservatism that have been widely applied (and therefore constitutes a significant strand of the conservatism literature) and have been published in peer-reviewed journals through to May 2009. Application of these criteria leads us to review the five measures of conservatism identified above, and my literature survey covers 53 journal articles as summarized in Table 1.1. ${ }^{2}$

The rest of this chapter is organized as follows: Section 1.2 reviews the techniques, strengths, weaknesses and the research applications of the five identified

\footnotetext{
${ }^{2}$ Papers that are not covered by the survey include Khan and Watts (2009) and Cotter and Donnelly (2006). Khan and Watts (2009) propose a measure of conservatism that is an extension of the Basu AT measure and assesses the firm-specific degrees of asymmetric timeliness. However, Khan and Watts' paper was published after May 2009, my cut-off date for the literature review, and the measure proposed has to date not been widely adopted. Cotter and Donnelly (2006) propose a firmspecific measure of conservatism that is based on the accounting-policy choices made by each firm. The measure requires researchers to form subjective judgments about the degree of conservatism of a firm based on reading the firm's statement of accounting policies in the annual report. The measure is inevitably subjective and would not be feasible for application to a large set of firms. The paper was published by a professional body and to date the proposed approach does not appear to have been adopted by other researchers.
} 
measures of accounting conservatism. Section 1.3 critically evaluates the construct validity of these measures against a number of key validation criteria. Section 1.4 discusses the main challenges to construct validity in the measures of conservatism, and offers some suggestions for future research. Section 1.5 concludes the chapter.

\subsection{Existing measures of conservatism}

In this section, I review the techniques, rationales, and the strengths and weaknesses of the five existing measures of accounting conservatism. The measures are:

1. Basu's (1997) asymmetric timeliness of earnings measure (AT),

2. Ball and Shivakumar's (2005) asymmetric-cash-flow-to-accruals measure (AACF),

3. The Market-to-Book (or Book-to-Market) ratio,

4. Penman and Zhang's (2002) hidden reserves measure (HR), and

5. Givoly and Hayn's (2000) negative accruals measure (NA).

Table 1.1 summarizes the use of these five measures in the empirical literature surveyed, including the main topic area and key findings of each paper. Table 1.2 summarizes the frequency of the use of each measure in the papers surveyed. It can be seen from Table 1.2 that the frequency of use differs significantly, and the Basu AT measure is by far the most frequently used measure of conservatism in the literature. Below, we discuss the five measures individually. 
Table 1.1: A summary of the empirical literature on conservatism

\begin{tabular}{|c|c|c|c|c|}
\hline Authors & Topic areas & Sample & Measures & Main findings \\
\hline $\begin{array}{l}\text { Ahmed and Duellman } \\
\text { (2007) }\end{array}$ & $\begin{array}{l}\text { Corporate governance } \\
\text { and conservatism }\end{array}$ & US (S\&P 500) & AT, BTM. NA & $\begin{array}{l}\text { Conservatism is negatively correlated with } \\
\text { the percentage of inside directors, and } \\
\text { positively correlated with the percentage of } \\
\text { shareholding by outside directors. }\end{array}$ \\
\hline Ahmed et al. (2002) & $\begin{array}{l}\text { Debt contracting and } \\
\text { conservatism }\end{array}$ & US & BTM, NA & $\begin{array}{l}\text { Conservatism reduces the cost of debt, in } \\
\text { support of the debt-contracting hypothesis of } \\
\text { conservatism. }\end{array}$ \\
\hline Ahmed et al. (2000) & $\begin{array}{l}\text { Testing residual } \\
\text { income valuation } \\
\text { model }\end{array}$ & US & HR & $\begin{array}{l}\text { Conservatism is positively correlated with } \\
\text { the valuation weight on operating assets. }\end{array}$ \\
\hline $\begin{array}{l}\text { Ball and Shivakumar } \\
\text { (2005) }\end{array}$ & $\begin{array}{l}\text { Comparing } \\
\text { conservatism in UK } \\
\text { private and public } \\
\text { firms }\end{array}$ & UK & $\begin{array}{l}\text { AACF, an } \\
\text { earnings } \\
\text { persistence } \\
\text { measure }\end{array}$ & $\begin{array}{l}\text { UK private firms have lower reporting } \\
\text { quality of earnings than do UK public firms, } \\
\text { as measured by the degree of accounting } \\
\text { conservatism }\end{array}$ \\
\hline $\begin{array}{l}\text { Ball and Shivakumar } \\
\text { (2006) }\end{array}$ & $\begin{array}{l}\text { Accrual models and } \\
\text { conservatism }\end{array}$ & US & AACF & $\begin{array}{l}\text { Existing accrual models (e.g. Jones (1991) } \\
\text { and others) are extended to incorporate } \\
\text { conservatism, for the purpose of further } \\
\text { investigating the role of conservatism in } \\
\text { accounting accruals. }\end{array}$ \\
\hline
\end{tabular}




\begin{tabular}{|c|c|c|c|c|}
\hline Authors & Topic areas & Sample & Measures & Main findings \\
\hline Ball et al. (2000) & $\begin{array}{l}\text { International } \\
\text { differences in } \\
\text { corporate governance } \\
\text { and legal environment } \\
\text { and conservatism }\end{array}$ & International & AT & $\begin{array}{l}\text { Common law countries are more } \\
\text { conservative in their financial reporting } \\
\text { practices than code law countries as } \\
\text { measured by Basu's AT measure. }\end{array}$ \\
\hline Ball et al. (2008) & $\begin{array}{l}\text { Equity vs. debt } \\
\text { markets demand for } \\
\text { conservatism }\end{array}$ & International & AT & $\begin{array}{l}\text { This paper finds that conservatism increased } \\
\text { with the relative importance of the debt } \\
\text { market in each country. }\end{array}$ \\
\hline Ball et al. (2003) & $\begin{array}{l}\text { Legal, political, and } \\
\text { institutional factors' } \\
\text { impacts on } \\
\text { conservatism }\end{array}$ & $\begin{array}{c}4 \text { East Asian } \\
\text { countries }\end{array}$ & AT & $\begin{array}{l}\text { In four East-Asia countries, conservatism is } \\
\text { affected by several legal, political and } \\
\text { institutional factors. }\end{array}$ \\
\hline Basu (1997) & $\begin{array}{l}\text { Asymmetric } \\
\text { timeliness of earnings, } \\
\text { litigation costs } \\
\text { demand for } \\
\text { conservatism }\end{array}$ & US & $\begin{array}{l}\text { AT, an earnings } \\
\text { persistence } \\
\text { measure }\end{array}$ & $\begin{array}{l}\text { Defined, measured and tested the } \\
\text { asymmetric timeliness of earnings concept } \\
\text { of conservatism, and show that conservatism } \\
\text { level increases with higher litigation costs }\end{array}$ \\
\hline Bauman (1999) & $\begin{array}{l}\text { Testing residual } \\
\text { income valuation } \\
\text { model (RIVM) }\end{array}$ & US & HR & $\begin{array}{l}\text { Fixed assets accounting and R\&D } \\
\text { accounting are the most significant } \\
\text { contributors to conservatism. Weak } \\
\text { association between conservatism and RIVM } \\
\text { parameters. }\end{array}$ \\
\hline
\end{tabular}




\begin{tabular}{|c|c|c|c|c|}
\hline Authors & Topic areas & Sample & Measures & Main findings \\
\hline Beatty et al. (2008) & $\begin{array}{l}\text { Debt-contracting } \\
\text { benefits of } \\
\text { conservatism }\end{array}$ & $\begin{array}{l}\text { US (debt } \\
\text { covenants) }\end{array}$ & AT, BTM, NA & $\begin{array}{l}\text { Debt-covenant modifications are associated } \\
\text { with the demand for accounting } \\
\text { conservatism. }\end{array}$ \\
\hline Beaver et al. (2008) & $\begin{array}{l}\text { The simultaneity of } \\
\text { the Basu AT measure }\end{array}$ & US & AT & $\begin{array}{l}\text { The Basu AT measure is significantly } \\
\text { weakened if jointly estimated with Hayn's } \\
\text { (1995) non-linear ERC model, using a 2SLS } \\
\text { method. }\end{array}$ \\
\hline $\begin{array}{l}\text { Beaver and Ryan } \\
\text { (2000) }\end{array}$ & $\begin{array}{l}\text { transitory vs. } \\
\text { permanent } \\
\text { components of BTM }\end{array}$ & US & BTM & $\begin{array}{l}\text { Separate BTM into the transitory and } \\
\text { permanent components. The permanent } \\
\text { component is regarded as a measure of } \\
\text { conservatism. }\end{array}$ \\
\hline Beekes et al. (2004) & $\begin{array}{l}\text { Corporate governance } \\
\text { of conservatism }\end{array}$ & UK & AT & $\begin{array}{l}\text { The percentage of outside directors is } \\
\text { positively associated with conditional } \\
\text { conservatism. }\end{array}$ \\
\hline Brown et al. (2006) & $\begin{array}{l}\text { Value-relevance and } \\
\text { conservatism }\end{array}$ & International & $\begin{array}{c}\text { AT, AACF, } \\
\text { BTM }\end{array}$ & $\begin{array}{l}\text { For countries with higher accrual levels, } \\
\text { some evidence shows that conservatism is } \\
\text { associated with a higher level of } \\
\text { value-relevance, although with conflicting } \\
\text { evidence. Accrual density is another } \\
\text { conditioning variable. }\end{array}$ \\
\hline $\begin{array}{l}\text { Bushman and } \\
\text { Piotroski (2006) }\end{array}$ & $\begin{array}{l}\text { Legal, political, and } \\
\text { institutional factors' } \\
\text { impacts on } \\
\text { conservatism }\end{array}$ & International & AT, AACF & $\begin{array}{l}\text { Country-level variations in conditional } \\
\text { conservatism associated with a variety of } \\
\text { legal \& political factors. }\end{array}$ \\
\hline
\end{tabular}




\begin{tabular}{|c|c|c|c|c|}
\hline Authors & Topic areas & Sample & Measures & Main findings \\
\hline Callen et al. (2009) & $\begin{array}{l}\text { Return/earning } \\
\text { relationship, } \\
\text { economic demands } \\
\text { for conservatism }\end{array}$ & US & $\begin{array}{l}\text { A VAR based } \\
\text { measure }\end{array}$ & $\begin{array}{l}\text { A new measure of conservatism is developed } \\
\text { based on the vector-auto-regressive (VAR) } \\
\text { decomposition of stock returns, and is used } \\
\text { to test the economic demands for } \\
\text { conservatism. }\end{array}$ \\
\hline Cheng (2005) & $\begin{array}{l}\text { Return on Equity } \\
\text { (ROE), RIVM }\end{array}$ & US & HR & $\begin{array}{l}\text { Abnormal return on equity (ROE) is } \\
\text { decomposed into a conservatism component } \\
\text { and an economic rent component. More } \\
\text { conservative accounting leads to a higher } \\
\text { ROE. }\end{array}$ \\
\hline Choi et al. (2006) & RIVM & US & $\begin{array}{l}\text { a RIVM-based } \\
\text { measure }\end{array}$ & $\begin{array}{l}\text { Using analyst forecast information, this } \\
\text { paper proposes and estimates a } \\
\text { conservatism-correction method for the } \\
\text { empirical tests of RIVM. }\end{array}$ \\
\hline Choi (2007) & $\begin{array}{l}\text { Debt-contracting } \\
\text { benefits of } \\
\text { conservatism }\end{array}$ & $\begin{array}{l}\text { Korea } \\
\text { (mid-cap) }\end{array}$ & AT & $\begin{array}{l}\text { Conditional conservatism is increasing in a } \\
\text { firm's bank-dependence. }\end{array}$ \\
\hline Dietrich et al. (2007) & $\begin{array}{l}\text { Econometrics of the } \\
\text { Basu model }\end{array}$ & $\begin{array}{l}\text { Monte Carlo } \\
\text { simulations }\end{array}$ & AT & $\begin{array}{l}\text { Basu's method is upwards biased and does } \\
\text { not measure accounting conservatism. }\end{array}$ \\
\hline Francis et al. (2004) & $\begin{array}{l}\text { Costs of equity and } \\
\text { conservatism }\end{array}$ & US & AT & $\begin{array}{l}\text { A study of the effects of various earnings } \\
\text { attributes on the cost of equity (information } \\
\text { risk proxy). Conservatism is one of them, } \\
\text { but is shown to be not significant. }\end{array}$ \\
\hline
\end{tabular}




\begin{tabular}{|c|c|c|c|c|}
\hline Authors & Topic areas & Sample & Measures & Main findings \\
\hline Gassen et al. (2006) & $\begin{array}{l}\text { Earnings management } \\
\text { and conservatism }\end{array}$ & International & $\begin{array}{l}\text { AT, NA, MTB, } \\
\text { skewness of } \\
\text { earnings }\end{array}$ & $\begin{array}{l}\text { Conditional conservatism and income } \\
\text { smoothing appear to be distinct concepts, } \\
\text { and are only weakly correlated. }\end{array}$ \\
\hline Giner and Rees (2001) & $\begin{array}{l}\text { International } \\
\text { differences }\end{array}$ & $\begin{array}{l}\text { France, } \\
\text { Germany \& } \\
\text { UK }\end{array}$ & AT & $\begin{array}{l}\text { Earnings of UK firms are more conservative } \\
\text { than the earnings of firms in France and } \\
\text { Germany, as explained by the litigation cost } \\
\text { hypothesis. }\end{array}$ \\
\hline $\begin{array}{l}\text { Givoly and Hayn } \\
\text { (2000) }\end{array}$ & $\begin{array}{l}\text { historic trend of } \\
\text { accounting } \\
\text { conservatism }\end{array}$ & US & $\begin{array}{l}\text { NA, an earning } \\
\text { persistence } \\
\text { measure }\end{array}$ & $\begin{array}{l}\text { An empirical survey of the historical patterns } \\
\text { of US accounting, developing the } \\
\text { non-operating accrual measure of } \\
\text { conservatism. }\end{array}$ \\
\hline Givoly et al. (2007) & $\begin{array}{l}\text { Validity tests of the } \\
\text { Basu model }\end{array}$ & US & AT & $\begin{array}{l}\text { An empirical investigation into the validity } \\
\text { of the Basu measure, and shows that the } \\
\text { Basu AT measure is not reliable. }\end{array}$ \\
\hline $\begin{array}{l}\text { Grambovas et al. } \\
\text { (2006) }\end{array}$ & $\begin{array}{l}\text { Conservatism in EU } \\
\text { and US }\end{array}$ & EU \& US & AT & $\begin{array}{l}\text { Applying the AT measure and panel data } \\
\text { techniques, financial reporting has become } \\
\text { more conservative in both the US and the } \\
\text { EU, and the degrees of conservatism in the } \\
\text { US and and the EU are not markedly } \\
\text { different. }\end{array}$ \\
\hline $\begin{array}{l}\text { Huijgen and } \\
\text { Lubberink (2005) }\end{array}$ & $\begin{array}{l}\text { UK-US Cross-listing } \\
\text { and conservatism }\end{array}$ & $\begin{array}{l}\text { UK } \\
\text { (cross-listed in } \\
\text { US) }\end{array}$ & AT & $\begin{array}{l}\text { UK firms cross-listed in the US are } \\
\text { significantly more conservative than UK } \\
\text { firms that are not cross-listed in the US. }\end{array}$ \\
\hline
\end{tabular}




\begin{tabular}{|c|c|c|c|c|}
\hline Authors & Topic areas & Sample & Measures & Main findings \\
\hline $\begin{array}{l}\text { Klein and Marquardt } \\
\text { (2006) }\end{array}$ & Accounting losses & US & NA & $\begin{array}{l}\text { Negative non-operating accruals are } \\
\text { associated with higher frequency of } \\
\text { accounting losses. But accounting losses are } \\
\text { determined by other non-accounting factors } \\
\text { as well. }\end{array}$ \\
\hline Krishnan (2005b) & $\begin{array}{l}\text { Auditor quality and } \\
\text { conservatism }\end{array}$ & US & $\begin{array}{l}\text { AT, an earnings } \\
\text { persistence } \\
\text { measure }\end{array}$ & $\begin{array}{l}\text { Ex Arthur Andersen's Houston clients } \\
\text { showed less conservative earnings than other } \\
\text { firms. }\end{array}$ \\
\hline Krishnan (2005a) & $\begin{array}{l}\text { Auditor quality and } \\
\text { conservatism }\end{array}$ & US & AT & $\begin{array}{l}\text { The big } 6 \text { auditor's industry experience is } \\
\text { positively correlated with conservative } \\
\text { reporting by their clients. }\end{array}$ \\
\hline Krishnan (2007) & $\begin{array}{l}\text { Auditor quality and } \\
\text { conservatism }\end{array}$ & US & AT, AACF & $\begin{array}{l}\text { Ex Arthur Andersen's clients switched to } \\
\text { more conservative accounting practices } \\
\text { compared to the control group, in order to } \\
\text { reduce litigation risk following the Arthur } \\
\text { Andersen's collapse }\end{array}$ \\
\hline $\begin{array}{l}\text { LaFond and } \\
\text { Roychowdhury (2008) }\end{array}$ & $\begin{array}{l}\text { Managerial-agency- } \\
\text { problem's demand for } \\
\text { conservatism }\end{array}$ & US & AT & $\begin{array}{l}\text { Conditional conservatism is negatively } \\
\text { associated with managerial ownership in a } \\
\text { firm. }\end{array}$ \\
\hline $\begin{array}{l}\text { LaFond and Watts } \\
\text { (2008) }\end{array}$ & $\begin{array}{l}\text { Information } \\
\text { asymmetry and } \\
\text { conservatism }\end{array}$ & US & AT & $\begin{array}{l}\text { Conditional conservatism is increasing in } \\
\text { information asymmetry, which is measured } \\
\text { by the probability of an information-based } \\
\text { trade (PIN score). }\end{array}$ \\
\hline
\end{tabular}




\begin{tabular}{|c|c|c|c|c|}
\hline Authors & Topic areas & Sample & Measures & Main findings \\
\hline Lara and Mora (2004) & $\begin{array}{l}\text { International } \\
\text { accounting differences }\end{array}$ & $\begin{array}{l}8 \text { European } \\
\text { countries }\end{array}$ & AT, MTB & $\begin{array}{l}\text { Continental countries show higher balance } \\
\text { sheet conservatism than the UK, however no } \\
\text { significant difference in earnings } \\
\text { conservatism. Also found negative } \\
\text { correlation between the Basu AT measure } \\
\text { and the MTB measure of conservatism. }\end{array}$ \\
\hline Lara et al. (2009a) & $\begin{array}{l}\text { Corporate governance } \\
\text { and conservatism }\end{array}$ & US (S\&P 1500) & AT, AACF, NA & $\begin{array}{l}\text { Corporate governance quality is positively } \\
\text { associated with the Basu measure of } \\
\text { conservatism. }\end{array}$ \\
\hline Lara et al. (2009b) & $\begin{array}{l}\text { Various determinants } \\
\text { of conservatism } \\
\text { (contracting, } \\
\text { litigation, tax and } \\
\text { political) }\end{array}$ & US & AT, BTM & $\begin{array}{l}\text { In general, this study confirms the known } \\
\text { factors that determine the degree of } \\
\text { accounting conservatism. }\end{array}$ \\
\hline Lara et al. (2005) & $\begin{array}{l}\text { Earnings management } \\
\text { and conservatism }\end{array}$ & $\begin{array}{l}\text { France, } \\
\text { Germany \& } \\
\text { UK }\end{array}$ & AT & $\begin{array}{l}\text { The Basu measure of conservatism is more } \\
\text { significantly different between code law and } \\
\text { common law countries, after discretionary } \\
\text { accruals are controlled for. }\end{array}$ \\
\hline Lobo and Zhou (2006) & $\begin{array}{l}\text { Sarbanes-Oxley Act } \\
\text { and conservatism }\end{array}$ & US & AT & $\begin{array}{l}\text { The level of conservatism increased after the } \\
\text { introduction of SOX in the US. }\end{array}$ \\
\hline Mason (2004) & $\begin{array}{l}\text { Testing residual } \\
\text { income valuation } \\
\text { model }\end{array}$ & US & HR, MTB & $\begin{array}{l}\text { Conservatism is positively correlated with } \\
\text { the valuation weight on operating accruals. }\end{array}$ \\
\hline
\end{tabular}




\begin{tabular}{|c|c|c|c|c|}
\hline Authors & Topic areas & Sample & Measures & Main findings \\
\hline Mensah et al. (2004) & Analyst forecast & US & HR, NA & $\begin{array}{l}\text { Conservatism is negatively correlated with } \\
\text { analyst forecast accuracy. The higher the } \\
\text { conservatism, the lower the accuracy. It is an } \\
\text { overt sign of market inefficiency. }\end{array}$ \\
\hline Monahan (2005) & $\begin{array}{l}\text { RIVM, Earning/return } \\
\text { relation }\end{array}$ & US & HR & $\begin{array}{l}\text { Conservatism affects the earning/return } \\
\text { relation only for firms with high growth in } \\
\text { R\&D, and impacts on the accuracy of RIVM } \\
\text { estimates. }\end{array}$ \\
\hline $\begin{array}{l}\text { Narayanamoorthy } \\
\text { (2006) }\end{array}$ & $\begin{array}{l}\text { Post-Earnings- } \\
\text { Announcement Drift } \\
\text { (PEAD) }\end{array}$ & US & $\begin{array}{l}\text { Asymmetric } \\
\text { autocorrelation } \\
\text { of standardized } \\
\text { unexpected } \\
\text { earnings (SUE) }\end{array}$ & $\begin{array}{l}\text { The stock market systematically overlooked } \\
\text { the predictable implications of conservatism } \\
\text { for the time-series of earnings, leading to } \\
\text { cross-sectional variations in PEAD. }\end{array}$ \\
\hline Pae (2007) & $\begin{array}{l}\text { Conditional } \\
\text { conservatism and } \\
\text { unexpected accruals }\end{array}$ & US & $\begin{array}{l}\text { AT, AACF, } \\
\text { MTB, HR }\end{array}$ & $\begin{array}{l}\text { Conditional conservatism is found to be } \\
\text { mainly achieved by managers manipulating } \\
\text { unexpected accruals. }\end{array}$ \\
\hline Pae et al. (2005) & $\begin{array}{l}\text { The negative } \\
\text { correlation between } \\
\text { the Basu measure and } \\
\text { MTB }\end{array}$ & US & AT, MTB & $\begin{array}{l}\text { This paper shows that Basu's AT measure } \\
\text { and the MTB measure are negatively } \\
\text { correlated, and proposes the conditional vs. } \\
\text { unconditional conservatism distinction. }\end{array}$ \\
\hline $\begin{array}{l}\text { Penman and Zhang } \\
\text { (2002) }\end{array}$ & $\begin{array}{l}\text { Equity valuation, } \\
\text { market efficiency }\end{array}$ & US & HR & $\begin{array}{l}\text { Conservatism results in lower earnings } \\
\text { quality and the market is not efficient enough } \\
\text { to see through the effects of conservatism on } \\
\text { earnings. }\end{array}$ \\
\hline
\end{tabular}




\begin{tabular}{|c|c|c|c|c|}
\hline Authors & Topic areas & Sample & Measures & Main findings \\
\hline $\begin{array}{l}\text { Pope and Walker } \\
\text { (1999) }\end{array}$ & $\begin{array}{l}\text { extraordinary items } \\
\text { and conservatism }\end{array}$ & US vs. UK & AT & $\begin{array}{l}\text { Compared to the US as a benchmark, UK's } \\
\text { FRS } 3 \text { tightens the reporting for } \\
\text { extraordinary items, reflected by a higher } \\
\text { degree of conservatism in UK firms after the } \\
\text { introduction of FRS-3. }\end{array}$ \\
\hline Qiang (2007) & $\begin{array}{l}\text { Various determinants } \\
\text { of conservatism } \\
\text { (contracting, } \\
\text { litigation, tax and } \\
\text { political) }\end{array}$ & US & $\begin{array}{l}\text { Modified BTM } \\
\text { and NA }\end{array}$ & $\begin{array}{l}\text { In general, this study confirms the known } \\
\text { factors that determine the degree of } \\
\text { accounting conservatism, as well as the } \\
\text { negative correlation between Basu measure } \\
\text { and MTB. }\end{array}$ \\
\hline Rajan et al. (2007) & $\begin{array}{l}\text { Return on Investment } \\
\text { (ROI), RIVM }\end{array}$ & US & HR & $\begin{array}{l}\text { Conservative and past growth jointly impact } \\
\text { on firms' return on investment (ROI). }\end{array}$ \\
\hline $\begin{array}{l}\text { Roychowdhury and } \\
\text { Watts (2007) }\end{array}$ & $\begin{array}{l}\text { Reconciling the Basu } \\
\text { measure and MTB }\end{array}$ & US & AT, MTB & $\begin{array}{l}\text { Basu measure and the MTB measure are } \\
\text { reconciled, based on a valuation model. }\end{array}$ \\
\hline Ruddock et al. (2006) & $\begin{array}{l}\text { Non-audit-services } \\
\text { and conservatism }\end{array}$ & Australia & AT & $\begin{array}{l}\text { High Non-Audit-Services are not related to } \\
\text { conservatism, offering evidence that NAS } \\
\text { does not impair audit quality/independence. }\end{array}$ \\
\hline $\begin{array}{l}\text { Sivakumar and } \\
\text { Waymire (2003) }\end{array}$ & $\begin{array}{l}\text { History of US railroad } \\
\text { accounting }\end{array}$ & US (history) & AT & $\begin{array}{l}\text { Early } 20 \text { th-century U.S. railroads } \\
\text { demonstrated increased conservatism } \\
\text { following new fixed asset accounting rules } \\
\text { issued by the Interstate Commerce } \\
\text { Commission (ICC) in } 1907 \text { and } 1908 \text {. }\end{array}$ \\
\hline
\end{tabular}




\begin{tabular}{|l|l|c|c|l|}
\hline Authors & Topic areas & Sample & Measures & Main findings \\
\hline Zhang (2008) & Debt-contracting & US & AT, NA, & Conservatism induces efficiency gains to \\
& benefits of & earnings & lenders and consequently results in lower \\
& conservatism & & skewness & cost of borrowing if the market is efficient. \\
\hline
\end{tabular}


Table 1.2: Statistics on the measures of conservatism in the paper survey

Panel A: Frequency of the measures of conservatism in the paper survey

\begin{tabular}{|l|c|c|c|c|c|c|}
\hline & AT & AACF & $\begin{array}{c}\text { MTB } \\
\text { /BTM }\end{array}$ & NA & HR & Others \\
\hline No. of papers & 37 & 7 & 13 & 10 & 9 & 9 \\
\hline
\end{tabular}

Panel B: Papers by the number of measures of conservatism used

\begin{tabular}{|l|c|c|c|c|}
\hline & 1 measure & 2 measures & $\geq 3$ measures & Total \\
\hline No. of papers & 32 & 13 & 8 & 53 \\
\hline
\end{tabular}

\subsubsection{Basu's Asymmetric Timeliness Measure (AT)}

Basu's (1997) operationalization of accounting conservatism focuses on the implication that earnings will reflect 'bad news' more quickly than 'good news', which is known as the asymmetric timeliness of earnings. Basu (1997) was the first to link asymmetric timeliness with accounting conservatism - the greater the asymmetric timeliness, the greater the degree of accounting conservatism. Empirically, Basu (1997) developed the following cross-sectional regression, also known as the Basu regression, to estimate the degree of conservatism (i.e. asymmetric timeliness):

$$
\frac{E P S_{i t}}{P_{i t}}=\alpha_{0}+\alpha_{1} D R_{i t}+\beta_{0} R_{i t}+\beta_{1} R_{i t} D R_{i t}+\varepsilon_{i t}
$$

where:

- $E P S_{i t}$ : Earnings per share for firm i year $\mathrm{t}$

- $P_{i t}$ : Opening stock market price for firm i year $\mathrm{t}$

- $R_{i t}$ : Stock markets return for firm i year $\mathrm{t}$ 
- $D R_{i t}$ : Dummy variable that is equal to 1 if the stock market return for firm i in year $t$ is negative, and equal to 0 if the stock market return for firm i in year $\mathrm{t}$ is non- negative.

In essence, Basu (1997) regresses accounting earnings $(E P S / P)$ on stock returns $(R)$ separately for 'good-news' and 'bad-news' firm-year observations. A firm-year is deemed as a 'good-news' firm-year, if its market return is positive or zero, i.e. $R_{i t} \geq 0$. Conversely, a firm-year is deemed as a 'bad-news' firm-year, if its stock return is negative, i.e. $R_{i t}<0$. The estimated slope coefficient measures how timely the news embodied in the stock return is recognized in earnings, conditional on the sign of stock returns.

Technically, the Basu regression model uses the dummy variable, DR, to distinguish between 'good-news' and 'bad-news', and thereby allows the slope coefficients and the intercepts to differ between these two groups. Under good news $\left(R_{i t} \geq 0\right), \mathrm{DR}$ is equal to 0 and the good-news timeliness coefficient is $\beta_{0}$. Under bad news $\left(R_{i t}<0\right)$, DR is equal to 1 and the bad-news timeliness coefficient is $\beta_{0}+\beta_{1}$. Clearly, $\beta_{1}$ is the asymmetric timeliness coefficient and is the primary indicator of accounting conservatism in the Basu model. The greater $\beta_{1}$ is, the higher the degree of conservatism.

Tables 1.1 and 1.2 show that Basu's AT measure was used in 37 of the 53 papers reviewed by this chapter, making AT the most frequently used measure of conservatism in this survey. This finding supports Ryan's (2006, p. 514) statement that the Basu AT measure is the most popular measure of conservatism in the literature. Table 1.1 also demonstrates that the papers using the AT measure cover a wide range of topic areas, including (i) the contracting hypothesis of conservatism, (ii) the litigation risk hypothesis of conservatism, (iii) the impact of corporate governance on conservatism, and (iv) the impact of auditor quality on conservatism, as well as 
other topic areas.

In particular, I find that all international comparative studies of conservatism have without exception adopted the Basu AT measure. These international studies typically test the impacts of a variety of legal, political and institutional factors on the firm's degree of accounting conservatism (for example: Bushman and Piotroski, 2006; Ball et al., 2000, 2003). Ball et al. (2008) use an international comparative empirical design to test the significance of the debt market relative to the equity market in influencing the firm's degree of accounting conservatism and find that firms' degree of financial reporting conservatism increases with the importance of the debt market in a country, but not with the importance of the equity market.

The literature has identified a number of strengths and weaknesses of the Basu AT measure [see Ryan (2006) for a comprehensive discussion on this topic]. The strengths of the Basu AT measure include: (1) it has been widely applied, and for nearly nine years it was the only measure in the literature to implement the asymmetric timeliness operationalization of conservatism; ${ }^{3}$ (2) many papers using the AT measure have produced results that are consistent with their theoretical predictions, which increases researchers' confidence not only in the theory but also in the measure itself (Ryan, 2006); (3) the AT measure is well suited to large-sample cross-sectional analysis, manifested by the use of the AT measure in the very large scale international comparative studies discussed earlier.

On the other hand, critics of the Basu AT measure have identified the following weaknesses: (1) the AT measure shows poor performance in time-series research designs (Givoly et al., 2007); (2) the AT measure does not work well when information is aggregated over a time-period (Givoly et al., 2007); (3) there are econo-

\footnotetext{
${ }^{3}$ The second measure implementing the asymmetric timeliness idea is the AACF measure, which was published in 2006 - 9 years after Basu's seminal paper in 1997.
} 
metric deficiencies in the AT measure, including a sample-variance-ratio bias and a sample-truncation bias ${ }^{4}$ (Dietrich et al., 2007); (4) there is a simultaneity problem in the relationship between earnings and stock returns (Beaver et al., 2008); (5) the AT measure does not provide a firm-specific measure of conservatism; (6) changes in economic rents should not be included in the stock return variable in the Basu regression (Roychowdhury and Watts, 2007); and (7) market mispricing may cause the stock returns to incorrectly reflect the true extent of the underlying economic news (Beatty, 2007).

These weaknesses suggest that the AT measure may be a biased estimator of the true degree of accounting conservatism in the sample. But the debate about the existence and the direction of the bias in the AT measure is still unsettled in the literature. Gigler and Hemmer (2001) and Dietrich et al. (2007) argue that the Basu measure may be biased upward. Although the conclusions are similar, these two studies are based on very different theoretical grounds. Gigler and Hemmer's (2001) study is based on an agency model of pre-emptive voluntary disclosure, while Dietrich et al.'s (2007) study is almost entirely based on econometric issues (see footnote 4 for Dietrich et al.'s main argument). Givoly et al. (2007) also come to a similar conclusion that the Basu measure is not valid, but do not provide any indication as to whether it is biased upward or downward.

On the other side of the debate, Ryan (2006) strongly supports the AT measure and argues that, with more robust model specifications as well as empirical designs, the AT measure may not be as strongly biased as it is argued by Dietrich et al.

\footnotetext{
${ }^{4}$ In Dietrich et al (2007), the sample-variance-ratio bias describes the well-known econometric result that reverse regressions are generally biased, except in certain limited situations. The sample truncation bias is caused by partitioning the sample into good-news and bad-news firms based on stock returns. However, at a more fundamental level, both problems appear to be caused by the fact that stock returns contain non-earnings news as well as earnings news, which introduces measurement errors to the regressor in the Basu AT regression.
} 
(2007). In particular, he suggests that the validity and robustness of the AT measure can be improved by incorporating industry-specific proxies for economic 'news' and by controlling for the effects of business cycles (Ryan, 2006).

\subsubsection{Asymmetric Accrual to Cash-flow Measure (AACF)}

Ball and Shivakumar (2005) developed the AACF measure in order to estimate the degree of accounting conservatism in private (unlisted) companies, as Basu's AT measure is not suitable for private companies given that there is no stock price information available for private companies. To overcome this difficulty, Ball and Shivakumar (2005) developed essentially the non-stock-market equivalent of the AT measure, which is based on the following cross-sectional regression:

$$
A C C_{i t}=\beta_{0}+\beta_{1} D C F O_{i t}+\beta_{2} C F O_{i t}+\beta_{3} D C F O_{i t} C F O_{i t}+\varepsilon_{i t}
$$

where

- $A C C_{i t}$ : Operating accruals, measured as $\Delta$ Inventory $+\Delta$ Debtors $+\Delta$ Other current assets - $\Delta$ Creditors - $\Delta$ Other current liabilities - Depreciation.

- $D C F O_{i t}$ : Dummy variable that is set to 0 if $C F O_{i t} \geq 0$, and is set to 1 if $C F O_{i t}<0$.

- $C F O_{i t}$ : Cash-flow for period t.

In the regression above, the coefficient $\beta_{3}$ is the AACF measure of accounting conservatism. A higher $\beta_{3}$ indicates a higher degree of accounting conservatism. Clearly, the AACF measure and the Basu AT measure are based on the same fundamental idea of asymmetric timeliness and are estimated from models with a very similar structure. In essence, both models regress an earnings variable on a proxy 
for economic 'news'. Both models employ dummy variables ( $D R$ and $D C F O)$ to distinguish between 'good-news' and 'bad-news'. The main difference between these two measures comes from their different choices of the proxies for economic 'news' and the response variable. The Basu AT model uses stock return as the proxy for news, whereas the AACF measure uses operating cash-flow as the proxy for news. In terms of the response variable, the Basu AT model uses total earnings, whereas the AACF measure selects only the accrual component of total earnings. Ball and Shivakumar $(2005 ; 2006)$ use the accrual component of total earnings because, in their view, accounting conservatism mainly influences the accruals component of earnings rather than the cash flows component.

Table 1.1 shows that, out of the 53 papers surveyed, only seven papers applied the AACF measure. This relatively low frequency is probably due to the AACF measure being the most recently developed among the five measures reviewed. However, it appears that conservatism researchers are increasingly interested in using the AACF measure as an alternative to the Basu AT measure, given the criticisms of the Basu AT measure. For example, the concerns about validity of the Basu AT measure have led Lara et al. (2009a) to estimate the AACF measure in addition to the AT measure in their study of the relationship between corporate governance and accounting conservatism. The main reason for adopting the AACF measure in addition to the AT measure, as explained by Lara et al. (2009a), is to ensure that the paper's main empirical results obtained by the AT measure are not spurious.

The strengths and weaknesses of the AACF measure have not been discussed to any great extent in the conservatism literature, possibly due to the fact that this measure is a relatively new one and its robustness has not yet been validated. To date, the conservatism literature has not identified any bias in the AACF measure either. Clearly, more validation research is required before the strengths, weaknesses and 
any potential bias in the AACF measure can be fully understood.

\subsubsection{The Market-to-Book ("MTB”) or Book-to-Market (“BTM”) ratio}

The idea underlying the use of MTB (or BTM) as a measure of accounting conservatism is that, ceteris paribus, a conservative accounting system tends to depress the net book value of a firm relative to the firm's 'true' economic value. Therefore, a higher MTB (and a lower BTM) implies a higher degree of accounting conservatism, and vice versa. ${ }^{5}$ The MTB measure is strongly rooted in the analytical work based on the Residual Income Valuation Model (RIVM) (Feltham and Ohlson, 1995; Zhang, 2000; Beaver and Ryan, 2000). Feltham and Ohlson (1995) first introduced accounting conservatism in the RIVM context, and characterize conservatism as a tendency to bias downwards the book value of a firm relative to its market value. This manifestation of conservatism has been carried into later analytical work on conservatism, such as Beaver and Ryan (2000; 2005) and Zhang (2000).

In addition to the raw MTB (or BTM) ratio, Beaver and Ryan (2000) developed a refinement in using the BTM as a measure of conservatism, which has been quite widely applied in the literature. This refinement decomposes the BTM ratio into two components - the bias component and the lag component. Beaver and Ryan (2000) argue that the bias component of BTM should be interpreted as a measure of accounting conservatism. In order to decompose BTM, Beaver and Ryan (2000) regress BTM on a series of lagged stock returns, leading up to six lagged years, as in the following fixed-effect panel data regression:

\footnotetext{
${ }^{5}$ It should be noted that MTB is positive measure of conservatism, whereas BTM is a negative measure of conservatism.
} 


$$
B T M_{i t}=\alpha_{t}+\alpha_{i}+\sum_{j=0}^{6} \beta_{j} R O E_{i, t-j}+\varepsilon_{i t}
$$

where

- $B T M_{i t}$ : Book-to-Market (BTM) ratio of firm i, at the end of year t.

- $\alpha_{t}$ : Year-to-year variation in the BTM common to the sample firms

- $\alpha_{i}$ : Bias component of BTM for firm i

- $R O E_{t-j}$ : Return on Equity (ROE) in each of the 6 years preceding year $t$.

- $\beta_{j}$ : Regression coefficients on $R O E_{i, t-j}$

In the regression above, the time intercept, $\alpha_{t}$, is fixed for all firms in any particular year, but may change from year to year. Therefore, $\alpha_{t}$ captures the time effect of market-wide BTM movements. The fixed effect coefficient, $\alpha_{i}$, captures the firmspecific persistent bias component of BTM for firm $i$, and is fixed for each firm. $\beta_{j}$ is the regression coefficient of the lag component of the BTM ratio. According to Beaver and Ryan (2000), the bias component of BTM, $\alpha_{i}$, is a more accurate measure of the firm's degree of conservatism than the raw BTM.

As Table 1.2 - Panel A demonstrates, 13 papers in the literature surveyed here have applied MTB (or BTM), making it the second most widely applied measure of conservatism. In general, the papers that apply the MTB (or BTM) measure use it to estimate the degree of 'unconditional' conservatism, as opposed to 'conditional' conservatism. ${ }^{6}$ For example, Lara and Mora (2004) use the MTB ratio as a measure

\footnotetext{
${ }^{6}$ Conditional conservatism is defined as news-dependent conservatism - the asymmetric treatment of good news and bad news. Unconditional conservatism is defined as news-independent conservatism - that is the accounting system always creates a downward bias to book values and earnings, irrespective of whether there is good news or bad news. According to Beaver and Ryan (2005), conditional conservatism is measured by Basu's AT measure, and unconditional conservatism is measured by MTB (or BTM). For further discussion see sub-section 1.4.1.
} 
for 'unconditional' conservatism, and find that continental European countries have a higher degree of 'unconditional' conservatism (i.e. higher MTB) than the UK.

A key advantage of the MTB (or BTM) measure of conservatism is that it is firmspecific. In comparison, the AT measure and the AACF measure generally cannot make firm-specific measurements. ${ }^{7}$ Another advantage is that the MTB measure has the theoretical underpinning of Feltham and Ohlson's RIVM model (1995), which is one of the most rigorous valuation models in the accounting literature.

In terms of weaknesses, the theory developed by Roychowdhury and Watts (2007) implies that the MTB (or BTM) ratio may be a (upward) biased estimator of the degree of conservatism, due to the existence of economic rents in most firms. They argue that the economic rents of a firm are generally not recognizable in the book value of the firm, per GAAP. Therefore, regardless of the degree of conservatism, economic rents generally depress the book value of a firm relative to the market value of the firm. The more economic rents the firm has, the more likely its MTB (or BTM) ratio overstates the true degree of conservatism in that firm. Only if the firm has zero economic rents, can the MTB ratio be an unbiased estimator of the firm's true degree of accounting conservatism.

Another problem is that the MTB (or BTM) ratio is also a well-known proxy for many factors other than accounting conservatism in the empirical accounting and finance research literature and therefore it is prone to confounding problems. For instance, MTB is widely used as a proxy for default risk by finance researchers (e.g. Fama and French, 1993, 1995). Varying roles played by MTB such as this creates considerable uncertainty as to how researchers should interpret MTB.

\footnotetext{
${ }^{7}$ Even though, in principle, the Basu AT measure can be estimated from time-series data for each individual firm, Givoly et al. (2007) show that in practice the AT measure performs very poorly in time-series in terms of detecting conservatism in firms. No studies have yet attempted to fit the AACF model to time-series data, and hence there is currently no evidence on how well AACF could perform as a firm-specific measure in time-series data.
} 


\subsubsection{The Negative Accruals Measure (NA)}

Givoly and Hayn (2000) propose a measure of conservatism that focuses on nonoperating accruals as a subset of the firm's book value. Non-operating accruals are calculated as total accruals minus operating accruals. Total accruals are equal to the firm's net income before depreciation minus the cash flow from operating activities, whereas operating accruals are calculated using the balance sheet approach, which is very similar to the calculation of operating accruals (i.e. $A C C$ ) used in the AACF method.

$$
N A=T A C C-O P A C C
$$

where

TACC : Total Accrual, calculated as Net Income (after depreciation) - Operating Cash Flow

$O P A C C$ : Operating accrual, measured as $\triangle$ Inventory $+\triangle$ Debtors $+\Delta$ Other current assets - $\Delta$ Creditors - $\Delta$ Other current liabilities.

The rationale behind using negative accruals as a measure of accounting conservatism is that accounting conservatism uses the mechanism of accruals to defer the recognition of economic gains and accelerate the recognition of economic losses. Through the process of delaying gains and accelerating losses, the level of accumulated non-operating accruals in a firm gradually becomes more and more negative (Givoly and Hayn, 2000). Using a sample of 896 firms, Givoly and Hayn (2000) show that the cumulative negative non-operating accruals for these sample firms increased significantly in the sample period 1965 to 1998. They also found that for the same period (positive) operating accruals of these 896 firms had increased. But on a net basis, the increases in operating accruals were not large enough to offset the increasingly negative non-operating accruals, which leads to decreasing total accruals 
(operating plus non-operating accruals) over that period. Givoly and Hayn (2000) argue that the trend of increasing negative accruals is a manifestation of increases in the overall degree of accounting conservatism in the sample firms that occurred between 1965 and 1998 .

One strength of the NA measure is that it is a firm-specific measure of conservatism. Another strength is that NA is generally easy to implement, as it does not require many data items. Furthermore, the NA measure is not market-based, and therefore, in contrast to the AT and MTB measures, it can also be applied to private firms.

However, this survey also indicates that the NA measure has two weaknesses: First, the original form of NA as in Givoly and Hayn (2000) requires researchers to measure the accumulated accrual over an extended time period beginning from a particular base year. But in practice, the base year is difficult to standardize across firms. A strategy adopted in recent studies is to calculate the average non-operating accruals over 3 years, centered around year $\mathrm{t}$ (that is, year $t-1$ to year $t+1$ ), and use the three-year average as the proxy for accounting conservatism (Lara et al., 2009a; Ahmed and Duellman, 2007). Obviously, at the same time that this new approach of measuring NA avoids the base-year problem, it creates another potential problem as it is no longer a measure of accumulated non-operating accruals, but rather an average measure of periodic non-operating accruals.

The second weakness of the NA measure is that the depreciation charge is an important element of accrual accounting, but is ignored in the NA measure. In fact, Givoly and Hayn (2000) added back the depreciation expense to earnings when they calculated the operating and non-operating accruals in order to make the adjusted earnings compatible with operating cash flows, as depreciation is a non-cash item. Although this exclusion of depreciation from the accruals calculation is justified, 
it nevertheless leaves a crucial item of accrual accounting entirely out of consideration. Therefore, it may be useful for researchers in the future to investigate the impact of conservatism on allowances assigned to depreciation and the possibility of designing new measures of accounting conservatism that incorporate depreciation allowances.

To date there has not been a discussion in the literature on any potential biases in the NA measure. I therefore encourage other researchers to consider this issue in future research.

\subsubsection{The Hidden Reserves Measure (HR)}

The fifth measure of accounting conservatism is the hidden reserves measure. Penman and Zhang (2002) argue that accounting conservatism creates hidden reserves (i.e. cookie jar reserves), the amount of which can be used to gauge the degree of conservatism in a firm. They argue that the higher the amount of the hidden reserves, the more conservative is the firm's financial reporting system. However, since hidden reserves are not explicitly reported in either the financial statements or anywhere else, they can only be estimated by the researchers themselves.

Two methods have been employed in the conservatism literature to estimate the amount of hidden reserves. The methods are similar and yield similar proxies for accounting conservatism. The first, developed by Ahmed et al. (2000), uses two ratios, $R \& D /$ sales and advertising expenditures/sales, as proxies for hidden reserves. But the second method, developed by Penman and Zhang (2002) is a more commonly used and more sophisticated method of estimating hidden reserves. Thus, this review concentrates on this second method. Penman and Zhang (2002) construct a hidden reserves measure of accounting conservatism, called the $C$ score, 
based on the following method:

$$
C_{i t}=\frac{E R_{i t}}{N O A_{i t}}
$$

where

$E R_{i t}$ : Estimated hidden reserves created by accounting conservatism, where $\mathrm{i}$ indicates firms and $\mathrm{t}$ balance sheet dates.

$N O A_{i t}$ : Net Operating Assets, the book value of operating assets minus operating liabilities, excluding financial assets and liabilities.

But estimating $E R_{i t}$ remains a non-trivial challenge. To address this issue, Penman and Zhang (2002) propose the following formula for estimating $E R_{i t}$ :

$$
E R_{i t}=I N V_{i t}^{r e s}+R D_{i t}^{r e s}+A D V_{i t}^{r e s}
$$

where

- INV $V_{i t}^{\text {res }}$ : Inventory reserve

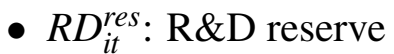

- $A D V_{i t}^{\text {res. }}$ Brands asset

$I N V_{i t}^{\text {res }}$ is the value under US GAAP of the LIFO reserve as reported in the footnotes to the financial statements. $R D_{i t}^{r e s}$ is the $\mathrm{R} \& \mathrm{D}$ reserve calculated as the estimated amortized R\&D asset that would have been capitalized had accounting standards permitted such capitalizations. The calculation involves two steps: first, capitalize all $R \& D$ expenses from the income statement as if $R \& D$ were an asset; second, amortize the balance of capitalized $\mathrm{R} \& \mathrm{D}$ asset, using the estimated average industry rates of amortization. The resulting $\mathrm{R} \& \mathrm{D}$ asset after amortization is the $R D_{i t}^{r e s}$. Similarly, the advertising reserve, $A D V_{i t}^{\text {res }}$, is an estimated brand asset, derived by 
first capitalizing all advertising expenses and then amortizing them, in much the same way as the estimation of $R D_{i t}^{r e s}$.

Several data items required by the Penman and Zhang method are frequently unavailable, such as $R \& D$ expense and advertising expense, as these items are often not disclosed by firms and do not often appear in the Compustat database. As a consequence, the sample size for HR is generally much smaller than in studies using the other measures of conservatism. This data requirement also makes the HR measure more difficult to apply to international studies of conservatism, as the accounting regulations in many countries do not mandate the disclosure of $R \& D$ and advertising expenses. Perhaps for this reason, I found that none of the existing international studies of accounting conservatism have applied the HR measure.

Table 1.2 - Panel A shows that 9 papers out of the 53 reviewed in this chapter have adopted the HR measure. For example, Mensah et al. (2004), apply the HR measure, and find that conservatism is negatively correlated with the accuracy of analyst forecasts of firm earnings. Also using the HR measure, Rajan et al. (2007) demonstrate that conservatism and a firm's growth rate jointly impact on the firm's return on investment (ROI). They find that a higher past growth rate combined with a conservative accounting system leads to a lower ROI, while a higher past growth combined with a liberal accounting system leads to a high ROI (Rajan et al., 2007).

The theoretical and empirical evidence by Penman and Zhang (2002) and Rajan et al. (2007) show that HR is intertwined with firms' investment growth rates. When a firm's investment growth is high, HR tends to accumulate. In contrast, when a firm's investment growth slows down, HR decreases and tends to be released back into earnings. This pattern suggests that the HR measure may be biased. Depending on the firm's growth rate, HR may either overstate or understate the true degree of conservatism in a firm. If the growth rate is positive, the bias may be positive; and 
vice versa.

\subsection{Construct validity \& the existing measures of con- servatism}

The construct validity framework is a methodology of the social sciences that specifically addresses measurement issues (Messick, 1989; Campbell and Overman, 1988). Messick's (1989, p. 13) seminal chapter on construct validity theory defines it as "the degree to which empirical evidence and theoretical rationale support the adequacy and appropriateness of interpretations and actions based on test scores”. That is, construct validity is concerned with the degree of correspondence between the result of applying a measure (often called an operationalization) and the theoretical construct that the measure is supposed to operationalize. If a measure is valid, that is, there is a high degree of correspondence, then conclusions or inferences drawn from applying that measure are also likely to be valid. Conversely, if the measure is not valid, showing a low degree of correspondence, then the likelihood is that the conclusions or inferences are not valid either.

A theoretical construct, by its abstract nature, is inherently unobservable (Campbell and Overman, 1988). A construct is a subjective meaning, concept or interpretation in the world of ideas that is commonly shared by a certain group of people (such as researchers) which denotes an abstract physical or social being. However, a construct might and often does have observable operationalizations in the real world. For example, human intelligence is a theoretical construct that is inherently unobservable. Although the theoretical construct intelligence cannot be directly observed, its operationalizations, that is, its footprints, in society can be observed. 
Table 1.3: Validation Criteria (sub-validities)

\begin{tabular}{|c|c|}
\hline $\begin{array}{l}\text { Name of Validation } \\
\text { Criterion (sub-validity) }\end{array}$ & $\begin{array}{l}\text { Descriptions of key features and key questions asked } \\
\text { by each criterion. }\end{array}$ \\
\hline Convergent validity & $\begin{array}{l}\text { Are multiple methods of measuring the same } \\
\text { construct highly correlated? In other words, do } \\
\text { they converge? }\end{array}$ \\
\hline Concurrent validity & $\begin{array}{l}\text { (Comparing different groups under the same } \\
\text { construct) Is a measure able to distinguish } \\
\text { between groups that it should theoretically be } \\
\text { able to distinguish between? That is, is this } \\
\text { measure able to give a score that it is } \\
\text { theoretically expected to give under certain } \\
\text { predetermined conditions (criteria)? }\end{array}$ \\
\hline Discriminant validity & $\begin{array}{l}\text { (when measuring the same group of samples } \\
\text { under different constructs) Is a measure of } \\
\text { construct A significantly different from, or } \\
\text { uncorrelated with, measures of some other } \\
\text { constructs (say B or C), when there are no } \\
\text { reasons why these measures of different } \\
\text { constructs (A, B and C) should be significantly } \\
\text { similar and correlated with each other? }\end{array}$ \\
\hline Predictive validity & $\begin{array}{l}\text { Is the measure able to predict whatever it should } \\
\text { theoretically be able to predict? Although } \\
\text { similar to concurrent validity, predictive validity } \\
\text { is about a measure's ability to predict a future } \\
\text { condition, whereas concurrent validity is about a } \\
\text { measure's ability to describe a current condition. }\end{array}$ \\
\hline $\begin{array}{l}\text { Internal consistency } \\
\text { (reliability) }\end{array}$ & $\begin{array}{l}\text { Does the single measure give consistent results } \\
\text { for the same group in repeated measures? }\end{array}$ \\
\hline Content validity & $\begin{array}{l}\text { Does the measure include all the contents } \\
\text { pertinent to that theoretical construct, usually by } \\
\text { inspection by other experts in the field? }\end{array}$ \\
\hline $\begin{array}{l}\text { Statistical conclusion } \\
\text { validity }\end{array}$ & Is the statistical conclusion from the test valid? \\
\hline
\end{tabular}


An operationalization can be interpreted as the overt manifestation in the observable real world of some abstract construct that is inherently unobservable. For example, high scores in mathematics or language tests may be regarded as indicators of high intelligence. Similarly, a high memory score could be regarded as an indicator of high intelligence. Alternatively, a particular IQ test, devised by psychologists, might be used to indicate a person's level of intelligence. Philosophically, it is possible that there is an infinite number of operationalizations of any construct, but at the same time no single measure in itself is perfect (Campbell and Overman, 1988).

In this section, I evaluate the construct validity of the existing five measures of accounting conservatism described in the previous section. Construct validity is chiefly concerned with two issues: (1) How to operationalize (or measure) a theoretical construct? (2) How to determine which measures (operationalizations) represent the construct well and which ones do not? In order to deal with these two issues, construct validity methodologists have developed a set of rigorous criteria that can be employed to validate specific measures in a wide range of contexts. There are seven common operational criteria (also known as sub-validities) that may be used to assess construct validity. These are summarized in Table 1.3.

The criteria have been extensively applied in many areas of social sciences. For example, Adcock (2002) provide a review of the applications of these criteria in political science research. Also based on these criteria, Venkatraman and Grant (1986) report on a survey of the construct validity of the measures employed in the organizational behavior literature. Kwok and Sharp (1998) offer an excellent summary of the status of construct validity in behavioral accounting research and the issues arising from such research.

Each individual validation criterion in Table 1.3 emphasizes a particular aspect 
of construct validity. Taken together, these criteria provide the general evidential basis for concluding on the construct validity of a given measure of a theoretical construct. In general, satisfying only a single criterion is not sufficient to validate a measure and the interpretations of it. Rather, all, or at least the majority, of the criteria in Table 1.3 must be simultaneously met if a measure is to be judged as valid. On the other hand, depending on the particular construct and the measures, some criteria may be more relevant than others when we validate certain measures.

I wish to emphasize that construct validity is always a matter of degree, rather than being binary (yes or no). Therefore, it is rare, if ever, that a measure can perfectly represent the underlying construct without any errors. However, the degree to which a measure's validity should be regarded as being acceptable is a matter of judgment.

In this chapter, I evaluate the existing measures of accounting conservatism against only four of the criteria, or sub-validities: (1) convergent validity; (2) concurrent validity; (3) statistical conclusion validity; (4) internal consistency (reliability). An evaluation of the measures of conservatism against the other three criteria (predictive validity, discriminant validity, and content validity) cannot be carried out due to the absence of the relevant evidence in the literature.

\subsubsection{Convergent validity}

\section{Sources of convergent validity evidence}

Convergent validity is a validation criterion that considers whether several measures of the same construct tend to converge (Cook and Campbell, 1979; Campbell and Fiske, 1959; Shepard, 1993). If different measures of the same construct are measured with the same sample data and significantly different results emerge, those 
measures lack convergent validity. I examine convergent validity by looking at the pair-wise association of the five measures of conservatism. As the literature provides evidence on only three of the possible pair-wise associations among the measures (Basu's AT and MTB, MTB and NA, and Basu's AT and AACF) I estimate the missing associations myself. I thus consider the following sources of evidence on convergent validity:

(1) The correlations reported in the literature; and

(2) Supplementary estimates of associations: correlations and regressions.

As the AT and AACF measures are not firm-specific, it is not possible to calculate correlations involving these measures. To tackle this issue, I estimate the associations from augmented cross-sectional regressions, as implemented in Roychowdhury and Watts (2007) and Lara et al. (2009b). I run AT and AACF regressions augmented by each of MTB, NA and HR, and use the relevant regression coefficients to determine the direction of the association between the cross-sectional measures and the firm-specific measures. ${ }^{8}$ Details of this estimation procedure are given in the notes at the foot of Table 1.4. Given that regression and correlations coefficients are not comparable, I only report (in Table 1.4) the direction of the associations (as indicated by correlations and regression coefficients) along with their significance levels, but not the values of the associations.

My estimates of the associations are based on a US sample of publicly traded firms covered in Compustat that are or were listed on the NYSE, AMEX and NASDAQ stock exchanges, for the period from 1989 to 2007 . In forming this sample, I

\footnotetext{
${ }^{8}$ Augmented regressions are necessary because there is no natural way of calculating the correlation coefficient between a cross-sectional measure (e.g., AT and AACF) and a firm-specific measure (e.g., MTB, NA and HR). The augmented regressions approach employed in Table 1.4 has been widely applied in the accounting conservatism literature (e.g., Roychowdhury and Watts, 2007).
} 
deleted firms that had missing values on any of the measures of conservatism. After deleting the missing observations and trimming the key variables (see appendix) by $1 \%$ from both the top and the bottom, the final sample contained 15,735 firm-years. Using this sample, I obtain the MTB ratio from Compustat directly, and estimate the other 4 measures of conservatism according to the methods described in Section 1.2. The appendix to this chapter reports the descriptive statistics of this sample.

\section{Key convergent validity results}

Overall, Table 1.4 shows that the five measures of conservatism seem to fall into two distinct groups: (1) The AACF and the AT measures appear to belong to one group and (2) the MTB, NA and HR measures appear to belong to another group. More specific characteristics are outlined below.

First, the Basu AT measure and the AACF measure are positively associated, as shown in the top left corner of Table 1.4. The MTB, NA and HR measures are also all positively associated among themselves, as shown in the bottom right corner. This shows that within each group, the measures are all positively correlated.

Second, all the across-group associations were negative and, with the exception of AT and NA, were significant at the $1 \%$ or $5 \%$ levels. This suggests that, overall, the two groups of measures tend to diverge from each other.

Third, the values of both the Pearson and Spearman correlations among the firm- specific measures (MTB, NA and HR) appear rather low. For example, the Pearson correlation between MTB and NA is 0.141 and between MTB and HR is 0.114. Likewise, NA and HR have a Pearson correlation of 0.104. None of these correlations exceed 0.2. The Spearman rank correlations have similar values. The evidence obtained from Ahmed et al. (2000) corroborates these results. Ahmed et al. (2000) considered the correlation between (1-BTM), as a positive measure 
Table 1.4: Evidence of convergent validity

(Signs of pair-wise associations among different measures of conservatism)

\begin{tabular}{|c|c|c|c|c|c|}
\hline & $\begin{array}{l}\text { Basu- } \\
\text { AT }\end{array}$ & AACF & МTB & NA & HR \\
\hline Basu-AT & & $\begin{array}{l}+ \\
\text { (a) }\end{array}$ & $\begin{array}{l}- \\
* * *(b)\end{array}$ & $\begin{array}{l}- \\
\text { (c) }\end{array}$ & $\begin{array}{l}- \\
*(d)\end{array}$ \\
\hline$A A C F$ & $\begin{array}{l}+ \\
\text { (a) }\end{array}$ & & $\begin{array}{l}- \\
* * *(\mathrm{e})\end{array}$ & $\begin{array}{l}- \\
* * *(\mathrm{f})\end{array}$ & $\begin{array}{l}- \\
* *(\mathrm{~g})\end{array}$ \\
\hline$M T B$ & & & & $\begin{array}{l}+ \\
* * *(\mathrm{~h})\end{array}$ & $\begin{array}{l}+ \\
* * *(\mathrm{~h})\end{array}$ \\
\hline$N A$ & & & $\begin{array}{l}+ \\
* * *(\mathrm{~h})\end{array}$ & & $\begin{array}{l}+ \\
* * *(\mathrm{~h})\end{array}$ \\
\hline$H R$ & & & $\begin{array}{l}+ \\
* * *(\mathrm{~h})\end{array}$ & $\begin{array}{l}+ \\
* * *(\mathrm{~h})\end{array}$ & \\
\hline
\end{tabular}

Significance levels: $* 10 \%, * * 5 \%, * * * 1 \%$, two-tailed

Note: the sources or the method of estimation of each correlation/regression coefficient in the above table:

(a) AACF and Basu-AT: estimated by Brown et al. (2006). The Pearson correlation is above the main diagonal and the Spearman rank correlation is below it.

(b) Basu-AT and MTB: reported as the sign of $\beta_{3}$ from the following augmented Basu AT regression:

$E P S_{i t} / P_{i t-1}=\alpha_{0}+\alpha_{1} D R_{i t}+\alpha_{2} M T B_{i t}+\alpha_{3} D R_{i t} M T B_{i t}+\beta_{0} R_{i t}+\beta_{1} R_{i t} D R_{i t}+\beta_{2} R_{i t} M T B_{i t}+\beta_{3} R_{i t} D R_{i t} M T B_{i t}+\varepsilon_{i t}$

(c) Basu-AT and NA: reported as the sign of $\beta_{3}$ from the following augmented Basu AT regression:

$$
E P S_{i t} / P_{i t-1}=\alpha_{0}+\alpha_{1} D R_{i t}+\alpha_{2} N A_{i t}+\alpha_{3} D R_{i t} N A_{i t}+\beta_{0} R_{i t}+\beta_{1} R_{i t} D R_{i t}+\beta_{2} R_{i t} N A_{i t}+\beta_{3} R_{i t} D R_{i t} N A_{i t}+\varepsilon_{i t}
$$

(d) Basu-AT and HR: reported as the sign of $\beta_{3}$ from the following augmented Basu AT regression :

$$
E P S_{i t} / P_{i t-1}=\alpha_{0}+\alpha_{1} D R_{i t}+\alpha_{2} H R_{i t}+\alpha_{3} D R_{i t} H R_{i t}+\beta_{0} R_{i t}+\beta_{1} R_{i t} D R_{i t}+\beta_{2} R_{i t} H R_{i t}+\beta_{3} R_{i t} D R_{i t} H R_{i t}+\varepsilon_{i t}
$$

(e) AACF and MTB: reported as the sign of $\beta_{3}$ from the following augmented AACF regression

$$
\begin{aligned}
A C C_{i t}= & \alpha_{0}+\alpha_{1} D_{C F O} O_{i t}+\alpha_{2} M_{T B}+\alpha_{i t}{ }^{2 C F O} O_{i t} M T B_{i t}+\beta_{0} C F O_{i t}+ \\
& \beta_{1} C F O_{i t} D C F O_{i t}+\beta_{2} C F O_{i t} M T B_{i t}+\beta_{3} C F O_{i t} D C F O_{i t} M T B_{i t}+\varepsilon_{i t}
\end{aligned}
$$

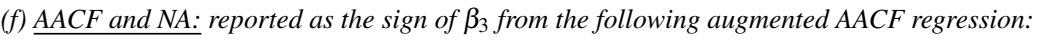

$$
\begin{aligned}
A C C_{i t}= & \alpha_{0}+\alpha_{1} D C F O_{i t}+\alpha_{2} N A_{i t}+\alpha_{3} D C F O_{i t} N A_{i t}+\beta_{0} C F O_{i t}+ \\
& \beta_{1} C F O_{i t} D C F O_{i t}+\beta_{2} C F O_{i t} N A_{i t}+\beta_{3} C F O_{i t} D C F O_{i t} N A_{i t}+\varepsilon_{i t}
\end{aligned}
$$

(g) $A A C F$ and HR: reported as the sign of $\beta_{3}$ from the following augmented AACF regression :

$$
\begin{aligned}
A C C_{i t}= & \alpha_{0}+\alpha_{1} D C F O_{i t}+\alpha_{2} H R_{i t}+\alpha_{3} D C F O_{i t} H R_{i t}+\beta_{0} C F O_{i t}+ \\
& \beta_{1} C F O_{i t} D C F O_{i t}+\beta_{2} C F O_{i t} H R_{i t}+\beta_{3} C F O_{i t} D C F O_{i t} H R_{i t}+\varepsilon_{i t}
\end{aligned}
$$

(h) These are Pearson correlations (above the main diagonal) and Spearman correlations (below the main diagonal) between firm-specific measures. 
for conservatism, and the NA measure and found that the Spearman correlation coefficient between (1-BTM) and NA was not statistically significant, while the Pearson correlation coefficient was 0.124 and significant at the $5 \%$ level.

Fourth, the correlations between the AT and AACF measures are reported by Brown et al. (2006). These correlations are not straightforward to obtain because both AT and AACF are based on cross-sectional regressions. Brown et al. (2006) circumvented this problem by calculating the country-level AT and AACF scores, and then estimating the correlation of AT and AACF scores across the countries. They found that the Pearson correlation was 0.266 , and the Spearman correlation is 0.298 . However, neither of them was significant at the $10 \%$ level. This lack of significance is probably due to the small country-level sample, which consists of only 20 country-observations.

\section{Basu's AT vs. MTB}

The empirical evidence in Table 1.4 is consistent with the finding in recent studies that there is a negative association between Basu's AT measure and the MTB measure $^{9}$ (Pope and Walker, 2003; Pae et al., 2005; Roychowdhury and Watts, 2007; Ryan, 2006; Beaver and Ryan, 2005). For example, Pae et al. (2005) find that when firms are clustered into several portfolios according to their MTB ratio, the high MTB group has consistently lower Basu measures than the low MTB group and vice versa.

However, the negative association is inconsistent with the theoretical prediction that if the AT and BTM measures are both measures of the same underlying construct (i.e. accounting conservatism) they should be highly positively correlated,

\footnotetext{
${ }^{9}$ To date, except Table 1.4 in this chapter, the extant literature has not tested whether the AACF measure is negatively associated with the MTB measure.
} 
rather than negatively correlated. But how can we explain this negative correlation?

The literature has two competing explanations for a negative correlation between the AT measure and the BTM measure. One explanation is that there are in fact two distinct and competing forms of conservatism: conditional conservatism and unconditional conservatism, and increases in one form decreases the other (Beaver and Ryan, 2005; Pope and Walker, 2003; Pae et al., 2005). Based on this argument, the proponents of this view, such as Beaver and Ryan (2005), argue that Basu's AT measure estimates the degree of conditional conservatism and the BTM measure is an estimate of the degree of unconditional conservatism. Therefore, these two measures tend to be negatively correlated.

A competing explanation is offered by Roychowdhury and Watts (2007), who show that the negative correlation between the AT and MTB measures is essentially an errors-in-variable problem in that both the AT and MTB measures contain measurement errors. As noted above, in Roychowdhury and Watts's view, the main source of measurement error is the inclusion of economic rents in the market values of the firm and the stock returns. Roychowdhury and Watts (2007) empirically demonstrate that if the earning-return window is lengthened to three to five years, the correlation between AT and beginning-of-the-period BTM actually becomes positive. Their explanation is that the error-in-measurement problem is substantially reduced when the measurement window is sufficiently longer than the standard one year.

To summarize Section 1.3.1 - convergent validity, I conclude that the evidence on convergent validity among the five measures of conservatism suggests a low degree of convergence among the measures. The convergent validity problem is not easy to resolve, because there seems to be two opposite categories of measures, and because the measures within the same category show low levels of correlation with 
each other.

\subsubsection{Concurrent validity}

Concurrent validity is a measure's ability to distinguish between sample groups that it should theoretically be able to distinguish between (Messick, 1989; Association. et al., 1985; Cronbach and Meehl, 1955; Cook and Campbell, 1979). That is, a measure with high concurrent validity should be quite sensitive to small degrees of change in the subject measured. In terms of accounting conservatism, a conservatism measure with high concurrent validity should be able to easily distinguish firms with a high degree of accounting conservatism from firms with a low degree of accounting conservatism, and vice versa. If a measure of conservatism cannot easily detect the differences between high-conservatism firms and low-conservatism firms, it has low concurrent validity.

In order to test the concurrent validity of a measure of accounting conservatism, it is necessary for us to have some a priori knowledge about the degree of conservatism in the sample firms that can serve as the benchmark against which the measure can be evaluated. This requirement means that we must already know whether the sample firms have a high or low degree of conservatism before we look at the conservatism measure to be evaluated. This is because one cannot test a measure based on the measure itself; rather there has to be some external benchmark for it to be evaluated against. In the conservatism literature, I found two tests evaluating the Basu's AT measure against independent criteria that can constitute tests of the concurrent validity of the AT measure. I have not found any empirical evidence that can be used to evaluate the concurrent validity of the other four measures of accounting conservatism. I consider this as another lacuna in the current conservatism 
literature. The two tests on the concurrent validity of the AT measure are presented below.

First, in the sensitivity analysis section of Basu (1997), he compares the results of the AT measure with a measure of the mean-reverting property of earnings. The mean-reverting property of earnings is another known property of the asymmetric timeliness of earnings interpretation of accounting conservatism, which can be regarded as an external benchmark of accounting conservatism. The result of this sensitivity test supports the concurrent validity of Basu's measure, as the Basu measure shows a higher degree of accounting conservatism when the mean-reverting trend is strongest in the sample data.

Second, Givoly et al. (2007) find that Basu's measure is not sensitive to situationally aggressive accounting practices. Conceptually, aggressiveness is the opposite of conservatism in financial reporting. Therefore, it is predicted that the degree of conservatism in those firms that are already known to have aggressive financial reporting practices should be significantly lower than in the other 'normal' firms (control group). If a measure has a high degree of concurrent validity, it should be able to detect the difference between the firms in the aggressive reporting group and the control group. Following this, Givoly et al. (2007) conducted tests of Basu's AT method on three groups: two aggressive reporting groups, and one control group. The two aggressive reporting groups are: Group 1: big issuer firms who owe a large amount of debt or who engage in equity capital raising activities; Group 2: 'restater' firms whose financial statements have been restated downwards in order to correct the effects of previous aggressive accounting practices or previous accounting fraud. Group 3: the control group, consists of 'normal' firms that do not fall into either of the first two aggressive accounting categories. When Givoly et al. (2007) use the AT measure on these three groups separately, the predicted differences in ac- 
counting conservatism between the two aggressive reporting groups and the control group did not show up as expected. In other words, no significant difference in the asymmetric timeliness coefficients could be detected between all three groups. The failure of this test suggests that the AT measure does not have concurrent validity. ${ }^{10}$ However, given the limited tests conducted in this area, no firm conclusions can be drawn yet and more tests are required.

\subsubsection{Statistical conclusion validity}

Statistical conclusion validity is a very broad term that includes any statistical issues relating to the measurement of a construct such as conservatism. In the case of accounting conservatism measures, Dietrich et al. (2007) examine the statistical properties of Basu's AT model and conclude that the observed asymmetry between earnings' responses to good news and to bad news is largely spurious: it is mainly due to a bias caused by the distribution of the sample data, rather than to the degree of accounting conservatism. This analytical result is tested in a Monte Carlo simulation, in which Basu's measure is applied to a sample of computer-generated companies. The results of this Monte Carlo simulation show that even when the computer-simulated data has zero degree of accounting conservatism, the AT measure still indicates that a significant degree of accounting conservatism is present. Based on both the statistical analysis and the simulations, Dietrich et al. (2007) conclude that the AT measure is biased upwards and hence is not valid as a measure of accounting conservatism.

\footnotetext{
${ }^{10}$ An alternative explanation is that Givoly et al.'s method of classifying firms into aggressive reporting and non-aggressive reporting samples may be flawed, in which case the AT measure would not be capable of detecting any difference in the degrees of conservatism between these two samples.
} 


\subsubsection{Internal consistency}

Internal consistency is a criterion of construct validity which requires a measure to be consistent with its own scores when being repeatedly taken on the same subjects, separated by relatively short time intervals (Messick, 1989). This criterion concerns the 'reliability' of a measure. However, good internal consistency alone does not guarantee high construct validity, because a measure could have a high internal consistency but be consistently wrong. Internal consistency is just one aspect of the general concept of construct validity. An overall evaluation of the construct validity of a measure requires a holistic approach in which all the criteria are considered and weighted.

Givoly et al.'s (2007) study is currently the only study that provides evidence on internal consistency of the current measures of conservatism. Givoly et al. (2007) test the internal consistency of Basu's measure and the BTM measure. In a repeatedmeasure research design, Givoly et al. find that Basu's AT measure, if repeatedly measured over a number of sequential years on the same sample of firms, shows no consistency. The autocorrelation of the AT measure for each firm over a 5- to 10year horizon is not significantly different from zero. However, there is no reasonable analytical justification for firms' real degree of conservatism to fluctuate so rapidly and widely that no autocorrelation would be detected. While it is true that financial reporting characteristics, including conservatism, are subject to changes from year to year, any such change is more likely to be incremental and gradual than rapid. We do not expect to observe wide fluctuations in accounting policy changes in most firms. It is therefore reasonable to expect that the first-order autocorrelation of the degrees of conservatism, exhibited in a time series, is significantly greater than zero. However, Givoly et al.'s empirical result indicates that the first-order autocorrelation 
of the AT measure is basically zero, which implies that the degree of conservatism would have been moving up and down completely randomly without any consistency from one year to another! That obviously contradicts the expected time-series behaviour of a reliable measure of the degree of accounting conservatism. On the other hand, Givoly et al.'s study (2007) show that the BTM ratio is fairly stable over time, which demonstrates a higher degree of internal consistency than the Basu AT measure.

\subsubsection{Overall evaluation}

The limited existing evidence on the four sub-validities constrains my ability to judge the construct validity of the existing five measures of accounting conservatism. The most frequently examined measure so far is Basu's AT measure. In comparison, the other measures of accounting conservatism have attracted much less attention in the literature, at least from a validation point of view.

Overall, the existing measures of conservatism do not strongly satisfy the tests relating to these four types of sub-validities. Convergent validity is the criterion on which there is the greatest amount of evidence, but this also shows the weakest result. The available empirical evidence shows only weak convergence among the five measures: AT, AACF, MTB, NA and HR. Regarding concurrent validity, Basu's concurrent validity appears low, while there is limited evidence on the other measures.

With respect to the third criterion considered - statistical conclusion validity - it is again Basu's AT measure that has attracted most attention in the literature. The evidence in this area is mixed: Dietrich et al. (2007) find that the AT measure has a low statistical validity. In the fourth type of sub-validity considered, internal 
consistency, the available evidence is negative regarding the internal consistency of Basu's AT measure but supports the BTM measure. In all four cases, Basu's AT measure is evaluated, and the results are primarily negative.

\subsection{Discussion}

In this last section, I consider some of the key challenges facing conservatism researchers regarding the construct validity of the measures of accounting conservatism, and I make some suggestions that may help to address these issues. In particular, I identify three areas that seem to be problematic in the existing measures of accounting conservatism: (1) the problems with defining the construct of accounting conservatism; (2) confounding bias in the measures of conservatism; and (3) mono-operation bias. I discuss these three problem areas in turn and also make some recommendations that address each area.

\subsubsection{How to operationalize accounting conservatism?}

Campbell and Cook (1979) called the need for a clearly defined theoretical construct the "pre-operational explication of the theoretical construct". They argue that this is probably the most important step towards designing valid measures of a construct. More often than not, the precise meaning of a theoretical construct cannot be agreed upon by different researchers, which leads to quite different empirical operationalizations of the construct. Not surprisingly, the result is a total lack of consistency between different measures of supposedly the same theoretical construct. For this reason, Campbell and Cook (1979, p. 64) list the inadequate pre-operational explication of constructs as the first major threat to construct validity.

In the case of accounting conservatism the different measures are operational- 
izations of different implications of the underlying construct and it is possible that even if conservatism is indeed the construct articulated in the IASB definition, the more specific constructs of asymmetric timeliness and MTB are not implied by the underlying main construct with equal strength. Below, I list and discuss the two major operationalizations of conservatism, and each operationalization's corresponding measures.

1. Basu's (1997) operationalization: also known as conditional conservatism, news- dependent conservatism, and earnings conservatism

- The Basu AT measure

- The AACF measure

2. Feltham and Ohlson's operationalization (1995): also known as unconditional conservatism, news-independent conservatism, and balance-sheet conservatism

- The MTB (or BTM) ratio measure

- The NA measure

- The HR measure

\section{Basu's operationalization}

The most frequently applied operationalization of conservatism is from Basu (1997), who focuses on the implication that conservatism results in faster recognition of bad news than good news. Basu has also suggested that an alternative implication is the tendency to require a higher degree of verification for good news than for bad news. This latter approach has been adopted in Watts (2003a) and described 
by Watts as the "asymmetric verification" property of accounting, as compared to Basu's "asymmetric timeliness" property. The empirical studies generally do not distinguish between asymmetric timeliness and asymmetric verification. The two implications are closely linked but there are subtle differences. For example, it appears that the asymmetric verification property of accounting is the more basic feature of conservatism than is asymmetric timeliness, and the asymmetric timeliness of earnings is caused by the asymmetric verification standard of accounting (Watts, 2003a). However, for empirical purposes, researchers generally do not recognize such differences.

\section{Feltham and Ohlson's operationalization}

Feltham and Ohlson's (1995) operationalization of conservatism focuses on the downward bias in the book value of a firm compared to the fundamental economic value, as suggested by the authors' analysis of the RIVM. This characterization of accounting conservatism in the RIVM has been analytically extended by Zhang (2000) and has been adopted in a number of empirical studies, including Beaver and Ryan (2000), Penman and Zhang (2002), and Monahan (2005).

While Feltham and Ohlson (1995) focus on the downward bias of the book value compared with the economic value of the firm, they do not explicitly state how the accounting system creates this bias. In contrast, Basu's (1997) focus is more on how the accounting mechanism produces that downward bias in book value. Thus, while Feltham and Ohlson's operationalization focuses more on the end result, Basu's operationalization emphasizes the specific mechanism that produces that end result.

Roychowdhury and Watts's (2007) theory of conservatism can be regarded as a refinement of Feltham and Ohlson's operationalization of accounting conservatism. What sets the theory of Roychowdhury and Watts (2007) apart from that of Feltham 
and Ohlson (1995) is that Roychowdhury and Watts (2007) argue that not all understatements of book values as compared to economic values are caused by accounting conservatism. Although economic rents of a firm increase the firm's value, they are generally non- recognizable in the book values via accounting rules. Since economic rents are generally not reflected in the book value whether a firm's accounting system is conservative or not, it would be misleading to compare the total market value of the firm, which includes economic rents, with the book value, which does not include economic rents. As a solution, Roychowdhury and Watts (2007) propose that, when using MTB as a measure for conservatism, economic rents should be excluded from the market value, which will likely produce lower estimates of MTB for most firms.

To summarize Section 1.4.1, I have shown that the measures of conservatism currently operationalize different implications of the same underlying construct of accounting conservatism. Overall, the pattern of the associations among the five measures, as shown in Table 1.4, is consistent with there being two sets of measures of conservatism corresponding to two different operationalizations of the underlying construct of conservatism. The AT and AACF measures belongs to one group that adopts Basu's (1997) operationalization of conservatism, and the MTB, NA and HR measures belong to another group of measures that adopts Feltham and Ohlson's (1995) operationalization of conservatism. The different operationalizations of conservatism appear to have led to disagreements among the empirical measures themselves. I therefore suggest that further studies are required to clarify the meaning and characteristics of conservatism. 


\subsubsection{Confounding bias}

In addition to the problems associated with the meaning of conservatism, another challenge to empirical assessment of conservatism is confounding bias. Confounding bias describes a source of measurement error where a measure is influenced by not only the theoretical construct of interest, but also other factors, and there is no adequate control for the effects produced by those other "confounding" factors. In the following paragraphs, I briefly discuss the confounding factors of the Basu AT measure, as well as the MTB and HR measures of conservatism. The extant literature contains no discussions regarding the potential confounding factors of the AACF and NA measures.

\section{Confounding bias in the Basu AT measure}

The literature has recognized a number of confounding factors that may bias the Basu AT measure of conservatism. First, Gigler and Hemmer (2001) contend that the pre- emptive voluntary disclosures that occurred before the 1 year stock return window in the Basu model bias upward the asymmetric timeliness estimate. Gigler and Hemmer (2001) argue that if one wishes to obtain unbiased estimates of the degree of accounting conservatism from the Basu AT measure, the extent and timing of voluntary disclosure must be controlled for.

Second, Beaver et al. (2008) have identified another source of confounding bias for the Basu AT measure - a simultaneity bias. Beaver et al. (2008) argue that the relationship between the two sides of the Basu regression - earnings and stock returns - is not uni-directional, but bi-directional. Basu (1997) recognizes stock returns as a proxy for economic news that causes accounting earnings to change in an asymmetric manner. However, Hayn (1995) proposes the opposite causal direction, 
and argues that earnings also contain information that may lead cause stock prices to change in an asymmetric manner. Hayn's (1995) empirical evidence is almost identical to that obtained by Basu (1997), except that Hayn's regression model is the reverse of the Basu AT model. But Hayn explains the observed asymmetry by the theory of abandonment options rather than accounting conservatism. Using the 2-Stage Least Squares method, Beaver et al. (2008) jointly estimated both Basu's and Hayn's models, and found that the Basu AT measure is significantly weakened, which indicates that the Basu AT measure may overstate the true degree of conservatism in empirical studies as a consequence of the simultaneity bias.

Third, Ryan (2006) points out that big bath accounting can also lead to observed asymmetric timeliness of earnings in the Basu AT regression. However, Ryan (2006) does not offer any practical solutions on how to distinguish between conservatism and big bath accounting empirically.

\section{Confounding bias in the MTB and HR measures}

There is theoretical and empirical evidence showing that both the MTB and HR measures are confounded by a firm's growth rate because hidden reserves tend to accumulate at the growth stage in a firm's life cycle, and release back into earnings when the firm's growth slows (Zhang, 2000; Lev et al., 2005; Penman and Zhang, 2002). As hidden reserves are part of firms' market value, this process of hidden reserves accumulation and release affects the MTB measure as much as it affects the HR measure. Therefore, when a firm is growing, MTB and HR tend to overstate conservatism; but when the firm's growth slows down, these measures tend to understate conservatism. Even when a firm's true degree of conservatism stays constant, the MTB and HR measures may change according to the firm's growth rate, creating an erroneous impression that the firm's degree of conservatism is changing. 
GAAP requires different degrees of conservatism for different classes of assets. For example, GAAP is highly conservative in the context of R\&D expenditure, requiring that most $R \& D$ expenditures be expensed. In contrast, financial assets are normally marked-to-market by GAAP. Therefore, different investment profiles, that is, portfolios of asset allocations, can lead to very different book values and hidden reserves, which may confound the MTB and HR measures of conservatism.

Suppose firm A and firm B have exactly the same degree of conservatism and use exactly the same set of accounting standards and policies. And suppose A mainly invests in Research and Development (R\&D), while B mainly invests in liquid financial assets. Although A and B apply the same GAAP and the same set of accounting policies, A's MTB and HR will be generally higher than B's, leading to the impression that $\mathrm{A}$ is more conservative than $\mathrm{B}$. But in fact $\mathrm{A}$ and $\mathrm{B}$ have the same degree of conservatism, since their accounting policies are identical. What is causing the difference is that A's assets are different from B's, such that conservatism forces A not to recognize most of its R\&D (intangible) assets in the book value while B's assets are marked-to-market. This example illustrates that the MTB and HR measures generally do not yield reliable comparisons of conservatism across firms, if the firms' asset investment profiles are different.

In addition, Beatty (2007) suggests that the possibility of stock market mispricing, such as the dot-com bubble of the late 1990s, leads to high MTB ratios. Therefore, market over-valuation could potentially create an upward bias to MTB as a measure for conservatism. Similarly, market under-valuation could lead to a downward bias to MTB as a measure of conservatism. 


\subsubsection{Mono-operation Bias}

The problem of mono-operation bias is articulated by Cook and Campbell (1979) as follows:

Since single operations both under-represent constructs and contain irrelevancies, construct validity will be lower in single exemplar research than in research where each construct is multiply operationalized in order to triangulate on the reference. (Cook and Campbell, 1979, p. 65)

Table 1.2 - Panel B shows that out of the 53 papers included in this review, 32 of them use just one measure for conservatism and draw every inference from that measure alone. That accounts for more than $60 \%$ of all the papers reviewed here. In contrast, only 13 papers applied two measures simultaneously, and even fewer papers (eight of them) adopted three measures or more. This shows the typical symptom of the mono-operation bias.

As a consequence of mono-operation bias, the risk of errors is high in each single measure of conservatism, especially as none of these measures have been wellvalidated. The controversy regarding the cause of the negative correlation between AT and MTB illustrates the confusion that over-reliance on any single measure of conservatism can potentially create (see the discussion in Section 1.3.1 of the key arguments on each side of this controversy).

As Cook and Campbell (1979) suggest, the solution to this mono-operation bias is to use multiple measures of accounting conservatism simultaneously in the same research and triangulate the results from multiple measures. This approach can effectively reduce the measurement error arising from each individual measure in empirical studies (Campbell and Overman, 1988). 
Furthermore, I suggest that empirical researchers can go beyond simply using several measures of conservatism first and then comparing the results from each measure afterwards. In my opinion, researchers can further improve the power of the empirical measures by designing composite measures of conservatism, which are measures that combine the information from individual measures of conservatism, along with other control variables, if applicable. Provided that the errors in individual measures are not strongly positively correlated, composite measures have the advantage of being able to use more efficiently the information from each individual measure, by off-setting the measurement errors of individual measures against each other. ${ }^{11}$ In addition, there is another benefit of designing composite measures of conservatism: the logic underpinning composite measures could potentially provide a framework for conservatism researchers to reconcile the differences between single measures of conservatism.

In order to design composite measures of conservatism, it is important for empirical researchers to know the directions of the biases (i.e. systematic measurement errors) in each individual measure. Without knowing the directions of biases, a composite measure can potentially be incorrectly designed such that it may actually compound the biases in the individual measures rather than reduce them. However, the extant literature contains no comprehensive analysis of the biases in the existing measures of conservatism, although some papers have made isolated comments about the biases in particular measures of conservatism. These known biases have been discussed in Sections 1.2 through 1.4.2 above, and thus will not be repeated here.

\footnotetext{
${ }^{11}$ Efficiency in this context means the efficiency of statistical estimators. An estimator (i.e. measure) is efficient if it uses all the relevant information to form the most accurate measure of the population parameter, with the least possible variance.
} 
It is beyond the scope of this review to design and test new composite measures of conservatism. Despite that, the short synthesis provided earlier on the known biases in the existing measures may help other researchers to design new composite measures of conservatism. Apart from the biases already reviewed in this chapter, there are likely other biases yet unknown, such as potential biases in the AACF or NA measures. Clearly, more research in this area is required to fill this gap in the literature.

\subsection{Conclusions}

In this chapter, I have reviewed five measures of conservatism in the accounting literature and employed construct validity as a means of exploring the validity of these measures. My analysis suggests that the measures of conservatism employed in the literature may have a low degree of construct validity. In summary, I have identified the following key challenges to the construct validity of the existing measures of conservatism in the extant literature.

1. The lack of general agreement in the literature regarding how accounting conservatism, as a theoretical construct, should be operationalized.

2. The possibility of confounding bias in the existing five measures of conservatism.

3. The literature's over-reliance on a single measure of conservatism in each study, which leads to the mono-operation bias.

In response to these challenges, I have suggested several solutions, which include:

1. Clarifying the meaning and properties of accounting conservatism, as well as the relationships among the existing measures of conservatism; 
2. Controlling for the confounding factors in empirical designs; and

3. Using multiple measures of conservatism in the same study, and designing composite measures of conservatism.

I acknowledge that a truly comprehensive and rigorous assessment of the construct validity of all five measures of accounting conservatism is a major scientific endeaver that is beyond the scope of any single study. A more comprehensive and rigorous assessment would require a large amount of theoretical analyses and empirical tests, and these cannot be easily accomplished by any single study or indeed by any single researcher. Furthermore, as an individual researcher making an assessment of the construct validity of the measures of conservatism, I inevitably suffer from some personal biases of my own, although I have tried to avoid them as much as possible. That highlights the need to have more researchers conducting more analyses on the construct validity of the measures of accounting conservatism, based on different methodologies and different datasets. Only with repeated testing from different angles can the construct validity of the measures of accounting conservatism be truly understood.

Despite all its limitations, I hope that my analysis of the literature presented in this chapter can at least raise the awareness of conservatism researchers to the limitations of the existing measures of conservatism. Since our scientific understanding of accounting conservatism crucially depends on our ability to accurately and reliably measure it, sorting out the construct validity of the measures of accounting conservatism is an important and rewarding scientific endeaver to undertake. Thus, let me conclude Chapter 1 by inviting other accounting researchers to take on the challenge of further analysing and testing the construct validity of the measures of accounting conservatism. 


\subsection{Appendix}

Table 1.5: Descriptive statistics

\begin{tabular}{lrrrrrrr}
\hline & Min & $\begin{array}{r}\text { 1st } \\
\text { Quartile }\end{array}$ & Median & Mean & $\begin{array}{c}\text { 3rd } \\
\text { Quartile }\end{array}$ & Max & Std. Dev. \\
\hline EPS/P & -2.06 & -0.04 & 0.04 & 0.00 & 0.06 & 0.76 & 0.14 \\
$\boldsymbol{R}$ & -0.84 & -0.23 & 0.07 & 0.21 & 0.45 & 3.98 & 0.69 \\
MTB & 0.39 & 1.54 & 2.60 & 3.64 & 4.42 & 25.41 & 3.37 \\
HR & -1.90 & 0.07 & 0.21 & 0.27 & 0.36 & 3.74 & 0.35 \\
NA & -0.13 & 0.00 & 0.02 & 0.03 & 0.04 & 0.33 & 0.05 \\
ACC (\$ million) & $-8,409.12$ & -3.14 & 0.53 & 2.86 & 7.84 & $6,831.19$ & 420.37 \\
CFO (\$ million) & $-3,657.00$ & -0.13 & 9.78 & 147.72 & 65.02 & $24,550.00$ & 654.27 \\
TA (\$ million) & 1.05 & 46.53 & 158.80 & $1,418.00$ & 697.50 & $250,800.00$ & $6,612.71$ \\
$\boldsymbol{B V}$ (\$ million) & 0.06 & 29.20 & 101.20 & 637.60 & 374.50 & $103,200.00$ & $2,600.88$ \\
$\boldsymbol{M V}$ (\$ million) & 0.71 & 66.81 & 258.90 & $2,314.00$ & $1,042.00$ & $155,900.00$ & $8,327.51$ \\
\hline
\end{tabular}

Note: The sample consists of 15,735 US firms listed on the NYSE, AMEX and NASDAQ stock exchanges, excluding ADR firms, from 1989 to 2007. I trimmed the raw sample by the top and bottom 1\% of EPS/P, R, MTB, HR, NA, and ACC. I deleted observations that have any missing value in any of the variables listed above. I calculated the hidden reserves measure of conservatism (HR) according to Penman and Zhang's [2002] method. I calculated the Negative Accruals (NA) measure by taking the negative of the three-years average non-operating accruals, centered on year t, per Lara et al. [2007] and Ahmed and Duellman [2007], although the definition of yearly non-operating accrual follows the balance-sheet approach taken by Givoly and Hayn [2000]. I take the negative of the average non-operating accrual for the purpose of turning NA into a positive measure of conservatism. ACC is defined by Ball and Shivakumar [2005], and is deflated by the closing market value of the firm in order to control for scaling biases. 


\section{Chapter 2}

\section{The Impact of Default Risk on the}

\section{Basu Measure of Accounting}

\section{Conservatism}

\subsection{Introduction ${ }^{1}$}

Basu (1997) introduced the first, and currently the most popular, empirical measure of accounting conservatism, commonly known as the 'Basu measure'. The resulting measure is described by Basu as the asymmetric timeliness of earnings coefficient

\footnotetext{
${ }^{1}$ Acknowledgment: A paper based on this chapter, co-authored with my thesis supervisors, is currently under the 2nd review at Journal of Accounting \& Economics. I thank the editor, Thomas Lys, and the anonymous referee of Journal of Accounting \& Economics for their invaluable constructive criticisms and suggestions. I am especially grateful to Robert M. Bushman for suggesting the option-pricing based method of estimating default risk. I also thank the numerous comments on earlier versions of this chapter by the following people: Michael Bradbury at the 2009 New Zealand Accounting PhD Students Colloquium; Richard Morris at University of New South Wales Research Seminar; Stephen L. Taylor at the AFAANZ 2009 Annual Meeting; and Peter Wells at the University of Technology Sydney 2009 Summer Accounting Consortium. I also with to extend my gratitude to all other people who have provided comments on earlier versions of this chapter in the above conferences and seminars, as well as in the EAA 2009 Annual Meeting, and AAA 2009 Annual Meeting.
} 
(abbr. "AT" measure). Since Basu's influential paper, a large and still growing literature has emerged applying the Basu measure to examine accounting conservatism from a variety of theoretical perspectives.

However, the validity and characteristics of the Basu measure of accounting conservatism have received limited attention. Only recently, Dietrich et al. (2007), Givoly et al. (2007), Ryan (2006) and others have begun to directly examine the validity of the Basu measure. These recent studies have highlighted a number of weaknesses in the Basu measure. Dietrich et al. (2007), for example, find that the Basu measure is biased upward, because of what they call the sample-varianceratio bias and the sample-truncation bias. Givoly et al. (2007) empirically test the validity of the Basu measure, and discover that the measure can demonstrate neither the power to distinguish conservative firms from aggressive ones, nor the stability expected in a time-series context.

The analysis in this chapter has two related objectives: First, I extend this recent critical appraisal of the Basu measure by investigating the relationship between the Basu measure and a firm's default risk. Using Merton's (1974) call-option pricing model of equity, I argue that the Basu AT measure is a biased measure of the degree of accounting conservatism. The higher the default risk, the higher the bias in the Basu AT measure. In general, default risk means the uncertainty around a firm's ability to repay its debts when the debts fall due. In this chapter, I use Merton's (1994) Distance-to-Default concept as the analytical definition of default risk.

Second, I use the insight provided by my analysis of the Basu measure to construct an improved version of the 'Basu' measure, and I call the new measure the Default-Adjusted-Basu ("DAB”) measure, because it makes adjustments for the effects of default risk on the Basu measure. I contend that the DAB measure can substantially reduce the bias caused by default risk, and hence is a more robust 
measure of accounting conservatism than is the standard Basu measure.

Empirically, I adopt Vassalou and Xing's (2004) iterative procedure for estimating firms' distance-to-default. I find that firms with higher default risk indeed tend to have a higher Basu measure of conservatism, consistent with my analytical prediction. I also test the validity of the DAB measure of conservatism empirically, and the result suggests the the DAB measure likely provides a more robust measure of accounting conservatism than does the original Basu measure.

My analysis of the Basu measure bears a close relationship to the analysis of the earnings response coefficient (ERC) by Dhaliwal et al. (1991). Dhaliwal et al. (1991) show that ERC is negatively correlated with the default risk of the firm. Since the Basu model is essentially a reversed ERC model, the negative association between ERC and default risk implies that there exists a positive association between Basu regression coefficients and default risk. This positive association is exactly what this chapter attempt to analyze. In addition, this chapter has another similarity with Dhaliwal et al. (1991) — both papers use the classic Merton (1974) model as the analytical foundation.

There are, however, also major differences between this chapter and Dhaliwal et al. (1991). The most significant difference is that Dhaliwal et al. (1991) treat the value of the firm as a function of earnings, but this chapter treats earnings as a function of the changes of the value of the firm. This difference is perhaps the defining characteristic that sets the Basu model apart from the more traditional ERC models.

Before I proceed to the main analysis, I briefly introduce the Basu measure itself. The Basu (1997) measure is based on a cross-sectional, piece-wise regression of accounting earnings on stock returns, as follows: 


$$
\frac{E P S_{i t}}{P_{i, t-1}}=\alpha_{0}+\alpha_{1} D R_{i t}+\beta_{0} R_{i t}+\beta_{1} R_{i t} D R_{i t}+\varepsilon_{i t}
$$

where

$E P S_{i t} \quad$ : Earnings per share for firm i year $\mathrm{t}$

$P_{i, t-1} \quad$ : Opening stock market price for firm i year $\mathrm{t}$

$R_{i t} \quad:$ Stock market return for firm i year $\mathrm{t}$

$D R_{i t} \quad$ : Dummy variable that is equal to 1 if the stock market return for firm i year $\mathrm{t}$ is negative, and equal to 0 if the stock market return for firm $\mathrm{i}$ year $\mathrm{t}$ is non-negative.

The regression model above, known as the "Basu model", regresses accounting earnings $(E P S / P)$ on stock returns $(R)$ separately for 'good-news' and 'bad-news' firms. A firm-year is deemed a 'good-news' one if the return on its stock return is positive or zero. Likewise, a firm-year is deemed a 'bad-news' one, if its stock return is negative. By using the dummy variable, $D R_{i t}$, the Basu model allows the slope coefficients to differ between the good-news and bad-news groups ( $\beta_{0}$ and $\beta_{0}+\beta_{1}$, for good- and bad- news coefficients respectively). The difference between the bad- and good- news timeliness coefficients, $\beta_{1}$, is the Basu asymmetric timeliness coefficient, which measures the degree of conservatism in the sample of firms.

The rest of this chapter proceeds as follows: Section 2.2 examines analytically how default risk impacts on the Basu measure. Section 2.3 develops the DefaultAdjusted-Basu (DAB) measure of accounting conservatism, which, I argue, is more robust to default risk than is the original Basu measure. Section 2.4 discusses the sample selection and the proxies used in the empirical tests. Section 2.5 reports the main empirical results with respect to both the original Basu measure and the $\mathrm{DAB}$ 
measure. Section 2.6 reports the results of the robustness tests. Finally, I conclude the chapter in Section 2.7.

\subsection{The link between the Basu asymmetric timeliness coefficient and default-risk}

In this section, I derive analytically the relationship between the default-risk and the Basu measure of conservatism. The analysis in this section is built on the classic call-option model of equity developed by Merton (1974) and Black and Scholes (1973), commonly known as the Merton model in the finance literature. I also develop a simple stochastic process of accounting earnings to model the impacts of conservatism on earnings. Finally, I use both the Merton model and the stochastic process of accounting earnings to derive the relationship between the Basu measure and default risk.

\subsubsection{The Merton option-pricing model of equity}

The Merton (1974) model characterizes equity as a European call option written on the value of a firm's total assets ${ }^{2}$, with the firm's debt as its strike price, and the maturity date of that debt (or the date of refinancing, if the debt is rolled over) as the exercise date. In order to derive the price of equity as a call option, Merton (1974) assumes that the value of the firm, $V_{t}$, follows a geometric Brownian motion with a constant drift and constant volatility, as described by the following stochastic differential equation:

\footnotetext{
${ }^{2}$ In this chapter, I use the two terms - 'value of the gross assets of the firm' and 'the value of the firm' - interchangeably. In contrast, the 'value of equity' is a completely different construct.
} 


$$
d V_{t}=\alpha V_{t} d t+\sigma V_{t} d W_{1 t}
$$

In the stochastic differential equation (2.2) above, $\alpha$ represents the (steady-state) constant growth rate of the value of the firm; $\sigma$ denotes the standard deviation of the value of the firm; $W_{1}$ is a standard Brownian motion that generates the value shocks to the firm; lastly, the subscript $t$ denotes a point in time. Merton also makes the following assumptions: (1) The maturity value of debt, $D$, is the strike price of the call-option; (2) the debt is a zero-coupon, carrying no regular interest payments; (3) the maturity value, $D$, is non-stochastic, and is known ahead of the maturity time with certainty; (4) the debt can only be paid back at the maturity date; (5) the firm has only one type of debt; (6) there exists a riskless bond in the economy, with a continuous rate of return $r$; (7) there exists a frictionless market for the trading of the equity (E) and the underlying assets (V) of the firm, without any long- and shorttrading restrictions.

By the method of dynamic hedging, Merton derived the following standard Black-Scholes-Merton (BSM) formula for the value of equity $\left(E_{t}\right)$ :

$$
E_{t}=V_{t} N\left(d_{1}\right)-D e^{-r t} N\left(d_{2}\right)
$$

where

$$
d_{1}=\frac{\ln \left(V_{t} / D\right)+\left(r+\sigma^{2} / 2\right) t}{\sigma \sqrt{t}} ; d_{2}=d_{1}-\sigma \sqrt{t}
$$

In equation (2.3), $t$ is the time until the exercise date $T$, and counts down with the passage of time. The exercise date, $T$, is the date on which the firm must pay back its debt (or the date on which the firm refinances its debt). $N($.$) is the cumulative$ 
probability function for the standard normal distribution, which has a mean of zero and a variance of one.

By Ito's lemma, we can derive the stochastic process followed by equity $\left(E_{t}\right)$ :

$$
\begin{aligned}
d E & =\frac{\partial E}{\partial t} d t+\frac{\partial E}{\partial V} d V+\frac{1}{2} \frac{\partial^{2} E}{\partial V^{2}} d V d V \\
& =\left[\Theta+\Delta \alpha V+\frac{1}{2} \Gamma \sigma^{2} V^{2}\right] d t+\Delta \sigma V d W_{1}
\end{aligned}
$$

which can also be stated in the following integral form:

$$
E(t)=E\left(t_{0}\right)+\int_{t_{0}}^{t}\left[\Theta+\Delta \alpha V_{t}+\frac{1}{2} \Gamma \sigma^{2} V_{t}^{2}\right] d t+\int_{t_{0}}^{t} \Delta \sigma V_{t} d W_{1}(t)
$$

$E\left(t_{0}\right)$ is the initial value of the equity at time $t_{0}$. In Equations 2.4 and 2.5, I use three the standard option-pricing variables, which are defined as follows:

$$
\begin{aligned}
\Delta & =\frac{\partial E_{t}}{\partial V_{t}}=N\left(d_{1}\right) \\
\Theta & =\frac{\partial E_{t}}{\partial t}=-\frac{V_{t} \sigma}{2 \sqrt{t}} N^{\prime}\left(d_{1}\right)-r D e^{-r t} N\left(d_{2}\right) \\
\Gamma & =\frac{\partial^{2} E_{t}}{\partial V_{t}^{2}}=\frac{1}{V_{t} \sigma \sqrt{t}} N^{\prime}\left(d_{1}\right)
\end{aligned}
$$

\subsubsection{A simple stochastic model of accounting earnings}

This sub-section presents a simple stochastic process of earnings that can capture the concept of 'conditional' accounting conservatism. Basu (1997), Watts (2003a) and Ryan (2006) interpret 'conditional' conservatism as the asymmetric timeliness 
of earnings, by which the managers recognize good-news into earnings in a less timely manner than they do with bad-news. I explicitly model this concept of conservatism in a continuous-time context. I begin by introducing the intuitions underlying this model. Then I formally set-up the stochastic model of accounting earnings.

First, economic news items are reflected in the changes in the value of the firm. In this model, the changes in the value of the firm is described by the Geometric Brownian Motion:

$$
d V_{t}=\alpha V_{t} d t+\sigma V_{t} d W_{1}(t)
$$

The second term, $\sigma V_{t} d W_{1}(t)$, is the underlying value shock that generates uncertainty and therefore produces unexpected changes in equity prices and earnings. Thus, economic 'news' is best represented by $\sigma V_{t} d W_{1}(t)$.

Second, the managers of a firm learn about the firm's value shocks by observing its operating conditions, and then map each value shock (out of infinitely many) into the accounting earnings of that firm, according to the rule of accounting conservatism. ${ }^{3}$ Positive value shocks (which is, informally, $\sigma V_{t} d W_{1}(t) \geq 0$ ) will make a smaller contribution to the contemporary earnings than do negative value shocks [which is, informally, $\left.\sigma V_{t} d W_{1}(t)<0\right] .^{4}$

Third, contemporary earnings of a firm may not only reflect the contemporary value shocks, but also other factors, which include: (1) past value shocks to the firm to the extent that they have not been incorporated in past earnings; (2) other accruals

\footnotetext{
${ }^{3}$ For the sake of simplicity, it is also assumed that the debt level of the firm is fixed and the interest is not accrued in earnings until the end of the debt covenant.

${ }^{4}$ The expressions in brackets are informal representations of value shocks, because, strictly speaking, the differentials used here are not defined. The formal representations in the integral forms are given in Equation 2.6.
} 
which lead to higher or lower earnings then what is justified by the current value shock or economic income; (3) earnings management.

The above intuitions can be formalized into the following stochastic process of earnings. The net income, $N I(\varepsilon)$, over a period of time $\varepsilon$, where $\varepsilon$ is any given positive number, beginning from time $t$, is defined as:

$$
N I(\varepsilon)=\int_{t}^{t+\varepsilon} \alpha V_{t} d t+\int_{t}^{t+\varepsilon} k_{j} \sigma V_{t} d W_{1}(t)+\int_{t}^{t+\varepsilon} \sigma_{e} V_{t} d W_{2}(t)
$$

where

$$
\begin{aligned}
& k_{j}=k_{0}, \text { if } \int_{t}^{t+\varepsilon} \sigma V_{t} d W_{1}(t) \geq 0 ; \\
& k_{j}=k_{2}, \text { if } \int_{t}^{t+\varepsilon} \sigma V_{t} d W_{1}(t)<0 ; \\
& 0<k_{0}<k_{2} ; \\
& \int_{0}^{\varepsilon} d W_{1}(t) d W_{2}(t)=\rho \varepsilon, \forall \varepsilon>0 .
\end{aligned}
$$

The following two variables in Equation 2.6 have not been defined before:

$W_{2}$ : A second Brownian motion acting as a random disturbance to the accounting earnings.

$\sigma_{e}: \quad$ A constant rate of volatility for the random disturbance to earnings $W_{2}$; $\sigma$ and $\sigma_{e}$ can have different values.

The income-smoothing literature argues that managers often discretionarily lower earnings when the real profit for the year is high, and increases earnings when the real profit is low. This implies that $W_{2}$, which captures discretionary accruals, might be negatively correlated with $W_{1}$, which captured fundamental value shocks to the 
firm (i.e. real economic income). While this correlation between $W_{1}$ and $W_{2}$ does not alter the main result in any fundamental way, I still incorporate this correlation into the model nonetheless, primarily for the purpose of showing that the result holds whether or not there is any income smoothing activity in the firm. I formally write the correlation between these two Brownian motions as: $\int_{0}^{\mathcal{E}} d W_{1}(t) d W_{2}(t)=$ $\rho \varepsilon, \forall \varepsilon>0$. Because $\rho$ is a correlation coefficient, $-1 \leq \rho \leq 1$, and in particular, if the correlation coefficient is negative, then $-1 \leq \rho<0$.

All three terms on the right-hand side of Equation (2.6) have clear economic interpretations:

(1) A permanent earnings component $\left(\int_{t}^{t+\varepsilon} \alpha V_{t} d t\right)$ : This reflects the steady growth rate of the firm. It does not generate any 'news', since it is not random.

(2) A news-dependent earnings component $\left(\int_{t}^{t+\varepsilon} k_{j} \sigma V_{t} d W_{1}(t)\right)$ : This reflects the impact of value-shocks, or economic 'news', on the earnings of a firm. This term is the core of my model, because it reflects the degree of asymmetric timeliness of earnings, which is captured by the different values of $k_{j}$, conditional on the sign of the value-shock $\int_{t}^{t+\varepsilon} \sigma V_{t} d W_{1}(t)$. If $\int_{t}^{t+\varepsilon} \sigma V_{t} d W_{1}(t) \geq 0$, I set $k_{j}=k_{0}$; if $\int_{t}^{t+\varepsilon} \sigma V_{t} d W_{1}(t)<0$, I set $k_{j}=k_{2}$. The first situation arises when there is goodnews to the firm, while the second situation arises when there is bad-news to the firm. Since bad-news is recognized in earnings faster than good-news, we have the following basic inequality: $0<k_{0}<k_{2}$. The degree of conservatism $\left(k_{1}\right)$ is defined as below:

Definition. The degree of asymmetric timeliness, $k_{1}$, is defined as $k_{1} \equiv k_{2}-k_{0}$. Since $0<k_{0}<k_{2}$, it follows immediately that $k_{1}>0$.

(3) A random-error/discretionary earnings component $\left(\int_{t}^{t+\varepsilon} \sigma_{e} V_{t} d W_{2}(t)\right)$ : This term represents the idiosyncratic part of earnings. This term may well be negatively 
correlated with the second (new-dependent) term due to possible income-smoothing activities.

\subsubsection{Main proposition}

Definition. The instantaneous Basu regression coefficients at time $t$ are defined as follows:

$$
\beta_{j t} \equiv \lim _{\varepsilon \rightarrow 0^{+}} \frac{\operatorname{cov}\left[\frac{N I}{E(t)}, \frac{\Delta E}{E(t)}\right](\varepsilon)}{\operatorname{var}\left[\frac{\Delta E}{E(t)}\right](\varepsilon)} ; \text { where } j= \begin{cases}0, & \forall \int_{t}^{t+\varepsilon} \sigma V_{t} d W_{1}(t) \geq 0 \\ 2, & \forall \int_{t}^{t+\varepsilon} \sigma V_{t} d W_{1}(t)<0\end{cases}
$$

In the above definition, the following definitions of variance and covariance for stochastic processes are used: For two stochastic processes $X_{1}$ and $X_{2}$, their means, variances and covariance over any positive time interval $\left[t_{0}, t_{0}+\varepsilon\right]$, where $\varepsilon>0$, are defined as: ${ }^{5}$

$$
\begin{aligned}
M_{i}(\varepsilon)= & \mathbb{E}\left[X_{i}\left(t_{0}+\varepsilon\right)-X_{i}\left(t_{0}\right) \mid \mathscr{F}\left(t_{0}\right)\right] \\
\operatorname{cov}\left[X_{1}, X_{2}\right](\varepsilon)= & \mathbb{E}\left[\left(X_{1}\left(t_{0}+\varepsilon\right)-X_{1}\left(t_{0}\right)\right)\left(X_{2}\left(t_{0}+\varepsilon\right)-X_{2}\left(t_{0}\right)\right) \mid \mathscr{F}\left(t_{0}\right)\right] \\
& -M_{1}(\varepsilon) M_{2}(\varepsilon) \\
\operatorname{var}\left[X_{i}\right](\varepsilon)= & \mathbb{E}\left[\left(X_{i}\left(t_{0}+\varepsilon\right)-X_{i}\left(t_{0}\right)\right)^{2} \mid \mathscr{F}\left(t_{0}\right)\right]-M_{1}^{2}(\varepsilon)
\end{aligned}
$$

I have already obtained the stochastic process of equity value $E$ from the Merton model ( $\Delta E$ is the gross return on equity), and defined the stochastic process of earnings, $N I$, as below:

\footnotetext{
${ }^{5}$ See Shreve (2004, pp. 201-203) for details.
} 


$$
\begin{aligned}
\Delta E(\varepsilon) & =\int_{t}^{t+\varepsilon}\left[\Theta+\Delta \alpha V_{t}+\frac{1}{2} \Gamma \sigma^{2} V_{t}^{2}\right] d t+\int_{t}^{t+\varepsilon} \Delta \sigma V_{t} d W_{1}(t) \\
N I(\varepsilon) & =\int_{t}^{t+\varepsilon} \alpha V_{t} d t+\int_{t}^{t+\varepsilon} k_{j} \sigma V_{t} d W_{1}(t)+\int_{t}^{t+\varepsilon} \sigma_{e} V_{t} d W_{2}(t)
\end{aligned}
$$

Equation 2.7 is the continuous-time equivalence of the Basu regression coefficients. The term $\frac{\Delta E}{E}$ is equivalent to $R$ in Equation 2.1, and the term $\frac{N I(\varepsilon)}{E}$ is equivalent to $\frac{E P S}{P}$ in Equation 2.1. Depending on the value of $k_{j}$, equation 2.7 can be used to calculate two Basu coefficients: (1) the Basu good-news timeliness coefficient $\left(\beta_{0 t}\right)$, when $\int_{t}^{t+\varepsilon} \sigma V_{t} d W_{1}(t) \geq 0$, and (2) the bad-news timeliness coefficient $\left(\beta_{2 t}\right)$, when $\int_{t}^{t+\varepsilon} \sigma V_{t} d W_{1}(t)<0$.

Definition. The instantaneous Basu asymmetric timeliness coefficient, which is the Basu measure of conservatism, is defined as $\beta_{1 t}=\beta_{2 t}-\beta_{0 t}$.

It should be noted that the Basu measure, $\beta_{1 t}$, is an empirical estimator of the actual degree of asymmetric timeliness, $k_{1}$. In other words, $k_{1}$ is the theoretical parameter of interest, and the Basu measure, $\beta_{1 t}$, is the empirical estimator of $k_{1}$. The primary focus of this chapter is to find out whether $\mathrm{t} \beta_{1 t}$ is an unbiased estimator of the degree of asymmetric timeliness, $k_{1}$. To do that, I first prove the following lemma:

Lemma. The Basu asymmetric timeliness coefficient, $\beta_{1 t}$, is related to the actual asymmetric timeliness parameter, $k_{1}$, by $\beta_{1 t}=\frac{k_{1}}{\Delta}$.

Proof. See Appendix.

Proposition 2.1. Holding $\alpha, \sigma$ and $k_{j}$ constant, when a firm's distance-to-default (DD) decreases, the firm's Basu asymmetric timeliness coefficient $\left(\beta_{1 t}\right)$ increases and vice versa. 
Proof. See Appendix.

In Proposition 2.1, I adopt Merton's (Merton, 1974) well-known 'distance-todefault' construct (abbr. $D D$ ) as this chapter's definition of default-risk. The distanceto-default measures how many standard deviations the value of a firm's total assets lies away from its debt level. $D D$ is a negative measure of default risk: the lower $D D$, the higher the default risk.

Following Merton (1974), distance-to-default (DD) of a firm at time t, for a specific forecasting period into the future, $t$, is defined as:

$$
D D=\frac{\ln \left(V_{t} / D\right)+\left(\alpha-\sigma^{2} / 2\right) t}{\sigma \sqrt{t}}
$$

It is common for practitioners and academicians to calculate the distance-todefault for 1 year ahead, i.e. $t=1$ (Crosbie and Bohn, 2003; Vassalou and Xing, 2004). Following this practice by setting $t=1$, the $D D$ formula in Equation 2.8 can be simplified to:

$$
D D=\frac{\ln \left(V_{t} / D\right)+\left(\alpha-\sigma^{2} / 2\right)}{\sigma}
$$

Since $\alpha$ and $\sigma$ are fixed, the only source of variability in $D D$ must come from the ratio $\frac{V_{t}}{D}$. This ratio has a very intuitive economic meaning: it is the Assets-toDebt ratio of a firm at time $t$, which indicates the firm's financial leverage. Merton (1974) shows that the firm's naive Asset-to-Debt ratio is $\frac{V_{t}}{D e^{-r t}}$, in which the debt is discounted at the appropriate rate of interest, $r$. Merton (1974) called it a "naive" measure of Asset-to-Debt ratio because the debt is discounted at the risk-free rate rather than its appropriate risk-adjusted risk. The aim of Proposition 2.1 is to show that default risk can impact on the Basu coefficients, $\beta_{j t}$, by altering the $\frac{V_{t}}{D}$ term. 
I emphasize that Proposition 2.1 only establishes the relationship between $D D$ and the Basu measure of conservatism $\left(\beta_{1 t}\right)$. As the Appendix shows, there is no such unambiguous relationship between $D D$ and the other two Basu coefficients $\left(\beta_{0 t}\right.$ and $\left.\beta_{2 t}\right)$.

Proposition 2.1 implies that the distance-to-default in the sample firms can create a confounding bias in the Basu measure as a proxy for the (average) degree of 'conditional' conservatism in the sample. Regardless of whether the Basu model is fitted to a cross-sectional sample of different firms or to a time-series sample of the same firm, $D D$ is unlikely to stay the same in all individual observations in the sample. Some firms (or some particular years of the same firm, as in a timeseries regression) are almost bound to have higher or lower $D D$ than other firms (or different years of the same firm). This would almost surely create a major omittedvariable problem to the estimation of the degree of conservatism using the Basu regression model. If this omitted variable - distance-to-default - is not controlled for in the Basu model, an increase in the sample firms' average degree of conservatism may lead to a higher Basu measure of conservatism $\left(\beta_{1}\right)$, while the actual degree of asymmetric timeliness, $k_{1}$, stays constant. This will lead to an upward bias in the Basu measure of accounting conservatism.

\subsection{A new measure of conservatism}

In light of the theoretic result that the Basu measure of conservatism, $\beta_{1}$, contains an upward bias in financially distressed firms, I propose a new measure of accounting conservatism, by modifying the original Basu measure. The aim is to propose a measure of 'conditional' conservatism that can not only preserve all the attractive features of the original Basu (1997) measure, but also substantially reduce the extent 
of the bias from default risk. I call this new measure the Default-Adjusted-Basu (or " $D A B$ ”) measure of accounting conservatism.

The underlying idea for this refined Basu measure is simple, in that I attempt to remove the influences of default risk from both the dependent and independent variables of the Basu regression as much as possible. To remove any impact of default risk is equivalent to remove any effect of leverage on both the earnings and the equity values of the firm. In my view, the most natural way to achieve this goal is to regress net income before interest expense $\left(N I B I_{i t}\right)$ on the return on the total value of the firm $\left(T R_{i t}\right)$, as below:

$$
\frac{N I B I_{i t}}{V_{i t-1}}=a_{0}+a_{1} D T R_{i t}+b_{0} T R_{i t}+b_{1} T R_{i t} D T R_{i t}+\varepsilon_{i t}
$$

where

$N I B I_{i t}: \quad$ Net Income before Interest Expense, calculated as Net Income After Tax + Pre-tax Interest Expense. ${ }^{6}$

$V_{i t-1}: \quad$ The total opening value of the firm, as defined earlier when introducing the Merton (1974) model. It is the sum of the market values of equity and debt of the firm. Section 2.4 describes these 2 methods of estimating this variable.

$T R_{i t}$ : The rate of return of the total value of the firm, $V$, calculated as: $T R_{i t}=$ $\left(V_{i t}-V_{i t-1}-C F F_{i t}\right) / V_{i t-1} . C F F_{i t}$ is the net cashflow from financing activities for firm $i$ in year $t$. $C F F_{i t}$ is positive for net cash inflow from financing activities, and negative for net cash outflow from financing

\footnotetext{
${ }^{6}$ In a robustness test in Section 2.6.3, I demonstrate that the results of the DAB measure are not sensitive to whether we add back After-tax Interest Expenses or Pre-tax Interest Expenses to Net Income, because both specifications produce very similar results.
} 


$$
\text { activities. }^{7}
$$

$D T R_{i t}$ : A dummy variable that is set to 1 , if $T R_{i t}<0$; and is set to 0 , if $T R_{i t} \geq 0$.

Regression model 2.10 follows the Basu (1997) model but with different proxies for accounting earnings and economic 'news'. $b_{1}$ is DAB measure of accounting conservatism. In the DAB model, both the (deflated) earning, $N I B I_{i t} / V_{i t-1}$, and the assets return, $T R_{i t}$, are theoretically free from the influences of default risk, because these variables are all for the assets of the firm instead of the equity of the firm. To this end, the Miller and Modigliani Theorem has long established that the capital structure of the firm, and thus the default risk, are irrelevant to the value of the firm itself or its expected return on assets, assuming a zero income tax rate (Modigliani and Miller, 1958). Therefore, I expect equation 2.10 to be a more robust regression model for estimating the degree of accounting conservatism than the standard Basu regression model (i.e. Equation 2.1).

\subsection{Proxies and data}

\subsubsection{Measure of Distance-to-Default $(D D)$}

In this chapter, I employ Vassalou and Xing's (2004) method of calculating firms' distance-to-default $(D D)$ as the main empirical proxy for default risk. ${ }^{8}$ Vassalou and Xing (2004) offer a robust iterative algorithm for calibrating the volatility $(\sigma)$ and

\footnotetext{
${ }^{7}$ Unlike IFRS, US GAAP does not allow the option of classifying dividends and interests paid as either cash flows from operating activities or cash flows from financing activities. Under US GAAP, all dividends paid must be classified as cash flows from financing activities while all interests paid must be classified as cash flows from operating activities (FASB, 2009). Therefore, the classification of dividends and interests payments does not cause any problem to my calculation of $T R$ under US GAAP. However, some problems may arise if this calculation is performed under IFRS, where the classification of dividends and interests paid may be inconsistent across firms.

${ }^{8}$ I especially thank Robert M. Bushman for suggesting to us Vassalou and Xing's (2004) iterative method of estimating distance-to-default.
} 
the daily values $(V)$ of the firm, based on the Black-Scholes-Merton model of equity value (Equation 2.3). Once the volatility and the value of the firm are estimated, one can simply plug them into Equation 2.8 to obtain the Distance-to-default for each firm-year.

Vassalou and Xing's (2004) method is a relatively modern technique of calculating default risk and has shown considerable power in predicting firms' default probabilities (Crosbie and Bohn, 2003). Credit-rating agencies, such as Moody's $K M V$, also employ similar methods to evaluate default risk for credit-rating purposes (Crosbie and Bohn, 2003). In accounting research, Bushman and Williams (2009) have recently employed a similar approach to measure the default risk in banks which was first used by Ronn and Verma (1986). Although the approach taken by Ronn and Verma (1986) and Bushman and Williams (2009) is similar to the Vassalou and Xing (2004) method, it differs from the Vassalou and Xing (2004) method in not involving any iterations. Crosbie and Bohn (2003, pp. 1617) point out that the iterative procedure developed by Moody's $K M V$, which was later adopted in the academic literature by Vassalou and Xing (2004), has a significant advantage over the non-iterative approach, because the actual market leverage moves too fast for the simpler approach to yield a reliable estimate of asset volatility $\sigma$.

Vassalou and Xing's (2004) iterative estimation method consists of the following steps: (1) Use daily stock prices over the 12 months prior to the desired balance date to form an initial estimate of the volatility of equity $-\sigma_{E}$. (2) Use the initial $\sigma_{E}$ to derive an initial estimate of the assets volatility, $\sigma$, by $\sigma=\frac{E}{E+D} \sigma_{E}$. (3) Use the new $\sigma$ to solve the Black-Scholes-Merton equity-pricing equation (Equation 2.3) for the value of $V_{t}$ in each of the trading days over a 12 months period. ${ }^{9}$ (4) Obtain

\footnotetext{
${ }^{9}$ On average, there are 251 trading days per year.
} 
a new $\sigma$ from the newly estimated daily values of $V_{t}$. This new $\sigma$ is then used as the input to the Black-Scholes-Merton equity-pricing equation in the next iteration. (5) Repeat Steps 3 and 4, until the values of $\sigma$ from two consecutive iterations converge, specifically, where the difference between two consecutive $\sigma$ is less than $10^{-3}$. In the actual computation of this Vassalou and Xing algorithm using the sample data, most of the sample firm-years converge pretty quickly, usually within 2 to 3 iterations.

This iterative procedure is conducted once each year for every firm at the December fiscal year-end. ${ }^{10}$ Due to the considerations of data availability and consistent with Vassalou and Xing (2004), the time until debt repayment or refinancing, $t$, is kept at 1 year for all firms. The firm's steady growth rate $\alpha$, which is also its weighted average cost of capital ("WACC"), is calculated according to the Capital Assets Pricing Model (CAPM). ${ }^{11}$ I first estimate the equity beta for each firm-year using prior monthly returns up to 60 months, ending in December of the year of estimation. In the case that there are less than 24 months of stock return data available, I estimate the equity beta based on daily stock returns in the year of estimation itself. Once the equity betas $\left(\beta_{E}\right)$ are estimated, I then convert them into asset betas $\left(\beta_{A}\right)$ by Hamada's formula (ignoring income tax): $\beta_{A}=\frac{E}{E+D} \beta_{E}$ (Hamada, 1972). After that, I can easily calculate the WACC for each firm-year using the estimated $\beta_{A}$ and the appropriate market risk premium and risk-free rates. Per Dimson et al. (2009), I set the risk premium of the US market at 5\%. The risk-free rate, $r$, is the average rate of 3-Month US Treasury Bills in the relevant year. The default point, $D$, is approximated by the firm's total liabilities (Debt) reported at each year-end

\footnotetext{
${ }^{10} \mathrm{I}$ remove all firms that do not have their fiscal year-ends in December.

${ }^{11}$ I disagree with Vassalou and Xing's (2004) choice of the current year's realized assets growth rate as the firm's expected steady growth rate, because the expected rate is usually different from the realized rate. Many firms have negative realized growth rates, but not many firms, if any, would have negative expected growth rates.
} 
from the Compustat database.

Also using the Vassalou and Xing (2004) procedure, I obtain the first set of estimates for the value of the firm $\left(V_{i t}\right)$. From $V_{i t}$, I can also calculate the rate of total return of the firm $\left(T R_{i t}\right)$ in any particular year, using the formula $T R_{i t}=$ $\left(V_{i t}-V_{i t-1}-C F F_{i t}\right) / V_{i t-1}$. These two variables, $V_{i t}$ and $T R_{i t}$, enable us to estimate the $D A B$ measure of conservatism via Equation 2.10. Later, in Section 2.5, I will offer a simpler, but less accurate, method of estimating these two variables.

\subsubsection{Sample and descriptive statistics}

The raw sample consists of all non-financial firms listed on NYSE, AMEX, and NASDAQ (national and OTC) exchanges from 1999 to 2006, excluding ADR firms. In order to simplify the computations of the Vassalou and Xing (2004) algorithm, I delete any firm-years that do not have a December year-end. In doing so, the sample firms' fiscal years coincide with the calendar years. To reduce the effects of outliers, as the standard practice, I trim the top and bottom $1 \%$ of the following variables $^{12}: R_{i t}, E P S_{i t} / P_{i t-1}, A C C_{i t} / T A_{i t-1}, C F O_{i t} / T A_{i t-1}, N I B I_{i t} / V_{i t-1}$, and two estimated variables $D D_{i t}$ and $T R_{i t}$. In addition, I delete those observations with a missing value in any of the key variables, and those observations with a zero or negative Market-to-Book (MTB) ratio. Since the Vassalou and Xing (2004) algorithm requires 12 months of un-interrupted daily stock price data, I also delete those firmyears that do not have un-interrupted daily stock price data in the relevant calendar year. After this trimming process, the final sample consists of 12,531 firm-years, covering 8 calendar years from 1999 to 2006 .

Table 2.1 provides the descriptive statistics of the final sample. All scale-related

\footnotetext{
${ }^{12}$ I obtained similar results by alternatively trimming $0.5 \%$ and $2 \%$ from the top and bottom of each variable.
} 
Table 2.1: Descriptive statistics

\begin{tabular}{|c|c|c|c|c|c|c|}
\hline & & mean & median & $\min$ & $\max$ & st. dev. \\
\hline CFO & (\$'million) & 229 & 18 & $-4,447$ & 24,110 & 832 \\
\hline$D D$ & & 4.28 & 4.05 & -1.44 & 12.73 & 2.82 \\
\hline$D E B T$ & (\$'million) & 1,635 & 111 & 0 & 205,700 & 6,192 \\
\hline EPS & $(\$)$ & 0.07 & 0.29 & -400.00 & 212.20 & 8.53 \\
\hline$E P S / P$ & & -0.01 & 0.03 & -0.90 & 0.33 & 0.14 \\
\hline MTB & & 3.49 & 2.20 & 0.12 & 86.77 & 4.97 \\
\hline$M V$ & (\$'million) & 2,600 & 344 & 0 & 116,800 & 8,184 \\
\hline$N I$ & (\$'million) & 89 & 5 & $-27,450$ & 13,530 & 553 \\
\hline$N I B I / V$ & & 0.01 & 0.03 & -0.29 & 0.15 & 0.06 \\
\hline ACC & (\$'million) & 4 & 0 & -8409 & 15080 & 276 \\
\hline$P$ & $(\$)$ & 19.20 & 12.35 & 0.03 & $2,375.00$ & 50.04 \\
\hline $\boldsymbol{R}$ & & 0.18 & 0.06 & -0.82 & 4.11 & 0.65 \\
\hline$T A$ & (\$'million) & 2,394 & 258 & 0 & 247,300 & 8,344 \\
\hline$V$ & (\$'million) & 4,303 & 593 & 1 & 244,500 & 13,420 \\
\hline$V 2$ & (\$'million) & 3,944 & 473 & 0 & 250,600 & 12,530 \\
\hline VOL $(\sigma)$ & & 0.44 & 0.34 & 0.02 & 4.37 & 0.34 \\
\hline$T R$ & & 0.10 & 0.03 & -0.93 & 7.49 & 0.50 \\
\hline$T R 2$ & & 0.18 & 0.07 & -1.21 & 12.62 & 0.63 \\
\hline
\end{tabular}

CFO: cash-flow from operating activities; DD: distance-to-default estimated with the Vassalou \& Xing (2004) iterative procedure; DEBT: total current and long-term liabilities; $E P S$ : basic earnings per share before extra-ordinary items; $E P S / P$ : earnings per share divided by opening share price; $M T B$ : closing market value of equity divided by closing net book value; $M V$ : closing market value of equity; $N I$ : net income including extra-ordinary items; $N I B I_{i t} / V_{i t-1}$ : net income including extra-ordinary items but before interest expense, then divided by opening $V$; ACC: operating accrual according to Ball \& Shivakumar's (2005) balance sheet method (see section 2.6.1); $P$ : opening share price; $R$ : buy-and-hold rate of return of equity stocks; TA: opening total assets; $V$ : opening value of (of the assets of) the firm, calculated per Vassalou \& Xing (2004) method; V2: opening value of (of the assets of) the firm, calculated as: $V 2_{i t}=M V+D E B T ; V O L(\sigma)$ : assets volatility of the firm, i.e. volatility of the value of the firm, calculated per Vassalou \& Xing (2004) method; $T R$ : return on the value of the firm, defined as $T R_{i t}=\left(V_{i t}-V_{i t}+C F F_{i t}\right) / V_{i t}$, where $C F F_{i t}$ is the net cash-flow from financing activities; $T R 2$ : a simpler proxy for the return on the value of the firm, defined as $T R 2_{i t}=\left(V 2_{i t}-V 2_{i t-1}+C F F_{i t}\right) / V 2_{i t-1}$. 


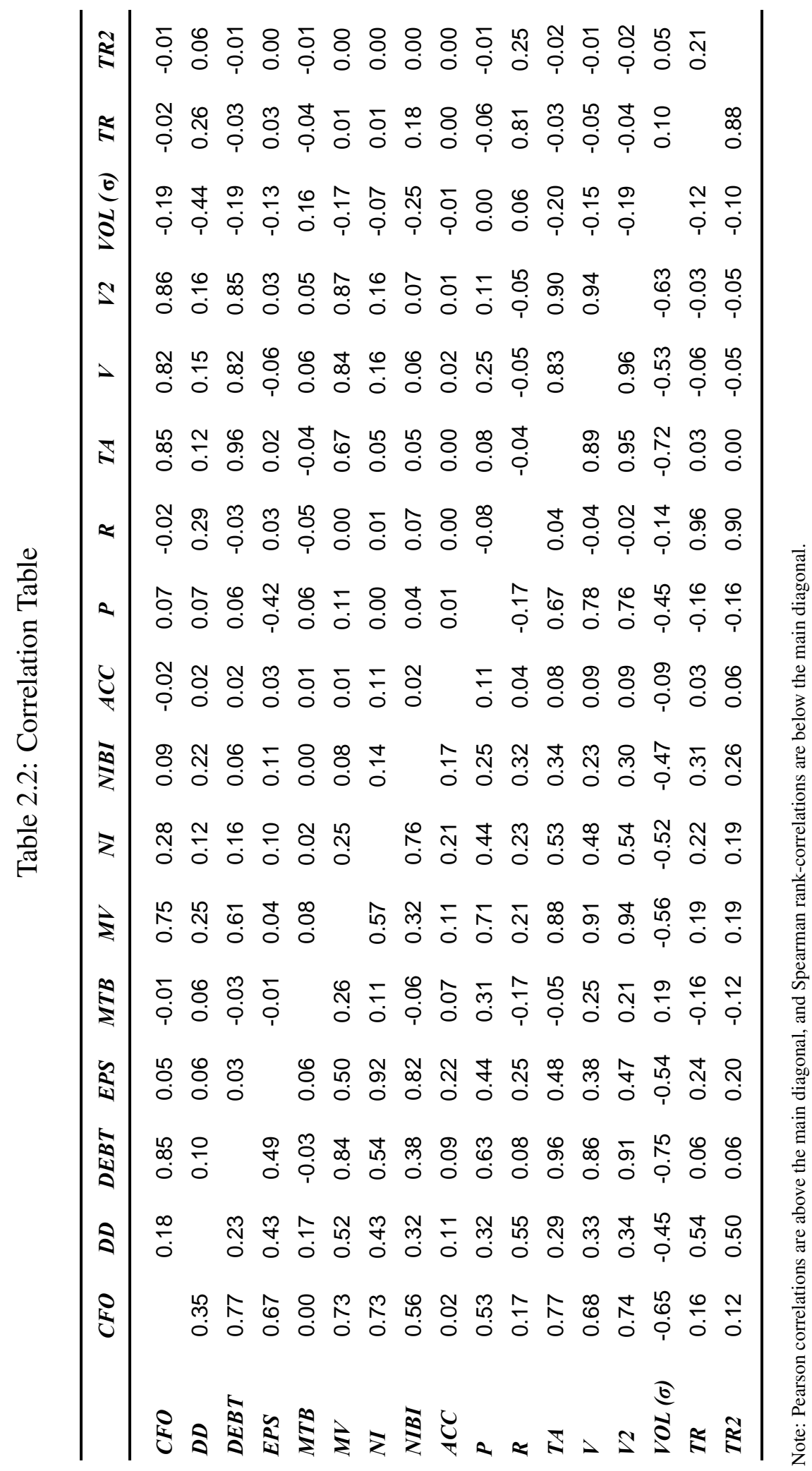


variables, such as Operating Accruals $(A C C)$, Book Value of Equity $(B V)$, Cash Flows from Operating Activities $(C F O)$, Market Value of Equity $(M V E)$, Total of Current and Long-term Liabilities (DEBT) and Total Assets (TA), vary significantly across firms, because of the varying sizes of the firms. Some of these scale-related variables are directly used in the main empirical tests of this chapter (e.g. MVE and DEBT) or in the process of calculating the Vassalou and Xing (2004) algorithm (e.g. MVE and DEBT), while others are used in the robustness tests (e.g. ACC, BV, $\mathrm{CFO}$, and TA). The mean (median) of $E P S_{i t} / P_{i t-1}$ is $-1 \%$ (3\%). The mean (median) of stock returns, $R_{i t}$, is $18 \%(6 \%)$, and this fact is consistent with the existence of the "fat-tail" in the distribution of stock returns.

Several variables, $D D_{i t}, V O L_{i t}$ (i.e. $\sigma$ ), $V_{i t}$ and $T R_{i t}$, in Table 2.1 are calculated by ourselves using the Vassalou and Xing (2004) method. Table 2.1 shows that the mean $D D$ is 4.28 (in units of standard deviations), and the median is 4.05. Similarly, asset volatility, $V O L_{i t}$ (which, in my earlier notation used in the Merton model, is $\sigma_{i t}$ ), has a mean of $44 \%$ (annualized), and a median of $34 \%$ (annualized). The mean (median) of the unlevered rate of return, $T R_{i t}$, is $10 \%(3 \%)$, which is significantly lower than that of the levered return $\left(R_{i t}\right)$, as expected.

$V 2_{i t}$ and $T R 2_{i t}$ are the second set of estimates for the values of the firm and the total rates of returns on the value of the firm, similar to the $V_{i t}$ and $T R_{i t}$ above. However, the difference is that $V 2_{i t}$ and $T R 2_{i t}$ are estimated with a simpler and perhaps, more naive, method than Vassalou and Xing's sophisticated method. I will discuss how to calculate $V 2_{i t}$ and $T R 2_{i t}$ later in Section 2.5.3. Here, I only compare $V 2_{i t}$ with $V_{i t}$, and compare $T R 2_{i t}$ with $T R_{i t}$. It appears from Table 2.1 that $V 2$ and $V$ have very similar means and medians. However, there appears to be some major difference between $T R 2$ and $T R$, as $T R 2$ have a higher mean (17\%) and median (7\%) than $T R$. 
The correlation table is reported in Table 2.2, which shows no unexpectedly high or low correlation coefficients. As expected, all size variables, such as $M V$, $B V, N I, V$ and $V 2$, are positively correlated with each other. The (levered) equity return $(R)$ is highly positively correlated with (unlevered) asset return $(T R)$, as illustrated by a Pearson correlation of 0.81 and a Spearman rank-correlation of 0.96 , which is expected. But these two returns are not the same nevertheless, and the difference is important for the removal of the bias in the DAB measure of accounting conservatism.

\subsection{Main empirical results}

\subsubsection{Results for the standard Basu measure}

If default risk does indeed induce an upward bias in the Basu measure according to Proposition 2.1, then one can expect to empirically observe that the Basu asymmetric timeliness coefficient, $\beta_{1}$, increases with the level of default risk in the firm. This forms the first aspect of this chapter's empirical testing. To test this relationship, I follow the augmented regression approach taken by LaFond and Watts (2008); Roychowdhury and Watts (2007); Ahmed and Duellman (2007); Lara et al. (2009a) and others. In particular, I estimate the following Basu regression augmented by distance-to-default $(D D)$ :

$$
\begin{aligned}
\frac{E P S_{i t}}{P_{i, t-1}}= & \alpha_{0}+\alpha_{1} D R_{i t}+\alpha_{2} D D_{i t}+\beta_{0} R_{i t}+\beta_{1} R_{i t} \cdot D R_{i t} \\
& +\gamma_{0} R_{i t} \cdot D D_{i t}+\gamma_{1} R_{i t} \cdot D R_{i t} \cdot D D_{i t}+\varepsilon_{i t}
\end{aligned}
$$

In equation 2.11 , I wish to test whether $\gamma_{1}$, which is the coefficient on interac- 
tion between default risk and the asymmetric timeliness coefficient, has the desired sign. Since Proposition 2.1 predicts that $D D$ is negatively correlated with the Basu asymmetric timeliness coefficient, I expect $\gamma_{1}$ to be (statistically) significantly less than zero.

Table 2.3 presents the results of regression 2.11. First, I estimate the standard Basu model (on the left of Table 2.3), and the result shows that the standard Basu asymmetric timeliness coefficient, $\beta_{1}$, is 0.210 , and significant at $1 \%$ level. This estimate of $\beta_{1}$ is consistent with the values reported in prior research (Basu, 1997; Ball et al., 2000; Bushman and Piotroski, 2006; Pope and Walker, 1999). The goodnews timeliness $\left(\beta_{0}=-0.022\right)$ is significantly negative at $1 \%$ level. This is also consistent with the prior studies that measure the degrees of conservatism in US firms in roughly the same time period (late-1990s to 2000s) as ours (eg. Bushman and Piotroski, 2006; Zhang, 2008).

The main proposition that the Basu asymmetric timeliness coefficient, $\beta_{1}$, increases in the degree of default risk (and decreases in $D D$ ) is tested in the second (middle) and third (right) regressions in Table 2.3. The second regression augments the standard Basu regression model with distance-to-default $(D D)$. The coefficient, $\gamma_{1}$, on the interaction term, $D D \cdot D R \cdot R$, is -0.011 , and is (statistically) significant at $1 \%$ level. The sign of $\gamma_{1}$ is consistent with Proposition 2.1, which states that $D D$ (default risk) is negatively (positively) associated with the Basu asymmetric timeliness coefficient.

In order to control for the non-linearity between $D D$ and the Basu measure, the third regression augments the Basu model with the percentile ranking of distance-todefault $D D R A N K$. By replacing $D D$ with $D D R A N K$, the third regression becomes purely interested in the impacts of the relative ranking of distance-to-default on the Basu measure of conservatism. The resulting coefficient on the interaction term, 
Table 2.3: The association between the Basu measure of conservatism and distanceto-default (DD)

\begin{tabular}{|c|c|c|c|c|c|c|c|c|c|}
\hline \multirow{2}{*}{$\begin{array}{l}\text { Independent } \\
\text { Variables }\end{array}$} & \multicolumn{3}{|c|}{$\begin{array}{l}\text { Standard Basu } \\
\text { Measure }\end{array}$} & \multicolumn{3}{|c|}{$\begin{array}{l}\text { Effects of DD on } \\
\text { Basu Measure }\end{array}$} & \multicolumn{3}{|c|}{$\begin{array}{c}\text { Effects of } \\
\text { DDRANK on Basu } \\
\text { Measure } \\
\end{array}$} \\
\hline & Estimate & t-stat & & Estimate & t-stat & & Estimate & t-stat & \\
\hline Intercept & 0.027 & 12.40 & $\star \star \star *$ & -0.029 & -4.43 & $* * *$ & -0.050 & -6.07 & $* * *$ \\
\hline$D R$ & -0.009 & -2.53 & ** & 0.011 & 1.18 & & 0.029 & 2.66 & $* * *$ \\
\hline $\boldsymbol{R}$ & -0.022 & -5.70 & $\star \star \star \star ~$ & -0.035 & -3.17 & 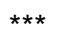 & -0.039 & -2.86 & $* * *$ \\
\hline$D R * R$ & 0.210 & 22.05 & $\star \star \star \star ~$ & 0.182 & 10.13 & $\star \star \star$ & 0.190 & 8.94 & $* * *$ \\
\hline$D D$ & & & & 0.010 & 10.56 & $\star \star \star *$ & & & \\
\hline$D D * D R$ & & & & -0.003 & -2.03 & ** & & & \\
\hline$D D^{*} R$ & & & & 0.002 & 1.44 & & & & \\
\hline$D D * D R * R$ & & & & -0.011 & -2.52 & ** & & & \\
\hline DDRANK & & & & & & & 0.121 & 11.01 & $* * *$ \\
\hline$D D R A N K * D R$ & & & & & & & -0.055 & -3.45 & $* * *$ \\
\hline$D D R A N K^{*} R$ & & & & & & & 0.025 & 1.35 & \\
\hline$D D R A N K^{*} D R^{*} R$ & & & & & & & -0.091 & -2.19 & $* *$ \\
\hline Adj. R_sq. & & $7.95 \%$ & & & $11.10 \%$ & & & $11.60 \%$ & \\
\hline F-stat & & 362 & $\star \star \star$ & & 225 & $\star \star \star$ & & 235 & $\star \star * \star$ \\
\hline
\end{tabular}

$D R$ is 0 if $R \geq 0$ and 1 otherwise. $R$ : arithmetic rate of stock return; $D D$ : distance-to-default estimated with Vassalou \& Xing's (2004) iterative method; $D D R A N K$ : percentile of $D D$. The dependent variable is $E P S_{i t} / P_{i t-1}$. Significance levels: $* 10 \%, * * 5 \%, * * * 1 \%$. All t-statistics are White-adjusted. 
Table 2.4: The association between the Default-Adjusted-Basu (DAB) measure and distance-to-default (DD)

\begin{tabular}{|c|c|c|c|c|c|c|c|c|c|}
\hline \multirow[b]{2}{*}{ Independent Variables } & \multicolumn{3}{|c|}{ DAB Measure } & \multicolumn{3}{|c|}{$\begin{array}{l}\text { Effects of DD on } \\
\text { DAB Measure }\end{array}$} & \multicolumn{2}{|c|}{$\begin{array}{l}\text { Effects of DDRANK } \\
\text { on DAB Measure }\end{array}$} & \\
\hline & Estimate & t-stat & & Estimate & t-stat & & Estimate & t-stat & \\
\hline Intercept & 0.034 & 38.40 & $* * *$ & 0.011 & 4.51 & $* \star *$ & 0.003 & 1.08 & \\
\hline DTR & -0.010 & -7.00 & 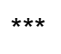 & 0.003 & 0.50 & & 0.010 & 2.34 & ** \\
\hline$T R$ & -0.019 & -10.00 & $\star \star \star *$ & -0.024 & -3.62 & $\star \star \star *$ & -0.026 & -3.81 & $* * *$ \\
\hline$D T R * T R$ & 0.129 & 30.20 & $\star \star \star *$ & 0.118 & 13.56 & $\star \star \star *$ & 0.119 & 12.48 & $* * *$ \\
\hline$D D$ & & & & 0.004 & 11.55 & $\star \star \star *$ & & & \\
\hline$D D * D T R$ & & & & -0.002 & -2.80 & ** & & & \\
\hline$D D^{*} T R$ & & & & 0.001 & 0.75 & & & & \\
\hline$D D^{*} D T R^{*} T R$ & & & & 0.002 & 1.04 & & & & \\
\hline DDRANK & & & & & & & 0.048 & 11.20 & $\star \star \star *$ \\
\hline DDRANK*DTR & & & & & & & -0.025 & -3.95 & $* *$ \\
\hline$D D R A N K^{*} T R$ & & & & & & & 0.008 & 0.87 & \\
\hline$D D R A N K * D T R * T R$ & & & & & & & 0.021 & 1.06 & \\
\hline Adj. $R \_s q$. & & $12.50 \%$ & & & $14.40 \%$ & & & $14.60 \%$ & \\
\hline F-stat & & 596.0 & $\star \star \star *$ & & 301.0 & $\star * \star$ & & 307.0 & $* * *$ \\
\hline
\end{tabular}

$D T R$ is 0 if $T R \geq 0$ and 1 otherwise. $T R$ : growth rate (i.e return) of the value of the firm; $D D$ : distance-to-default estimated with Vassalou \& Xing's (2004) iterative method; DDRANK: percentile of $D D$. Dependent variable in all 3 models is $N I B I_{i t} / V_{i t-1}$. Significance levels: $* 10 \%, * * 5 \%, * * * 1 \%$. All t-statistics are White-adjusted. 
$D D R A N K \cdot D R \cdot R$, is -0.091 , and is statistically significant at $5 \%$ level. This result further supports Proposition 2.1.

\subsubsection{Results for the DAB measure}

In Section 2.3 above, I proposed the DAB measure of accounting conservatism, via Equation 2.10. I expect that the DAB measure exhibits very little or no correlation with $D D$. I test this prediction by the following augmented regression:

$$
\begin{aligned}
\frac{N I B I_{i t}}{V_{i t-1}}= & a_{0}+a_{1} D T R_{i t}+a_{2} D D_{i t}+b_{0} T R_{i t}+b_{1} T R_{i t} \cdot D T R_{i t} \\
& +c_{0} T R_{i t} \cdot D D_{i t}+c_{1} T R_{i t} \cdot D T R_{i t} \cdot D D_{i t}+\varepsilon_{i t}
\end{aligned}
$$

First, I expect that $c_{1}$ is not statistically different from zero in 2.12 . Second, due to the fact that the original Basu measure is biased upward and the DAB measure is theoretically unbiased, I also expect that the DAB measure of conservatism $b_{1}$ is lower than the standard Basu measure $\beta_{1}$.

Table 2.4 presents the results of testing the DAB measure. In general, the evidence shown in Table 2.4 is supportive of my argument that the DAB measure is indeed more robust to the influence of default risk than is the standard Basu measure. First, Table 2.4 shows that $c_{1}$ is not significantly different from zero in both the second (middle) and the third (right) regressions, consistent with the first prediction. This lends direct support to the validity of the DAB model. Second, the absolute value of the asymmetric timeliness coefficient estimated from the DAB model $\left(b_{1}=0.129\right.$ in Table 2.4$)$ is $34 \%$ lower than the standard Basu asymmetric timeliness coefficient (i.e. $\beta_{1}=0.210$ in Table 2.3). I apply the Student's $t$ test of unequal variances to test the difference between $\beta_{1}$ and $b_{1}$, and the resulting 
$\mathrm{t}$-statistic for the difference $\left(\beta_{1}-b_{1}=0.081\right)$ is 7.80 , which is highly significant at $1 \%$ level. ${ }^{13}$ This shows that, in the presence of default risk in the sample firms, the DAB measure indicates a significantly lower degree of accounting conservatism than the original Basu measure. This is consistent with the prediction that the Basu measure is upwards biased by default risk.

To summarize, there is strong empirical evidence indicating that the DAB measure is more robust than the standard Basu measure to default risk. Thus, the DAB measure can potentially enable accounting researchers to achieve a higher level of precision and validity in their measurements of accounting conservatism.

\subsubsection{A simplified version of the DAB measure}

The DAB measure of conservatism (Equation 2.10) in the previous subsection requires the estimation of $V_{i t}$ and $T R_{i t}$ using the Vassalou and Xing (2004) method, which has both advantages and disadvantages. The main advantage of the Vassalou and Xing (2004) method is that it can produce very precise estimates of $V_{i t}$ and $T R_{i t}$ based on the Merton (1994) model. However, a major disadvantage of this method is that it is more difficult to programme and compute than most estimation/statistical procedures typically used in accounting research and it requires a large volume of daily price data. Furthermore, a computer program must be written to repeatedly solve the Black-Scholes-Merton option-pricing model for every single trading day in every firm-year, and for each iteration in that firm-year.

Given this computational complexity of the Vassalou and Xing (2004) method, it would be desirable to have a simpler way of estimating $V_{i t}$ and $T R_{i t}$, while achieving perhaps a slightly lower but still acceptable level of precision. To this end, I propose the following two new proxies as the alternatives to $V_{i t}$ and $T R_{i t}$ :

\footnotetext{
${ }^{13}$ The formula is: $t=\left(\beta_{1}-b_{1}\right) / \sqrt{S E}\left(\beta_{1}\right)^{2}+S E\left(b_{1}\right)^{2}$.
} 
$V 2_{i t}$ : The economic value of the firm (including equity and debts), calculated as: $V 2_{i t}=M V E_{i t}+D E B T_{i t} . M V E_{i t}$ is the market value of equity, and $D E B T_{i t}$ is the book value of the total liabilities of the firm.

$T R 2_{i t}: \quad$ Return on the value of the firm, calculated as $T R 2_{i t}=\left(V 2_{i t}-V 2_{i t-1}-\right.$ $\left.C F F_{i t}\right) / V 2_{i t-1}$. As above, $C F F_{i t}$ is the net cash-flow from financing activities.

These two new variables ( $V 2$ and $T R 2)$ are much simpler and quicker to calculate than are $V$ and $T R$. But they may not be as accurate as $V$ and $T R$ because the book value of debt instead of the market value of debt is used in calculating $V 2$. The results of re-estimating the regression models with these variables are reported in Table 2.5.

On the one hand, the standard model (on the left) in Table 2.5 shows an asymmetric timeliness coefficient of 0.211 , which is very close to the standard Basu asymmetric timeliness coefficient (i.e. 0.210 in Table 2.3), but is significantly higher than that of the "full-blown" version of the DAB model (0.129 in Table 2.4). On the other hand, the coefficients on the three-way interaction terms, $D D \cdot D T R 2 \cdot T R 2$ and $D D R A N K \cdot D T R 2 \cdot T R 2$, are not significantly different from zero, in the second and the third regressions of Table 2.5. This result indicates that the simplified version of the DAB measure does not interact with default risk. It is therefore possible that the simplified DAB measure is also robust to the influences of default risk. However, the estimate of conservatism from the simplified DAB measure is much the same as the estimate of conservatism from the standard Basu measure. Given the mixed results regarding the validity of the simplified DAB measure, I suggest that the Vassalou and Xing (2004) method is probably the best approach for estimating 
Table 2.5: A simpler (and naive) version of the Default-Adjusted-Basu (DAB) measure

\begin{tabular}{|c|c|c|c|c|c|c|c|c|c|}
\hline \multirow[b]{2}{*}{ Independent Variables } & \multicolumn{3}{|c|}{$\begin{array}{c}\text { Simplified DAB } \\
\text { Measure }\end{array}$} & \multicolumn{3}{|c|}{$\begin{array}{c}\text { Effects of DD on } \\
\text { Simplified DAB } \\
\text { Measure } \\
\end{array}$} & \multicolumn{2}{|c|}{$\begin{array}{c}\text { Effects of DDRANK } \\
\text { on Simplified DAB } \\
\text { Measure } \\
\end{array}$} & \\
\hline & Estimate & t-stat & & Estimate & t-stat & & Estimate & t-stat & \\
\hline Intercept & 0.035 & 12.24 & $\star \star \star *$ & 0.012 & 2.16 & * & 0.002 & 0.31 & \\
\hline DTR2 & -0.016 & -4.45 & $\star \star *$ & -0.006 & -0.88 & & 0.002 & 0.22 & \\
\hline$T R 2$ & -0.039 & -5.60 & $\star \star \star$ & -0.067 & -4.32 & $\star \star *$ & -0.070 & -3.86 & $; * \star *$ \\
\hline DTR2*TR2 & 0.211 & 19.73 & $\star \star \star *$ & 0.223 & 10.99 & $* * *$ & 0.225 & 9.66 & $* \star \star \star$ \\
\hline$D D$ & & & & 0.004 & 6.17 & 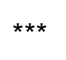 & & & \\
\hline$D D * D T R 2$ & & & & -0.001 & -0.87 & & & & \\
\hline$D D * T R 2$ & & & & 0.005 & 2.46 & $\star *$ & & & \\
\hline$D D * D T R 2 * T R 2$ & & & & -0.006 & -1.32 & & & & \\
\hline DDRANK & & & & & & & 0.055 & 6.65 & $* \star \star$ \\
\hline DDRANK*DTR2 & & & & & & & -0.021 & -1.85 & * \\
\hline DDRANK*TR2 & & & & & & & 0.044 & 1.99 & ** \\
\hline$D D R A N K * D T R 2 * T R 2$ & & & & & & & -0.050 & -1.18 & \\
\hline Adj. R_sq. & & $11.60 \%$ & & & $13.70 \%$ & & & $13.90 \%$ & \\
\hline F-stat & & 548 & *** & & 286 & $* \star *$ & & 289 & $9 * * *$ \\
\hline
\end{tabular}

$D T R 2$ is 0 if $T R 2 \geq 0$ and 1 otherwise. $T R 2$ : return on the value of the firm, estimated with the simpler (naive) method; $D D$ : distance-to-default estimated with Vassalou \& Xing's (2004) iterative method; DDRANK: percentile of $D D$. Dependent variable in all 3 models is $N I B I_{i t} / V 2_{i t-1}$. Significance levels: $* 10 \%$, **5\%, ***1\%. All t-statistics are White-adjusted. 
the DAB measure of conservatism. ${ }^{14}$

\subsection{Robustness tests}

\subsubsection{Controlling for the potential identification issue}

In the previous section, the empirical evidence showed that there is a positive (negative) correlation between default risk $(D D)$ and the Basu AT measure of conservatism. However, simply finding the correlation may not be a sufficient condition for the existence of bias in the Basu AT measure. That is because the real degree of accounting conservatism could also have increased with default risk. Therefore, we face an identification problem: Is the increase in Basu AT measure when default risk increases the result of upward bias or an increase in the actual degree of conservatism or both?

To see this problem, let us recall the key equation from Section 2.2: $\beta_{1}=k_{1} / \Delta$. I showed how default risk impacts on $\beta_{1}$ via its impact on $\Delta$, by holding $k_{1}$ constant. While it is easy to hold $k_{1}$ constant in the theoretical analysis, it is virtually impossible to hold $k_{1}$ constant across different sample firms in the empirical setting. In fact, the debt-contracting theory of conservatism has argued that $k_{1}$ might increase

\footnotetext{
${ }^{14}$ Apart from the sophisticated and the simplified DAB measures introduced above, I have also empirically tested a third (unreported) method of removing the default-risk bias from the Basu measure of accounting conservatism, based on Altman's (1968) Z score. In the third method, I use Altman's Z score as a control variable in an augmented Basu regression, as follows:

$E P S_{i t} / P_{i t-1}=\alpha_{0}+\alpha_{1} D R_{i t}+\alpha_{2} Z_{i t}+\alpha_{3} D R_{i t} Z_{i t}+\beta_{0} R_{i t}+\beta_{1} R_{i t} D R_{i t}+\beta_{2} R_{i t} Z_{i t}+\beta_{3} R_{i t} D R_{i t} Z_{i t}+\varepsilon_{i t}$ Because the $\mathrm{Z}$ score is a measure of default risk, by including the $\mathrm{Z}$ score as a control variable in the Basu regression, I could at least partially remove the impact of default risk on the Basu asymmetric timeliness coefficient. The empirical results based on this method are consistent with my theoretical prediction that the Basu measure of accounting conservatism is positively correlated with default risk. However, this $\mathrm{Z}$ score method is not introduced in the main body of this thesis due to a possible self-selection bias. As Earnings (EPS) is a key input to the Z score, and as EPS is the dependent variable in the regressions, introduction of the $\mathrm{Z}$ score would effectively result in having EPS on both sides of the equation.
} 
as as a result of increasing risk-shifting to debt-holders from equity-holders under high default risks (Beatty et al., 2008; Watts, 2003a; Zhang, 2008). If this theory is true, the Basu measure of conservatism, $\beta_{1}$, will also increase as a result of the increase in $k_{1}$, even if there were no biases in the Basu measure itself. Therefore, it is important to control for the changes in the real degree of conservatism $k_{1}$ in the sample.

I therefore need another independent measure of accounting conservatism to control for the changes in the underlying degree of conservatism $k_{1}$. In an earlier study, Ahmed et al. (2002, pp. 383-384) show that, when using the MTB ratio and the Negative Accruals (NA) measures of conservatism, leverage does not have any significant correlations with the degree of accounting conservatism. Their study period is from 1987 to 1992.

In this chapter, I use the Asymmetric Accrual to Cashflow (AACF) measure of conservatism developed by Ball and Shivakumar (2005) as the control variable for the actual degree of conservatism. The AACF measure is not subject to the influences of default risk, because this measure depends on accruals and cashflows rather than stock prices, which are generally unaffected by the firm's default risk.

Apart from the Basu (1997) measure and Ball and Shivakumar's (2005) AACF measure above, there are several other measures of accounting conservatism that could potentially be used as the control for the underlying degrees of conservatism. They include Givoly and Hayn's (2000) negative non-operating accruals measure, Penman and Zhang's (2002) hidden-reserves measure, and the popular Market-toBook ("MTB") ratio measure. In Chapter 1, I have already surveyed and analyzed the measures of accounting conservatism and have found that only the Basu measure and the AACF measures are proxies of the so-called conditional accounting conservatism. In contrast, all of the other measures mentioned above are proxies 
for the so-called unconditional conservatism. I have shown, in Chapter 1, that the distinction between these two groups of measures is quite sharp empirically, as the measures within the same group tend to be positively correlated with each other, but the measures from different groups tend to be negatively correlated with each other. On this ground, I contend that the AACF measure is perhaps the most relevant benchmark for assessing the Basu measure, because both measures are proxies for the same 'type', or aspect, of accounting conservatism. ${ }^{15}$

The AACF measure regresses the firm's operating accrual on its operating cashflow in the same time period, as follows:

$$
A C C_{i t}=\beta_{0}+\beta_{1} D C F O_{i t}+\beta_{2} C F O_{i t}+\beta_{3} D C F O_{i t} \cdot C F O_{i t}+\varepsilon_{i t}
$$

where

- $A C C_{i t}$ : Accruals measured as: $\Delta$ Inventory $+\Delta$ Debtors $+\Delta$ Other current assets - $\Delta$ Creditors - $\Delta$ Other current liabilities - Depreciation, all deflated by beginning total assets.

- $D C F O_{i t}$ : Dummy variable that is set to 0 if $C F O_{i t} \geq 0$, and is set to 1 if $C F O_{i t}<0$.

- $C F O_{i t}$ : Cash-flow for period $\mathrm{t}$, deflated by beginning total assets.

- $\beta_{3}$ : the AACF measure of accounting conservatism.

\footnotetext{
${ }^{15}$ MTB ratio appears especially unsuitable for the kind of tests conducted in this chapter, because MTB ratio is not only a proxy for 'unconditional' conservatism but also a well-known proxy for default risk in the finance literature (See Chapter 1 and Fama and French, 1993, 1995; Roychowdhury and Watts, 2007). In a test that is designed to clearly separate default risk and accounting conservatism as two distinct factors, MTB's inability to separate them would lead to severe confounding issues.
} 
Table 2.6: Robustness Test - Ball \& Shivakumar's (2005) AACF measure of conservatism and Distance-to-Default (DD)

\begin{tabular}{|c|c|c|c|c|c|c|c|c|c|}
\hline \multirow{2}{*}{$\begin{array}{l}\text { Independent } \\
\text { Variables }\end{array}$} & \multicolumn{3}{|c|}{$\begin{array}{c}\text { AACF measure of } \\
\text { conservatism }\end{array}$} & \multicolumn{3}{|c|}{$\begin{array}{l}\text { Effects of DD on } \\
\text { AACF measure }\end{array}$} & \multicolumn{2}{|c|}{$\begin{array}{c}\text { Effects of } \\
\text { DDRANK on } \\
\text { AACF measure }\end{array}$} & \\
\hline & Estimate & t-stat & & Estimate & t-stat & & Estimate & t-stat & \\
\hline Intercept & 0.018 & 15.31 & 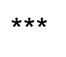 & 0.010 & 4.50 & $\star \star \star *$ & 0.008 & 3.17 & $\star * \star$ \\
\hline DCFO & 0.011 & 4.31 & 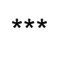 & 0.008 & 1.87 & * & 0.007 & 1.38 & \\
\hline CFO & -0.105 & -11.66 & 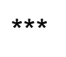 & -0.150 & -7.89 & $\star \star \star *$ & -0.164 & -7.09 & $\star \star \star$ \\
\hline$D C F O * C F O$ & 0.148 & 12.35 & $\star \star \star ~$ & 0.154 & 6.49 & $\star \star \star *$ & 0.158 & 5.57 & 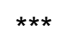 \\
\hline$D D$ & & & & 0.002 & 5.65 & $\star \star \star *$ & & & \\
\hline$D D * D C F O$ & & & & 0.001 & 1.26 & & & & \\
\hline$D D * C F O$ & & & & 0.004 & 1.40 & & & & \\
\hline$D D^{*} D C F O * C F O$ & & & & 0.007 & 1.53 & & & & \\
\hline DDRANK & & & & & & & 0.023 & 5.42 & $\star \star \star *$ \\
\hline$D D R A N K^{*} D C F O$ & & & & & & & 0.013 & 1.35 & \\
\hline DDRANK*CFO & & & & & & & 0.061 & 1.78 & * \\
\hline$D D R A N K^{*} D C F O * C F O$ & & & & & & & 0.052 & 1.14 & \\
\hline Adj. R_sq. & & $2.36 \%$ & & & $3.55 \%$ & & & $3.64 \%$ & \\
\hline F-stat & & 102 & $\star \star \star *$ & & 67 & $\star * *$ & & 69 & $* * *$ \\
\hline
\end{tabular}

$D C F O_{i t}$ is 0 if $C F O_{i t} \geq 0$, and 1 otherwise. $C F O$ : operating cashflow divided by opening total assets $(T A)$. $D D$ : distanceto-default estimated with Vassalou \& Xing's (2004) iterative method; DDRANK: percentile of DD. Dependent variable in all 3 models is operating accrual divided by opening total assets $-A C C_{i t} / T A_{i t-1}$. [For representational convenience, the denominator, $T A$, is not shown in the table.] Significance levels: *10\%, **5\%, ***1\%. All t-statistics are White-adjusted. 
Table 2.6 reports the results for the estimation of Ball and Shivakumar's (2005) AACF measure (Equation 2.13). The first regression (left) is the standard AACF model. Consistent with Ball and Shivakumar (2005), the standard AACF model shows a negative good-news timeliness coefficient (-0.105), and a positive asymmetric timeliness coefficient (0.148), and both coefficients are (statistically) significant at $1 \%$ level.

The results of the second (middle) and third (right) regressions in Table 2.6 show that the AACF measure of conservatism is not associated with the default risk of the firm, which supports the proposition that the observed increase in the Basu measure when default risk increases is due to bias. For example, the second (middle) regression augments the AACF model with $D D$, and the result shows that $\gamma_{1}$ is 0.007 and is not significant at $10 \%$ level of significance. The third (right) regression in Table 2.7 use $D D R A N K$ instead of $D D$ as the proxy for default risk, and yields a similar result. This result is consistent with the finding of Ahmed et al. (2002, pp. 383-384) that conservatism is not correlated with default risk. ${ }^{16}$

The regression results in Table 2.6 are in sharp contrast with the earlier results in Table 2.3. In Table 2.3 where the Basu model is tested, the Basu measure is highly negative correlated with $D D$, which suggests the Basu measure is positively correlated with default risk. But in Table 2.6 where the AACF measure of conservatism is tested, it shows no correlation between the AACF measure of conservatism and $D D$ at all. This comparison suggests that the increase in Basu measure as default risk increases is likely the consequence of the increasingly higher upward bias rather than changes in the actual degrees of conservatism.

\footnotetext{
${ }^{16}$ Ahmed et al. (2002) use leverage instead of default risk in their study. But these two proxies are closely related and tend to be highly correlated.
} 
Figure 2.1: Box-plot of distance-to-default (DD) - "normal firm-years" vs. "outliers"

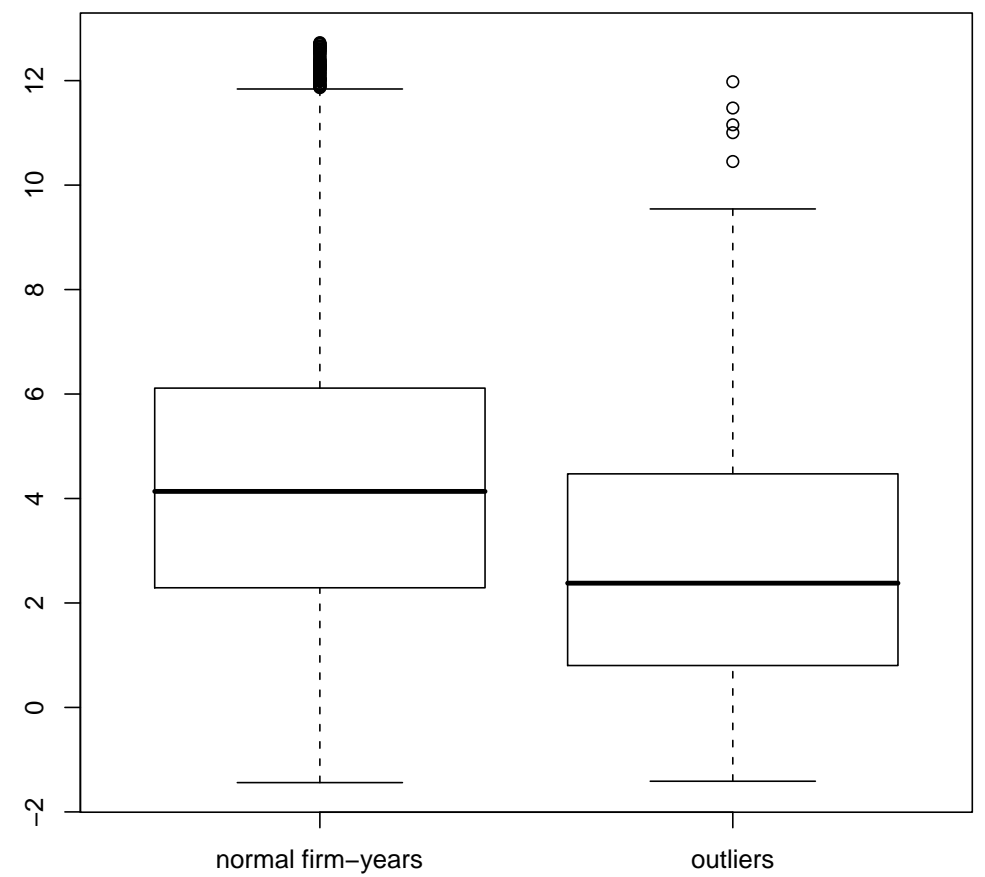

\subsubsection{Characteristics of "outliers"}

My final robustness test is of a different character compared to all previous empirical tests in the chapter. While all previous tests focus on testing certain priori theoretical predictions, this final test begins with no priori theory at all - instead I let the data to reveal their patterns and characteristics. That is done by detecting the "outliers" of the sample data based on a pure statistical technique, Cook's distance, which I introduce below.

In regression analysis, "outliers" are relative to the regression model itself. Fox (1997) contends that if a regression model has omitted some important (and correlated) explanatory variables, the data will likely show "outliers". In a strict sense, they are not "outliers" at all; rather, they are merely observations with special characteristics that the existing regression model fails to explain. 
In this chapter, the main regression model is, of course, the standard Basu (1997) model. To identify "outliers", I first separately estimate the Basu model in each year from 1999 to $2006 .{ }^{17}$ Then, the Cook's distance $(C D)$ is calculated for each observation. Using the cut-off recommended by Fox (1997), I label any firm-year with $C D>k /(n-k-1)$ as an "outlier". 18

After classifying firms into "normal" firms and "outliers" by their Cook's distances, I compare the levels of distance-to-default $(D D)$ between these two classes of firms. Figure 1.1 graphically depicts this comparison. An analysis of variance (ANOVA) shows that the "outliers" have lower $D D$ than the "normal" firms: The average $D D$ in "normal" firms is 4.374 , whereas the average $D D$ in "outliers" is 2.775. The difference is statistically significant at $1 \%$ level.

In summary, the analysis of "outliers" suggests that firms of high default risk possess quite different characteristics from firms of low default risk, and it appears that the Basu model fails to capture that difference. Thus, in an indirect way, the "outliers" analysis corroborates the argument that default risk is an omitted factor from the Basu measure.

\subsubsection{An alternative specification of NIBI}

Recall that in Section 2.3, I defined the Net Income Before Interest (NIBI) as net income (after tax) plus pre-tax interest expense. Now I conduct a robustness test to show that the results of the DAB measure are not fundamentally altered if aftertax interest expense, instead of pre-tax interest expense, are added back to net income. In the US, except for the smallest family owned companies, the average

\footnotetext{
${ }^{17}$ This robustness test does not include the trimmed data, or any data with non-December fiscal year-ends, because the purpose of this test is to show that "outliers" still exist in the Basu model even after extreme values have been trimmed way, and to understand the characteristics of the "outliers".

${ }^{18} n$ is the number of firms in any particular year; $k$ is the degree of freedom in the regression model.
} 
Table 2.7: Robustness test - An alternative specification of Net Income Before Interest ("NIBI2") in the DAB measure

\begin{tabular}{|c|c|c|c|c|c|c|c|c|c|}
\hline \multirow[b]{2}{*}{ Independent Variables } & \multicolumn{3}{|c|}{ DAB Measure } & \multicolumn{3}{|c|}{$\begin{array}{c}\text { Effects of DD on } \\
\text { DAB Measure }\end{array}$} & \multicolumn{3}{|c|}{$\begin{array}{c}\text { Effects of DDRANK } \\
\text { on DAB Measure }\end{array}$} \\
\hline & Estimate & t-stat & & Estimate & t-stat & & Estimate & t-stat & \\
\hline Intercept & 0.029 & 33.82 & $* * *$ & 0.004 & 1.57 & & -0.004 & -1.53 & \\
\hline DTR & -0.011 & -7.22 & $* * *$ & 0.002 & 0.62 & & 0.009 & 2.22 & ** \\
\hline$T R$ & -0.018 & -9.36 & $* \star *$ & -0.022 & -4.14 & $* * *$ & -0.024 & -3.61 & $* * *$ \\
\hline$D T R * T R$ & 0.121 & 28.64 & $* * *$ & 0.106 & 13.55 & $* * *$ & 0.106 & 11.31 & $* * *$ \\
\hline$D D$ & & & & 0.004 & 13.21 & $* * *$ & & & \\
\hline$D D^{*} D T R$ & & & & -0.001 & -2.16 & $* *$ & & & \\
\hline$D D^{*} T R$ & & & & 0.001 & 0.70 & & & & \\
\hline$D D * D T R * T R$ & & & & 0.002 & 1.01 & & & & \\
\hline DDRANK & & & & & & & 0.054 & 12.84 & $* * *$ \\
\hline$D D R A N K^{*} D T R$ & & & & & & & -0.022 & -3.58 & $* *$ \\
\hline DDRANK*TR & & & & & & & 0.007 & 0.81 & \\
\hline$D D R A N K * D T R * T R$ & & & & & & & 0.021 & 1.09 & \\
\hline Adj. R_sq. & & $11.72 \%$ & & & $14.34 \%$ & & & $14.63 \%$ & \\
\hline F-stat & & 555.5 & $\star \star \star *$ & & 300.6 & $* \star *$ & & 307.7 & 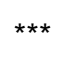 \\
\hline
\end{tabular}

The dependent variable in all 3 models is $N I B I 2_{i t} / V_{i t-1}$. NIBI $2_{i t}$ is equal to NI plus $65 \%$. Interest Expense. DTR is 0 if $T R \geq 0$ and 1 otherwise. $T R$ : growth rate (i.e return) of the value of the firm; $D D$ : distance-to-default estimated with Vassalou $\&$ Xing's (2004) iterative method; DDRANK: percentile of DD. Significance levels: $* 10 \%, * * 5 \%, * * * 1 \%$. All t-statistics are White-adjusted. 
marginal rate of coporation tax is approximately $35 \%$ of the company's taxable income, which means that the company's after-tax interest expense is approximately $65 \%$ of the pre-tax interest expenses. ${ }^{19}$ By adding back the estimated after-tax interest expenses to net income $(N I)$, I create an slightly different version of Net Income Before Interest. In order to avoid any confusion with the existing variable NIBI, which is calculated by adding back pre-tax interest expenses to net income, I call the new variable $N I B I 2$.

To test the robustness of the DAB measure to different specifications of NIBI, I re-run all three regressions in Table 2.4 with NIBI2 as the new dependent variable. The results of these new regressions are reported in Table 2.7. Comparison of Table 2.7 and Table 2.4 shows that there are no significant differences in the results obtained using either $N I B I$ or $N I B I 2$ as the dependent variable in the DAB regression. Thus, I conclude that these two alternative specifications of net income before interest expenses $(N I B I)$ cannot cause any significant difference to the accuracy of the DAB measure of conservatism.

\subsection{Conclusions}

In conclusion, Chapter 2 has analytically and empirically demonstrated that the Basu measure is, in general, upward biased due to the existence of default risk, and the magnitude of this bias tends to increase with the level of default risk. This chapter has also proposed a new measure of accounting conservatism, the DefaultAdjusted-Basu (DAB) measure, to address the issue of default risk. Empirical re-

\footnotetext{
${ }^{19}$ While the actual marginal tax rate slight varies from firm to firm depending on the specific level of income, the US corporate tax rates are designed such that the average tax rates for firms of all sizes converge to around $35 \%$ of their taxable incomes. Except for the smallest family-owned companies, the US marginal corporation tax rate fluctuate between $34 \%$ - 39\% depending on the actual level of taxable income, and is a flat rate of $35 \%$ for taxable incomes of $\$ 18.3$ million or higher.
} 
sults support that the DAB measure can substantially reduce or even eliminate the default-risk bias, and therefore can produce more accurate measures of the degree of accounting conservatism. 


\subsection{Appendix}

\section{Proof of the Lemma:}

First, from the definition of instantaneous Basu good- and bad- news coefficients $\left(\beta_{j t}\right)$, where $j=0$ and 2 , we have:

$$
\begin{aligned}
\beta_{j t} & =\lim _{\varepsilon \rightarrow 0^{+}} \frac{\operatorname{cov}\left[\frac{N I}{E(t)}, \frac{\Delta E}{E(t)}\right](\varepsilon)}{\operatorname{var}\left[\frac{\Delta E}{E(t)}\right](\varepsilon)} \\
& =\lim _{\varepsilon \rightarrow 0^{+}} \frac{\operatorname{cov}[N I, \Delta E](\varepsilon)}{\operatorname{var}[\Delta E](\varepsilon)} \\
& =\lim _{\varepsilon \rightarrow 0^{+}} \frac{\operatorname{cov}\left[\left\{\int_{t}^{t+\varepsilon} \alpha V_{t} d t+\int_{t}^{t+\varepsilon} k_{j} \sigma V_{t} d W_{1}(t)+\int_{t}^{t+\varepsilon} \sigma_{e} V_{t} d W_{2}(t)\right\}, \Delta E\right](\varepsilon)}{\operatorname{var}[\Delta E](\varepsilon)}
\end{aligned}
$$

In deriving the second line above, I can take $E(t)$ outside both the variance and covariance terms because the value of equity is already known at time $t$ [i.e., $E(t) \in \mathscr{F}(t)]$. In deriving the third line, I substitute the expressions for NI from Equation 2.6. After some simple algebra (omitted), I can break the last expression into two parts:

$$
\begin{aligned}
\beta_{j t}= & \ldots \\
= & \lim _{\varepsilon \rightarrow 0^{+}} \frac{\operatorname{cov}\left[\left\{\int_{t}^{t+\varepsilon} \alpha V_{t} d t+\int_{t}^{t+\varepsilon} k_{j} \sigma V_{t} d W_{1}(t)\right\}, \Delta E\right](\varepsilon)}{\operatorname{var}[\Delta E](\varepsilon)} \\
& +\lim _{\varepsilon \rightarrow 0^{+}} \frac{\operatorname{cov}\left[\left\{\int_{t}^{t+\varepsilon} \sigma_{e} V_{t} d W_{2}(t)\right\}, \Delta E\right](\varepsilon)}{\operatorname{var}[\Delta E](\varepsilon)}
\end{aligned}
$$

Now substitute the expression of $\Delta E$ into the above two terms (the resulting expressions are omitted due to length), and evaluate the resulting expression: 


$$
\begin{aligned}
\beta_{j t} & =\ldots \\
& =\lim _{\varepsilon \rightarrow 0^{+}} \frac{k_{j} \Delta \sigma^{2} V_{t}^{2} \cdot \varepsilon+o_{1}(\varepsilon)}{\Delta^{2} \sigma^{2} V_{t}^{2} \cdot \varepsilon}+\lim _{\varepsilon \rightarrow 0^{+}} \frac{\Delta \sigma \sigma_{e} V_{t}^{2} \cdot \rho \varepsilon+o_{2}(\varepsilon)}{\Delta^{2} \sigma^{2} V_{t}^{2} \cdot \varepsilon} \\
& =\frac{k_{j}}{\Delta}+\frac{\sigma_{e}}{\sigma} \frac{\rho}{\Delta}+\frac{1}{\Delta^{2} \sigma^{2} V_{t}^{2}}\left[\lim _{\varepsilon \rightarrow 0^{+}} \frac{o_{1}(\varepsilon)+o_{2}(\varepsilon)}{\varepsilon}\right] \\
& =\frac{k_{j}}{\Delta}+\frac{\sigma_{e}}{\sigma} \frac{\rho}{\Delta}+\frac{1}{\Delta^{2} \sigma^{2} V_{t}^{2}} \cdot 0 \\
& =\frac{k_{j}}{\Delta}+\frac{\sigma_{e}}{\sigma} \frac{\rho}{\Delta}
\end{aligned}
$$

In reaching the expression in the second line above, I applied the following two theorems for the variance and covariance of stochastic processes (For details, see Shreve (2004, p. 203)), as below.

Consider two stochastic processes:

$$
\begin{aligned}
& X_{1}(t)=X_{1}(0)+\int_{0}^{t} A_{1}(u) d u+\int_{0}^{t} B_{1}(u) W_{1}(u) \\
& X_{2}(t)=X_{2}(0)+\int_{0}^{t} A_{2}(u) d u+\int_{0}^{t} B_{2}(u) W_{2}(u)
\end{aligned}
$$

where $W_{1}(t)$ and $W_{2}(t)$ are Brownian motions satisfying $d W_{1}(t) d W_{2}(t)=\rho(t) d t$, and $A_{1}(t), A_{2}(t), B_{1}(t)$, and $B_{2}(t)$ are adapted processes. Then, it can be proved that 


$$
\begin{aligned}
M_{i}(\varepsilon)= & \mathbb{E}\left[X_{i}\left(t_{0}+\varepsilon\right)-X_{i}\left(t_{0}\right) \mid \mathscr{F}\left(t_{0}\right)\right] \\
= & A_{i}\left(t_{0}\right) \varepsilon+o(\varepsilon) \\
\operatorname{cov}\left[X_{1}, X_{2}\right](\varepsilon)= & \mathbb{E}\left[\left(X_{1}\left(t_{0}+\varepsilon\right)-X_{1}\left(t_{0}\right)\right)\left(X_{2}\left(t_{0}+\varepsilon\right)-X_{2}\left(t_{0}\right)\right) \mid \mathscr{F}\left(t_{0}\right)\right] \\
& -M_{1}(\varepsilon) M_{2}(\varepsilon) \\
= & \rho\left(t_{0}\right) B_{1}\left(t_{0}\right) B_{2}\left(t_{0}\right) \varepsilon+o(\varepsilon) \\
\operatorname{var}\left[X_{i}\right](\varepsilon)= & \mathbb{E}\left[\left(X_{i}\left(t_{0}+\varepsilon\right)-X_{i}\left(t_{0}\right)\right)^{2} \mid \mathscr{F}\left(t_{0}\right)\right]-M_{1}^{2}(\varepsilon) \\
= & B_{i}^{2}\left(t_{0}\right) \varepsilon+o(\varepsilon)
\end{aligned}
$$

These theorems above involve a small quantity o( $\varepsilon)$, which is defined as any quantity so small that

$$
\lim _{\varepsilon \rightarrow 0^{+}} \frac{o(\varepsilon)}{\varepsilon}=0
$$

Now I can derive the Basu asymmetric timeliness coefficient $\left(\beta_{1 t}\right)$ :

$$
\begin{aligned}
\beta_{1 t} & =\beta_{2 t}-\beta_{0 t} \\
& =\left(\frac{k_{2}}{\Delta}+\frac{\sigma_{e}}{\sigma} \frac{\rho}{\Delta}\right)-\left(\frac{k_{0}}{\Delta}+\frac{\sigma_{e}}{\sigma} \frac{\rho}{\Delta}\right) \\
& =\frac{k_{2}}{\Delta}-\frac{k_{0}}{\Delta} \\
& =\frac{k_{1}}{\Delta}
\end{aligned}
$$




\section{Proof of Proposition 2.1:}

I first differentiate $\beta_{1 t}$ with respect to $V_{t} / D$, then apply the chain rule in the following manner:

$$
\frac{\partial \beta_{1 t}}{\partial\left(\frac{V}{D}\right)}=\frac{\partial \beta_{1 t}}{\partial D D} \frac{\partial D D}{\partial\left(\frac{V}{D}\right)}
$$

Re-arranging Equation 2.15:

$$
\frac{\partial \beta_{1 t}}{\partial D D}=\frac{\partial \beta_{1 t}}{\partial\left(\frac{V}{D}\right)} / \frac{\partial D D}{\partial\left(\frac{V}{D}\right)}
$$

Now

$$
\begin{aligned}
\frac{\partial \beta_{1 t}}{\partial\left(\frac{V}{D}\right)} & =\frac{\partial}{\partial\left(\frac{V}{D}\right)}\left[\frac{k_{1}}{\Delta}\right] \\
& =-k_{1} \Delta^{-2} \frac{\partial \Delta}{\partial\left(\frac{V}{D}\right)} \\
& =-k_{1} \Delta^{-2}\left[\frac{\partial N\left(d_{1}\right)}{\partial d_{1}} \cdot \frac{\partial d_{1}}{\partial\left(\frac{V}{D}\right)}\right] \\
& =-k_{1} \Delta^{-2}\left[\exp \left(-\frac{d_{1}^{2}}{2}\right) \cdot \frac{D}{\sigma \sqrt{t} V}\right] \\
& <0
\end{aligned}
$$

In the last step above, the expression is less than zero because all of the terms, $k_{1}, \Delta^{-2}, \exp \left(-d_{1} / 2\right)$, and $\frac{D}{\sigma \sqrt{t} V}$ are positive and just -1 is negative. The product of all positive terms times -1 must be negative.

And 


$$
\frac{\partial D D}{\partial\left(\frac{V}{D}\right)}==\frac{\partial}{\partial\left(\frac{V}{D}\right)} \frac{\ln (V / D)+\left(\alpha-\sigma^{2} / 2\right)}{\sigma \sqrt{t}}=\frac{D}{\sigma V \sqrt{t}}>0
$$

It follows from Inequalities 2.17 and 2.18 and Equation 2.16 that

$$
\frac{\partial \beta_{1 t}}{\partial D D}<0
$$

This completes the proof of Proposition 2.1.

\section{Supplementary note on Basu good-news and bad-news coefficients:}

Here, I show that, although the Basu asymmetric timeliness coefficient is increasing in default risk, the Basu good-news and bad-news coefficients do not necessarily increase with default risk. As in the proof of Proposition 2.1, I first differentiate the Basu good-news (and bad-news) estimator, $\beta_{j t}(j=0$ or 2$)$, with respect to $V_{t} / D$, using the chain rule:

$$
\frac{\partial \beta_{j t}}{\partial\left(\frac{V}{D}\right)}=\frac{\partial \beta_{j t}}{\partial D D} \frac{\partial D D}{\partial\left(\frac{V}{D}\right)}
$$

Thus

$$
\frac{\partial \beta_{j t}}{\partial D D}=\frac{\partial \beta_{j t}}{\partial\left(\frac{V}{D}\right)} / \frac{\partial D D}{\partial\left(\frac{V}{D}\right)}
$$

But 


$$
\begin{aligned}
\frac{\partial \beta_{j t}}{\partial\left(\frac{V}{D}\right)} & =\frac{\partial}{\partial\left(\frac{V}{D}\right)}\left[\frac{k_{j}}{\Delta}+\frac{\sigma_{a c}}{\sigma} \frac{\rho}{\Delta}\right] \\
& =-\left[k_{j}+\frac{\sigma_{a c}}{\sigma} \rho\right] \Delta^{-2}\left[\exp \left(-\frac{d_{1}^{2}}{2}\right) \cdot \frac{D}{\sigma \sqrt{t} V}\right]
\end{aligned}
$$

It follows from Equations 2.21 and 2.22, and Inequality 2.18 that

$$
\left\{\begin{array}{l}
\frac{\partial \beta_{j t}}{\partial D D}<0, \quad \text { if } k_{j}+\frac{\sigma_{a c}}{\sigma} \rho>0 \\
\frac{\partial \beta_{j t}}{\partial D D} \geq 0, \quad \text { if } k_{j}+\frac{\sigma_{a c}}{\sigma} \rho \leq 0
\end{array}\right.
$$

Therefore, the Basu good-news and bad-news coefficients are increasing in default risk only if $k_{j}+\frac{\sigma_{a c}}{\sigma} \rho>0$. On the other hand, if $k_{j}+\frac{\sigma_{a c}}{\sigma} \rho \leq 0$, these coefficients will decrease in default risk. 


\section{Chapter 3}

\section{The Signalling Role of Accounting Conservatism in the Debt Market with Asymmetric Information}

\subsection{Introduction and background literature ${ }^{1}$}

The objective of Chapter 3 is to analytically examine firms' demand for accounting conservatism in a debt-contracting context. Towards this goal, I offer a new economic theory of accounting conservatism, which emphasizes the signalling role of conservatism in a debt market characterised by asymmetric information. In this theory, conservatism serves as a signal by which the borrower firms can convey their private information about their operating risk to the lenders, prior to signing the debt contract. This signalling model has a separating equilibrium, in which the low risk firms choose a high degree of accounting conservatism and the high risk firms choose a low degree of conservatism. In general, the results of my model show that

\footnotetext{
${ }^{1}$ I thank Jacek B. Krawczyk for his valuable comments on this chapter.
} 
(1) accounting conservatism can be used to reduce information asymmetry in the debt market; (2) in a debt market, a borrower firm's equilibrium degree of conservatism is partially determined by the firm's fundamental operating risk (defined as asset volatility).

As I discussed in the General Introduction of this thesis, accounting conservatism produces a downward bias in the reported net book values of the firm, and its accumulated earnings, mainly because conservatism delays the recognition of good news but accelerates the recognition of bad news, subject to economic uncertainty (Basu, 1997; Watts, 2003a; Guay and Verrecchia, 2006). While conservatism may produce the so-called 'distortions' to accounting numbers, accounting conservatism has been documented by overwhelming empirical evidence as a very fundamental and pervasive phenomenon in virtually all of the major economies in the world, both prior to and after the introduction of written accounting standards in the middle of the 20th century (Basu, 1997; Ball et al., 2000; Watts, 2003a,b). Historical records also show that conservatism has been a key principle of accounting since the 19th century, and possibly much earlier. But if conservatism distorts accounting information, why do so many firms still adopt the principle of conservatism in their financial statements? Furthermore, empirical data have shown that there are some significant cross-sectional differences in the degrees of conservatism across firms. So why do some firms choose a higher degree of conservatism than do other firms?

The prevailing view in the current accounting literature is that accounting conservatism has a number of benefits. Watts (2003a) contends that there are five main explanations for the existence of accounting conservatism. ${ }^{2}$ Of these five explanations, the debt-contracting theory is one of the most widely accepted economic

\footnotetext{
${ }^{2}$ These five explanation for the existence of accounting conservatism are: (1) litigation risk (2) debt-contracting, (3) managerial-contracting, (4) taxation, (5) political costs and regulatory pressures. These theories examines different sources of the demand for accounting conservatism but are not mutually exclusive.
} 
explanations for conservatism, and has been tested in a number of empirical studies (Ahmed et al., 2002; Beatty et al., 2008; Zhang, 2008). The debt-contracting theory of conservatism argues that conservatism improves the debt-contracting efficiency between lenders and borrowers, for two main reasons:

1. Under conservatism, earnings reflect bad-news more timely than good-news, triggering earlier technical defaults on the debt-covenants which allows the lenders to control the firm earlier and constrains any wealth transfers from debt-holders to equity-holders in a failing firm.

2. Because conservatism provides more protection to debt-holders in a firm, the interest rate on the firm's debt may be lowered as a result.

While the above arguments are intuitively appealing and have some empirical support (Ahmed et al., 2002; Ball et al., 2008; Beatty et al., 2008; Zhang, 2008), the debt-contracting theory of conservatism, as described above, has some weaknesses. The theory is, at best, an incomplete depiction of the role that accounting conservatism plays in the debt-contracting process. For example, Guay and Verrecchia (2006) criticised the common view held by Watts (2003a), Bushman and Piotroski (2006) and others that conservatism improves debt contracting efficiency by reducing the debt covenant slacks. Guay and Verrecchia (2006) said:

"And, under the assumption that difficult-to-verify information about anticipated profitability is costly to incorporate into financial statements, it may be more efficient (i.e., less costly) for firms to incorporate more of the difficult-to-verify bad news and less of the difficult-to-verify good news into financial statements in a timely manner (the difficultto-verify good news will be recognized into financial statements when it is realized and becomes easy-to-verify good news). 
Note that this role of conservatism in debt contracting is distinct from the argument made by Ball (2001), Bushman and Piotroski (2006) and others that conservatism serves a useful role in reducing slack in debt covenants. Borrowers and lenders will consider the existing accounting system and expected level of bias in reported financial reports when setting debt covenants. Further, as noted by Leuz (2001), it is inefficient to set covenants that trigger too often or too infrequently. As such, the parameters of the covenants are expected to be set so that slack is neither too little nor too great, regardless of whether the accounting system is more or less conservative." (Guay and Verrecchia, 2006, p. 157, Emphasis added)

To date, Gigler et al. (2009) offer the only analytical study on the role of conservatism in the debt-contracting setting, and their conclusion contradicts the above mentioned debt-contracting theory of conservatism. Gigler et al.'s (2009) model shows that conservatism may be 'inefficient' in debt-contracting because conservatism can trigger too many 'false alarms' in debt-contracts. By 'false alarms', the authors refer to the situations where an accounting-based debt covenant is violated when the actual performance of the firm is still sound. Gigler et al.'s paper clearly calls for a re-examination of the role of conservatism in the debt-contracting process.

I argue that a major weakness of the existing debt-contracting theory of conservatism is that the theory itself and the empirical tests of the theory over-emphasize the benefits of conservatism and ignore any potential costs associated with conservatism. If we could strictly follow this logic, then a higher degree of conservatism would always be desirable, because it offers greater benefits to the firm, but no additional costs. But if accounting conservatism was indeed so good at all times, why 
does not every firm just adopt the highest degree of conservatism? The empirical evidence that some firms adopt a higher degree of conservatism than others strongly suggests that there must be some "costs" associated with accounting conservatism. It is also likely that rational firms choose their own optimal degrees of conservatism based on the trade-off between their own costs and benefits of conservatism. But such a trade-off between costs and benefits of conservatism is a critically missing element from the debt-contracting theory of accounting conservatism.

The analytical studies of conservatism have not addressed this missing element in the literature. Gigler et al's (2009) analytical model assumes the degree of conservatism as an exogenous variable, which means the model does not really examine what has led the firm to adopt a particular degree of conservatism in the first place. For this reason, while Gigler et al's paper is illuminating in other respects, it does not directly help us to understand how firms determine their degrees of conservatism as a trade off between the costs and benefits of conservatism. An examination of this issue requires that the degree of conservatism be treated as an endogenous variable in the model.

There are also analytical models that examine the role of conservatism within the managerial contracting process, rather than the debt contracting process. For instance, a study by Chen et al. (2007) shows that the manager has incentives to manage earnings upwards in order to boost stock prices, and when the accounting system is conservative, the earnings management incentive diminishes. But Chen et al. (2007) assume that the degree of conservatism is pre-set by accounting standard setters, which effectively treats conservatism as an exogenous variable. Hence, this study cannot clearly tell us why a firm adopts a certain degree of conservatism in the first place. In comparison, Kwon et al. (2001) treat conservatism as an endogenous variable, and find that conservatism improves the incentive compatibility between 
managers and shareholders, when there is a lower limit on the penalty that can be imposed on the managers for bad performance. Another analytical study conducted by Bagnoli and Watts (2005) analyses firms' decisions on their degrees of conservatism in a signalling framework. The authors contend that a firm chooses a high degree of conservatism when the managers of the firm expect a high future profitablity, and conversely a low degree of conservatism when the managers expects a low future profitability. Bagnoli and Watts' (2005) study also treats conservatism as an endogenous variable. However, neither the Kwon et al. (2001) study nor the Bagnoli and Watts (2005) study analyses conservatism from a debt-contracting perspective.

In the signalling model of conservatism developed in this chapter, I explicitly recognise that the decrease in the value of equity is a cost of accounting conservatism. It is not hard to see why: when the degree of accounting conservatism increases in a firm, it will increase the value of debt in that firm, because conservatism provides more protections to the firm's debt-holders. Thus, since the total value of the assets of the firm remains the same, the value of equity must decrease correspondingly by the same amount. Therefore, the trade-off of conservatism in this chapter is essentially between the benefit of having lower interest rates on debt and the cost of lowering equity values. In this chapter, I approach the trade-off problem from the equity-holders' point of view, and assume that the managers make their decisions in the best interest of the equity-holders. ${ }^{3}$

My model of the debt market is based on a strand of economic literature, beginning from Stiglitz and Weiss (1981), that analyses adverse selection and signalling problems in the debt market. Stiglitz and Weiss (1981) shows that when borrower

\footnotetext{
${ }^{3}$ This assumption abstracts away the agency conflict between managers and equity-holders, and thereby allows the chapter to fully concentrate on the agency conflict between equity-holders and debt-holders.
} 
firms have more information about the risk levels of their investments than do the banks, the banks will ration the supply of credit to the market, which leads to an excessive demand for credit. In other words, the banks will keep the interest rate at a relatively low level, but not all borrowers willing to borrow at that interest rate can obtain loans. The main reason for credit-market rationing is that firms with very risky investments are willing to accept much higher interest rates than firms with lower risk investments, which would push up the market interest rate in the credit market. But in the absence of the bank's ability to differentiate between high risk firms and low risk ones, the market interest rate would be too high for the low risk borrowers to borrow. Therefore, the low risk borrowers would be 'squeezed' out of the credit market. That will leave only the risky borrowers in the market, gradually creating a market for "lemons" in the credit market (Akerlof, 1970). To prevent a "lemon" credit market from forming, the banks restrict the market interest rate to a lower level, thereby allowing the safe borrowers to exist in the credit market. But the banks would be unable to suppy all the loans asked for at such a low interest rate, which leads to the rationing behaviour in the credit market.

Since Stiglitz and Weiss (1981), there has been a stream of papers analyzing adverse selection and the signalling problems in credit markets (Bester, 1985; Grinblatt and Hwang, 1989; Milde and Riley, 1988; Stiglitz and Weiss, 1987). Some solutions to the credit rationing problem have been proposed and analyzed. For example, Bester (1985) and Grinblatt and Hwang (1989) argue that the credit-rationing may not be necessary if there are certain signalling mechanisms to help reduce information asymmetry in the market. For example, the size of the loan is proposed as one possible signalling mechanism Bester (1985).

As part of the signalling theory of accounting conservatism, I provide the analytical proof of four basic properties of accounting conservatism. These basic prop- 
erties are mostly related to the role of risk. While these basic properties are the foundation of the signalling theory developed here, they are also useful to other areas of accounting conservatism research.

The rest of Chapter 3 is structured as follows: Section 3.2 develops the four basic properties of conservatism. Section 3.3 sets up of the signalling game. Section 3.4 discusses the signaling equilibria of this game. Section 3.5 discusses the implications of this signalling theory of conservatism for research and accounting standards setting. Finally, Section 3.6 concludes the chapter.

\subsection{Four basic properties of conservatism}

In this section, I develop 4 basic properties of accounting conservatism - Lemma 3.1 to Lemma 3.4. The first two of these basic properties (Lemma $3.1 \& 3.2$ ) investigate the joint impact of accounting conservatism and the firm's risk on earnings. The second two basic properties (Lemma 3.3 and 3.4) postulate how accounting conservatism and risk jointly impact on the value of debt in the firm. These four properties of conservatism thus establish a set of relationships between accounting conservatism and risk. Although the fundamental relationship between conservatism and risk has been well recognized in the accounting literature, I explicitly derive it from Basu's (1997) definition of conservatism.

Accounting conservatism is inseparable from risk and uncertainty, because the fundamental role of the conservatism principle is to guide accountants in terms of recognizing and reporting economic transactions subject to risk and uncertainty. ${ }^{4}$ The role of conservatism as the accountants' guide through the waters of risk and uncertainty is evident in the IASB's definition of prudence (which is a synonym for

\footnotetext{
${ }^{4}$ I do not distinguish the two terms risk and uncertainty in this thesis, as in most other finance and accounting studies.
} 
conservatism):

"Prudence is the degree of caution in the exercise of the judgments needed in making the estimates required under conditions of uncertainty, such that assets or incomes are not overstated and liabilities or expenses are not understated." [Emphasis added] (IASB, 1989, pg. 39)

The FASB also states that:

(Conservatism) is a prudent reaction to uncertainty to try to ensure that uncertainty and risk inherent in business situations are adequately considered. [Emphasis added] (FASB, 1980)

The four properties (Lemmas 3.1 to 3.4) outlined below can be proved without making demanding assumptions about the economic and accounting structures. I analytically prove these properties with only two basic assumptions:

Assumption 1: Conservatism is operationally defined as Basu's (1997) asymmetric timeliness of earnings concept ${ }^{5}$

Assumption 2: A firm's operating risk, or simply risk, is measured by RothschildStiglitz's mean-preserving-spread (MPS) (Rothschild and Stiglitz, 1970).

Both assumptions have been generally accepted in the accounting and economics literatures. Assumption (1) has been widely embraced by accounting researchers in the last decade or so, as evidenced by the large number of published articles endorsing and citing the Basu definition of conservatism. Regarding assumption

\footnotetext{
${ }^{5}$ In this chapter, I follow Basu (1997) in defining conservatism as the asymmetric timeliness of earnings. However, the Basu defintion of conservatism, as a theoretical concept, is distinct from the Basu measure of conservatism. A clear distinction must be made between these two. The definition of conservatism is an abstract concept; by contrast, the Basu measure of conservatism is an empirical implemenation, or operationalisation, of that abstract concept.
} 
(2), the Rothschild-Stiglitz's MPS measure of risk is a widely accepted measure of risk in economics.

I would like to emphasize that all four properties of conservatism in this chapter hinge on the concept of the fundamental operating risk of a firm, or simply risk. By this term, I mean the volatility of the firm's 'news', which is a terminology used by Basu to describe the value-shocks to the firm, or more precisely, the information regarding such value shocks. 'News' is essentially the random value-shocks to the firm, and therefore the volatility of the random value-shocks is a logical measure of the operating risk of the firm. Firms subject to significant swings in their values are considered to have higher risks. The relative ranking of risk is measured by Rothschild and Stiglitz's (1970) Mean-Preserving-Spread (MPS). The analytical model in this chapter is only concerned with the relative ranking of risk among two or more firms, and the absolute level of risk does not matter.

\subsubsection{Definitions and assumptions}

Before formally stating the 4 lemmas, I first define some key terms, that definitions closely follow Basu (1997), as follows:

1. 'News': it represents the information about unexpected value-shocks to the firm, and is represented by a random variable, $\tilde{I},-$ the letter $I$ stands for "Information". Over a period of time, a firm receives a number of pieces of news, from 1 to infinity. But each piece of 'news' received by the firm must be an i.i.d. realization of $\tilde{I}$, and can be written as $I_{i}$. Furthermore, if a realization of $\tilde{I}$ is greater than or equal to zero, i.e. $I_{i} \geq 0$, then I say that the firm has received good 'news'; if on the other hand, the realization of $\tilde{I}$ is less than zero, i.e. $I_{i}<0$, then I say that the firm has received bad 'news'. 
Figure 3.1: Basu earnings function (with discontinuity)

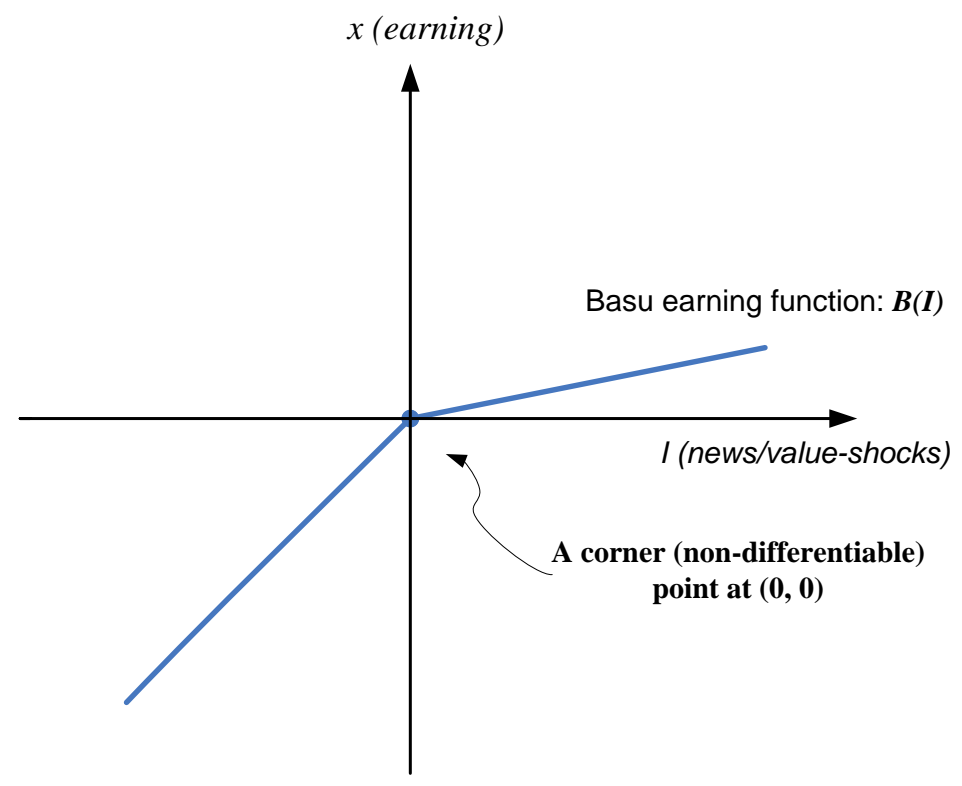

2. The degree of conservatism: it is defined according to Basu's asymmetric timeliness of earnings concept, which states that earnings recognize economic losses in a more timely manner than economic gains. Basu operationalizes this idea by specifying that: $\beta_{1}$, the percentage of 'good news' recognised in earnings and $\beta_{2}$, the percentage of 'bad news' recognized in earnings, are such that $\beta_{1}<\beta_{2}$. I let $c$ to be the difference between $\beta_{1}$ and $\beta_{2}$, that is, $c=\beta_{2}-\beta_{1}$. Thus, $c$ measures the degree of accounting conservatism in the firm. ${ }^{6}$

3. The Basu definition of conservatism, in essence, describes earnings as a concave function of realized 'news', I. I call it the Basu earnings function, expressed as $B(I)$. Fig. 1 illustrates the Basu earnings function graphically.

However, in a more realistic situation, a firm may receive many pieces of news about its economic gains or losses over a particular fiscal year, and each piece

\footnotetext{
${ }^{6}$ Note that the notations in this chapter are different from the notations in Chapter 2. $\beta_{1}, \beta_{2}$ and $c$ in Chapter 3 are equivalent to $k_{0}, k_{2}$ and $k_{1}$ in Chapter 2, respectively.
} 
Figure 3.2: Basu earnings function (without discontinuity)

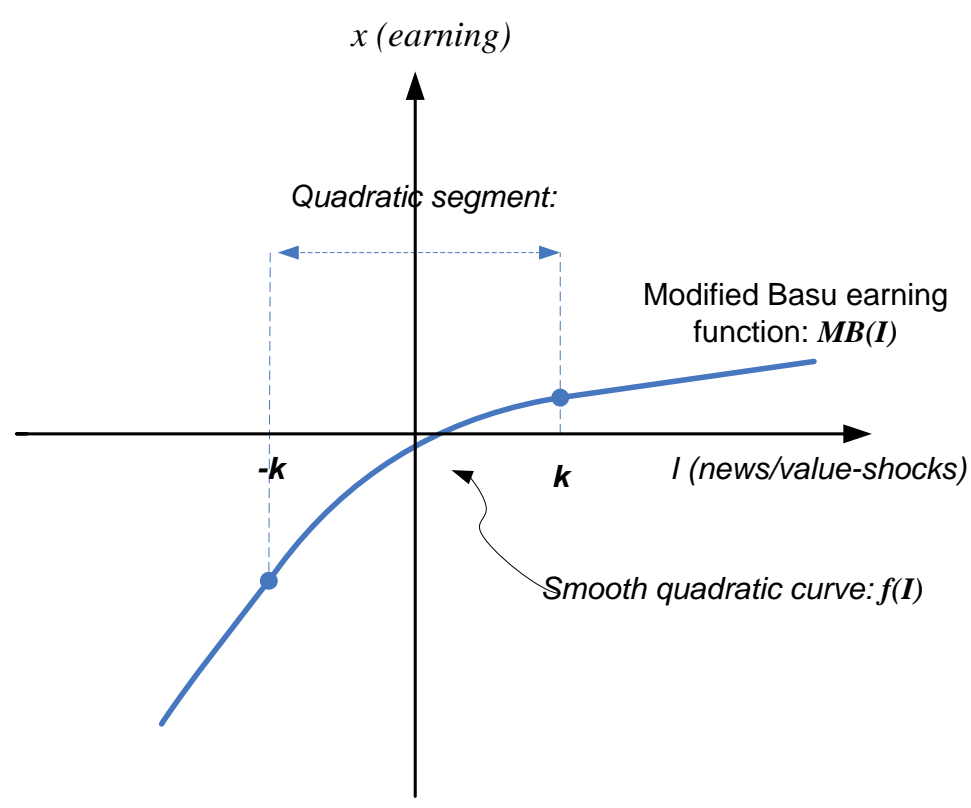

of news may indicate a different level of economic gains or losses that the firm experiences. A natural way to deal with such uncertainty contained in 'news' signals is to recognize the average earnings that are implied by all economic 'news' over a period of time. This idea can be expressed mathematically by letting earnings, $x$, equal the expected value of the Basu earnings function, as follows:

$$
x=\mathbb{E}[B(\tilde{I})]
$$

Equation 3.1 is structurally identical to the von Neumann-Morgenstern expected utility function.

4. The Basu earnings function $B(I)$ is unfortunately not differentiable at the point $(0,0)$, where $I=0$. (See Fig. 3.1) This point creates a technical issue for the proof of Lemma 3.1 and Lemma 3.2 using the Rothschild and Stiglitz Theorem, which requires the $B(I)$ function everywhere twice-differentiable. To 
solve this issue, I slightly modify $B(I)$ function to remove the non-differentiability at $I=0$, with the following method (see Fig. 3.2 for the modified function): In a small neighborhood around $I=0$, such as $[-k, k]$, I replace the two existing line-segments of $B(I)$ with a smooth curve, $f(I)$, which has the following properties

(a) $f(I)$ is increasing in $I$;

(b) $f^{\prime \prime}(I)$ is a negative constant, to ensure concavity.

(c) $f(I)$ 'smoothly' joins with the rest of the $B(I)$ curve at the two endpoints $-k$ and $k$, without any sharp corners.

In fact, these conditions above imply that the $f(I)$ is a quadratic curve, and as the Appendix shows, this quadratic curve always exists. The resulting Modified Basu earnings function, which we denote as $M B(I)$, consists of three parts: (1) the straight-line from $-\infty$ to $-k$ in the 'bad-news' part; (2) the quadratic curve $f(I)$ in the middle, from $-k$ to $k$; (3) the second straight-line from $k$ to $\infty$ in the 'good-news' part. (See Fig. 3.2) In order to minimise the distortions caused by this change, the middle part of the $M B(I)$ curve can be made arbitrarily small. Say, if a firm's earnings are in the scale of million dollars, we can carve the middle portion of $B(I)$ out and replace it by $f(I)$ from negative $\$ 1$ to positive $\$ 1$, i.e. $I \in[-1,1]$. Obviously, modifying the original Basu function at such a small scale, when the actual earnings run into millions of dollars, does not significantly impact on the original Basu earnings function. This maneuver ensures the removal of the non-differentiability at $I=0$. Within this new earnings function, the reported earnings can be re-written in 
terms of $M B(I)$, as below:

$$
x=\mathbb{E}[M B(\tilde{I})] \approx \mathbb{E}[B(\tilde{I})]
$$

A useful property of the $M B(I)$ curve is that, in the middle segment (i.e. the quadratic function $f(I)$ ), its second derivative, $M B^{\prime \prime}(I)$, is proportional to the degree of accounting conservatism, $c .^{7}$ This property allows us to use either $M B^{\prime \prime}(I)$ or $c$ as the measure of conservatism. See the appendix for the proof.

5. The operating risk of a firm is defined as the volatility of the market value of the firm, which is the sum of the value of debt and the value of equity. Since the change in the market value of the firm can be described by the value shocks to the firm, $\tilde{I}$, I can rank the degree of operating risk of each firm by ranking the degree of the dispersion of each firm's value shocks $\tilde{I}$ (it is also called the "news"). And the ranking of the degree of dispersion of $\tilde{I}$ can easily be accomplished by applying the well-known mean-preserving-spread concept of Rothschild and Stiglitz (1970). In particular, if a risky $(R)$ firm's 'news', denoted as $\tilde{I}_{r}$, is a mean-preserving-spread of a safe $(S)$ firm's 'news', denoted as $\tilde{I}_{s}$, then we say that firm $r$ is riskier than firm $s$. Furthermore, the statement that $\tilde{I}_{r}$ is a mean-preserving-spread of $\tilde{I}_{s}$ is equivalent to the statement that $\tilde{I}_{r}=\tilde{I}_{s}+\tilde{\varepsilon}$, where $\tilde{\varepsilon}$ is an independent random variable with a zero mean.

\footnotetext{
${ }^{7}$ But everywhere outside the middle segment, $M B^{\prime \prime}(I)=0$, because $M B(I)$ is a straight-line at these places.
} 


\subsubsection{Lemmas 3.1 and 3.2}

I present the first two properties of accounting conservatism in Lemma 3.1 and Lemma 3.2. Both lemmas focus on the (three-way) connection between conservatism, risk and earnings.

First, suppose that firm $\mathrm{R}$ is riskier than firm $\mathrm{S}$, in the sense that firm $\mathrm{R}$ 's valueshocks, $\tilde{I}_{r}$, is a mean-preserving-spread of the value-shocks of firm S, $\tilde{I}_{s}$. Let $x_{r}(c)$ and $x_{s}(c)$ denote the accounting earnings of the risky and the safe firms respectively, conditional on $c$, the degree of accounting conservatism.

Then, it can be proved that:

Lemma 3.1. The accounting earnings of the risky firm is lower than the earnings of the safe firm, for any given degree of conservatism, c. Or mathematically,

$$
x_{r}(c) \leq x_{s}(c)
$$

Proof. See the Appendix

and that,

Lemma 3.2. When the degree of accounting conservatism, $c$, increases in both firms $R$ and $S$ simultaneously, the marginal decrease in accounting earnings is greater in the riskier firm than in the safer firm. Mathematically, the following inequality holds:

$$
\frac{\partial x_{r}(c)}{\partial c}<\frac{\partial x_{s}(c)}{\partial c}<0
$$

Proof. See the Appendix.

Remark. Lemma 3.1 is simply a re-statement of the well-known fact that, when the degrees of conservatism are the same, riskier firms tend to have lower earnings than 
do safer firms.

Lemma 3.2 focuses on the marginal rate of change in earnings, when there is a small change in the degree of accounting conservatism. Lemma 3.2 shows the rate of change is greater for the riskier firm than for the safer firm. This relationship is graphically represented in Figure 3.3. Figure 3.3 plots earnings, $x$, against the degree of accounting conservatism, $c$. There are two curves in Figure 3.3 - one representing the earnings of the risky firms, the other representing the earnings of the safe firm. Figure 3.3 illustrates that the risky firm's earnings decrease at a faster rate than do the earnings of the safe firm, when $c$ increases.

Lemma 3.2 is akin to the situation where police try to catch drink-drivers on a Saturday night. If there are a lot of drink drivers in town on Saturday night, then dispatching more police onto the streets will result in a significant increase in the number of drink-drivers caught. If, however, there are very few drink-drivers on Saturday night at the first place, then sending more police onto the streets will not have as much an impact on the number of drink-drivers caught as in the previous situation. The relationship between risk, conservatism and earnings reflects the same idea.

Example. A simple numerical example can help illustrating both Lemma 3.1 and Lemma 3.2. Let us suppose that a particular firm has an average value-shock of $\$ 5$, in a given period. For simplicity, I assume that there are just two pieces of news for that firm, a good one and a bad one, which averages to $\$ 5$. By extending the spread between the good and bad 'news', I can create a series of 'news' of different levels of risks. Let me now write the good-news and bad-news in ordered pairs, such as $(20,-10),(30,-20),(40,-30)$ etc, where the first element in each pair is the goodnews and the second element is the bad news. All these pairs are mean-preserving, 
Figure 3.3: Earnings as a function of conservatism

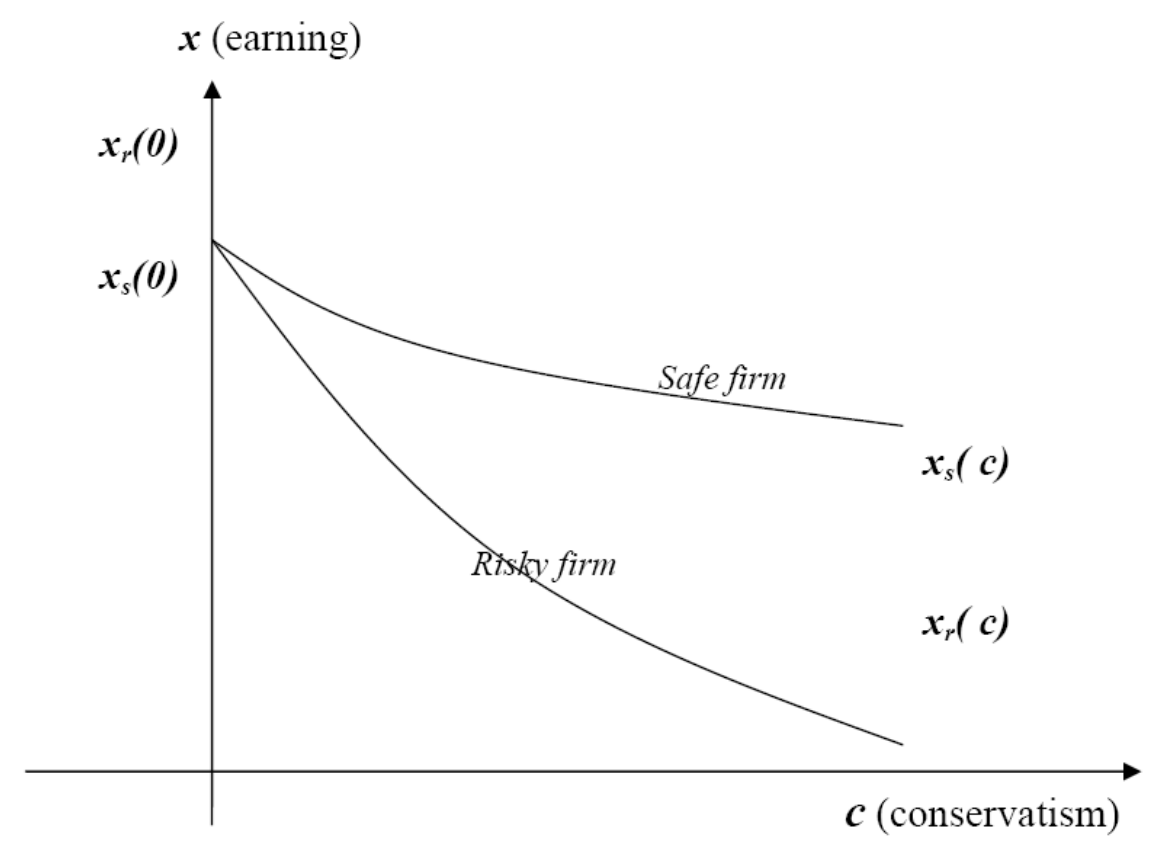

as they all have a mean of $\$ 5$.

Then I calculate the earnings for each pair of news, at five levels of conservatism ( $c=0.2,0.4,0.6,0.8$, and 1$)$. For simplicity, I set the bad-news timeliness $\left(\beta_{2}\right)$ to 1 . Table 3.1 reports the resulting earnings. It is easy to see two regularities from Table 3.1: First, as the risk level increases, all earnings decrease, which illustrates Lemma 3.1. Second, as $c$ increases, the earnings of the riskier firms decrease more rapidly than the earnings of the safer firms, which shows the effect of Lemma 3.2.

\subsubsection{Lemmas 3.3 and 3.4}

Several accounting researchers, including Watts (2003), Ahmed et al. (2002), Ball et al. (2008) and Zhang (2008), contend that a more conservative accounting system can reduce the interest rates charged by debtholders, and thereby increase the value of the debt in a firm, ceteris paribus. This effect can happen because 
Table 3.1: Numerical example of Lemma 3.1 and 3.2

\begin{tabular}{|c|c|c|c|c|c|c|c|c|c|c|}
\hline \multirow{3}{*}{\multicolumn{3}{|c|}{$\begin{array}{c}\text { Formula for earning according to the } \\
\text { Basu's asymmetric timeliness of } \\
\text { earnings: } \\
\text { Earning }=[\text { Good-news*(1-c)+bad- } \\
\text { news }] / 2\end{array}$}} & \multirow[b]{2}{*}{ c (asymmetric) } & \multicolumn{6}{|c|}{ Timeliness levels } & \multirow{4}{*}{$\begin{array}{c}\text { Earning } \\
\text { decrease per } \\
0.2 \text { extra } \mathrm{c}(\$)\end{array}$} \\
\hline & & & & 0.0 & 0.2 & 0.4 & 0.6 & 0.8 & 1.0 & \\
\hline & & & $\beta 1$ (good-news) & 1.0 & 0.8 & 0.6 & 0.4 & 0.2 & 0.0 & \\
\hline $\begin{array}{c}\text { Good-news } \\
\text { (\$) }\end{array}$ & $\begin{array}{c}\text { Bad-news } \\
\text { (\$) }\end{array}$ & $\begin{array}{c}\text { Std. } \\
\text { Dev/Risk }\end{array}$ & $\beta 2$ (bad news) & 1.0 & 1.0 & 1.0 & 1.0 & 1.0 & 1.0 & \\
\hline 20 & -10 & 21 & & 5 & 3 & 1 & -1 & -3 & -5 & -2 \\
\hline 30 & -20 & 35 & : & 5 & 2 & -1 & -4 & -7 & -10 & -3 \\
\hline 40 & -30 & 49 & 言 & 5 & 1 & -3 & -7 & -11 & -15 & -4 \\
\hline 50 & -40 & 64 & & 5 & 0 & -5 & -10 & -15 & -20 & -5 \\
\hline
\end{tabular}

conservatism influences accounting-based debt covenants. Accounting-based debt covenants are contractual agreements that specify the minimum or maximum levels of certain key accounting ratios that the borrower firm can have. The main purpose of these covenants is to align equity-holders' incentives with those of the debt-holders, and to restrain the transfer of wealth from debt-holders to equityholders. Examples of accounting-based debt covenants are the minimum net worth requirement, the minimum interest coverage requirement, the maximum leverage requirement and the minimum current ratio (working capital) requirements. When there is an accounting-based covenant in the debt contract, the value of the bond is simultaneously determined by two categories of factors: (1) market factors, which include the market value of the firm and its volatility; and (2) accounting factors, which include accounting earnings and book values to the extent that these accounting factors are used in the debt covenant. In fact, the signalling model of accounting conservatism is basically built upon the notion that the market factors and the accounting factors interact via accounting conservatism. 
Ahmed et al. (2002), Beatty et al. (2008), Watts (2003a) and Zhang (2008) all argue that, ceteris paribus, accounting conservatism forces the borrower firm to violate its accounting-based debt covenants more frequently and in a more timely manner. That makes the covenants more 'binding' and default more likely when the firm is performing badly. A more 'binding' covenant can convey bad news more quickly to the lenders and trigger early (technical) defaults, which provides a greater degree of protection to the lenders. As a consequence, the bond of the conservative firm is more valuable than the bond in a non-conservative firm. And correspondingly, the interest rate of the bond in the more conservative firm is lower, ceteris paribus, because it is less risky.

In addition, the Modigliani and Miller (1958) theorem states that, in absence of tax effects, the value of the assets of the firm, $A$, is the sum of the value of the debt, $D$, and the value of the equity, $E$ of that firm (i.e. $A=D+E$ ). Since the value of assets does not change, any increase in the value of debts, $D$, must be accompanied by an offsetting equal decrease in the value of equity, $E$. Therefore, an increase in the degree of accounting conservatism will not only lead to a higher value of debt in the firm, but also a lower value of equity. This idea is formally summarized in Lemma 3.3 below.

Lemma 3.3. Ceteris paribus, an increase in the degree of accounting conservatism, $c$, in the borrower firm, leads to an increase in the value of debt and a decrease in the value of equity of equal amounts. Mathematically,

$$
\frac{\partial D}{\partial c}=-\frac{\partial E}{\partial c}>0 \text { and } \frac{\partial E}{\partial c}<0
$$

I state Lemma 3.3 without a formal proof, because the basic idea of Lemma 3.3 has been extensively discussed by Ahmed et al (2002), Watts (2003), Zhang (2008), 
and others, and is supported by empirical evidence.

Now, suppose that firm $R$ is riskier than firm $\mathrm{S}$, in the sense that firm $\mathrm{R}$ 's valueshocks, $\tilde{I}_{r}$, is a mean-preserving-spread of the value-shocks of firm $\mathrm{S}, \tilde{I}_{s}$. Firm R and firm $\mathrm{S}$ both have debt, and we denote the value of debt as a function of conservatism - as $D_{r}(c)$ and $D_{s}(c)$ respectively. Let us also suppose that the debt in both types of firms is identical, with the same maturity value and maturity date.

Lemma 3.4. If the following conditions are satisfied: (1) Lemma 3.2 holds, and (2) ceteris paribus, the value of debt, D, is a decreasing and is a linear (or convex) function of accounting earnings, $x$, then the following two single-crossing properties (SCP) of conservatism hold:

$$
\frac{\partial D_{r}(c)}{\partial c}>\frac{\partial D_{s}(c)}{\partial c}>0
$$

and equivalently,

$$
\frac{\partial E_{r}(c)}{\partial c}<\frac{\partial E_{S}(c)}{\partial c}<0
$$

Proof. See the Appendix.

Lemma 3.4 states that the marginal benefit to debt-holders arising from increased degree of accounting conservatism is greater, if the borrower firm's risk level is higher. For example, if a lender holds some senior bonds in a AAA-rated firm, the interest rate on the bonds is likely to be very low due the low level of risk. It would then be very difficult to further decrease the interest rate on these bonds simply by making the accounting system more conservative. In contrast, if the lender invests in some junk bonds, then there exists a considerable default premium in the bond's interest rate. In this case, increasing the borrower firm's degree of accounting conservatism can potentially yield a much greater level of protection 
to the lenders, which in turn will lead to a significant reduction in the risk premium of these junk bonds. Lemma 3.4 captures this idea.

It might initially seem quite surprising that Condition (2) in Lemma 3.4 requires the value of debt to be a decreasing function of earnings. But this requirement, in fact, is entirely sensible. When Lemma 3.4 states that the earnings increase, it means that the reported earnings increase, while holding the value of the total assets constant, which is what the 'ceteris paribus' term is there for. If the value of assets increases, then without a doubt, the value of debt will also increase, as demonstrated by Merton (1974). ${ }^{8}$ However, if the asset value is being held constant, just increasing reported earnings does not make the firm worth more, but instead, only makes the firm's debt-covenant is less 'binding'. And a less binding debtcovenant lowers the value of debts, as discussed earlier. Thus, when holding all other factors constant, increasing reported earnings result in a lower value for the firm's debts.

In the economics literature, both of inequalities (3.3 and 3.4) are typically called the Single-Crossing Property, because if one draws $D$ as a function of $c$, the two curves $D_{r}(c)$ and $D_{s}(c)$ crosses with each other at most once (Fudenberg and Tirole, 1991). In this chapter, I assume that the increase in the value of the debt in the risky firm resulting from the increased conservatism is sufficiently large such that the the value of debt is higher in the risky firm than in the safe one, when $c$ is higher than a certain threshold value. That leads to $D_{r}(c)$ and $D_{s}(c)$ crossing each other exactly once, as in Figure 3.4. In practice, this may happen when the earnings of the risky firm become so low due to high conservatism, leading to a very high level of protection given to the lenders in that risky firm.

As Figure 3.4 shows, when the degree of conservatism is zero, the value of

\footnotetext{
${ }^{8}$ Chapter 2, Section 2.2 of this thesis discussed the Merton model in greater detail.
} 
Figure 3.4: Debt value as a function of conservatism (Single-crossing property)

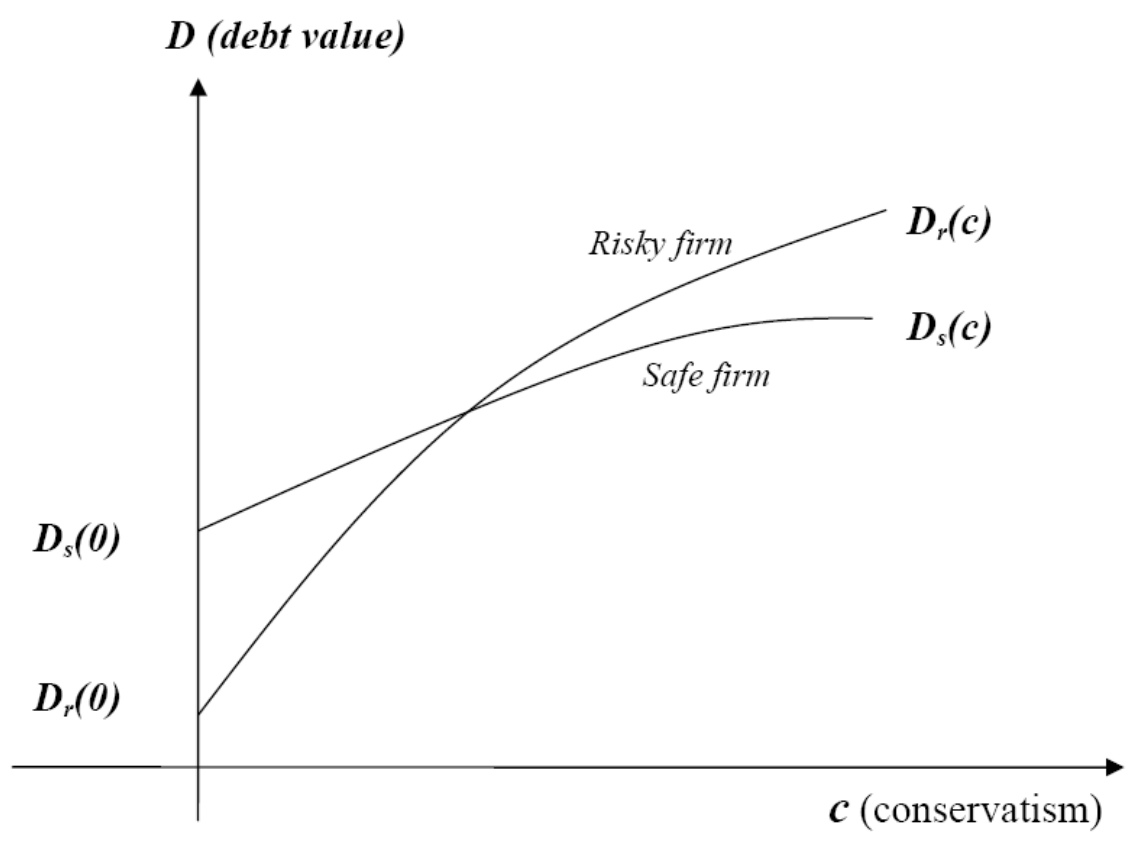

Figure 3.5: Equity value as a function of conservatism (Single-crossing property)

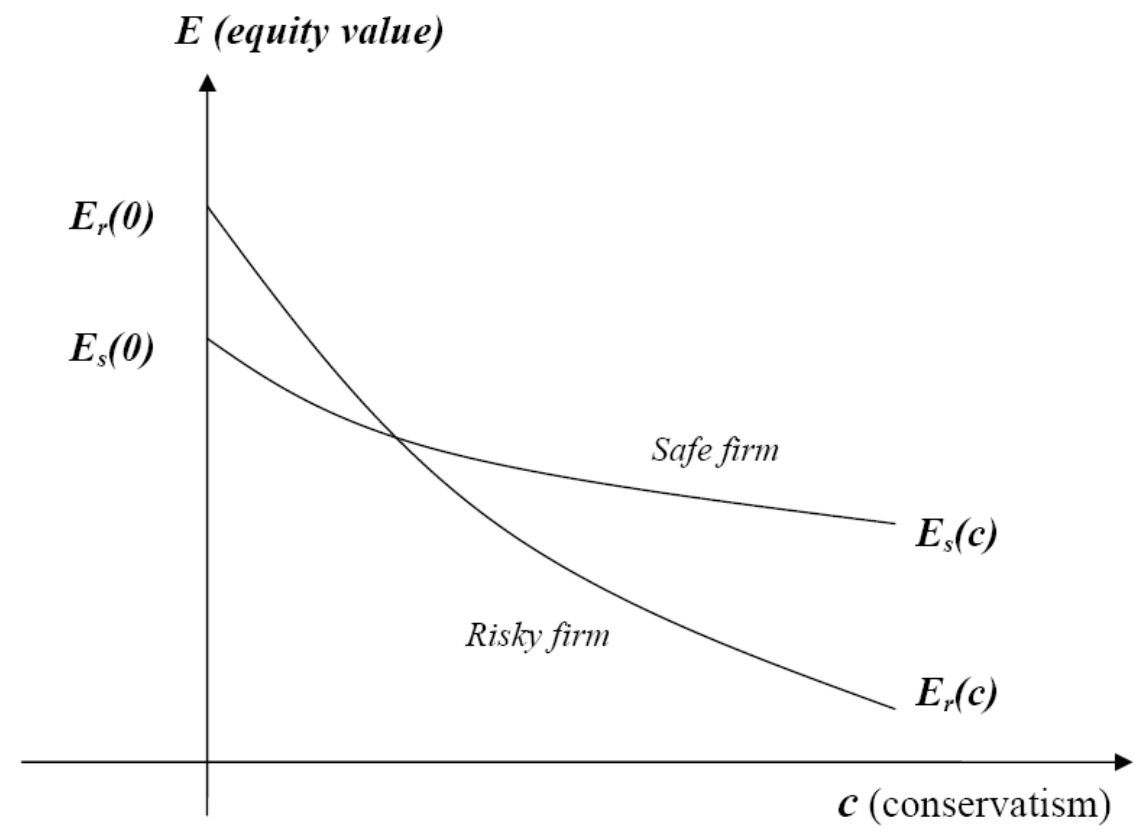


the risky debts, $D_{r}(0)$, is lower than the value of the safe debts, $D_{s}(0)$. But when the degree of conservatism increases, the debts in the risky firm gradually becomes more valuable than the debts in the safe firm. These two curves intercepts at point $c_{\text {min }}$. Figure 3.4 also shows that the Debt curve of the risky firm is steeper than that of the safe firm, which is also stated in Lemma 3.4. Similarly, the single-crossing property of conservatism regarding equity is shown in Figure 3.5, which is basically a mirror image of Figure 3.4.

\subsection{Model set-up}

In this section, I develop a signalling model of accounting conservatism in a debt market characterised by asymmetric information. First, I set up the basic structure of the signalling game.

Consider the following signalling game with two classes of players: (1) the firms who want to borrow money by selling their bonds, and (2) the lenders who wants to lend in the bond market. To simplify the exposition in this chapter, I treat all shareholders of a firm collectively as one individual, and call that individual the "equity-holder" of the firm. I further assume that the firm's goal is to maximize the wealth of the equity-holder, and hence there are no conflicts of interests between the firm and the equity-holders. So for all practical purposes of this model, such as determining the payoff for each party, the firm and its equity-holder can be treated as the same. I also assume that the firm has no initial assets or liabilities, and thus is just a shell company waiting for investment opportunities and injections of capital from the equity-holder and lenders. Finally, the debt market is competitive with many lenders competing against each other.

Suppose a firm has identified a new investment opportunity, but to make this 
Figure 3.6: Timeline of the conservatism-signalling game

\begin{tabular}{|c|c|c|c|}
\hline $\begin{array}{l}\text { Nature assigns } \\
\text { risk type }\{r, s\} \text { to } \\
\text { each firm, } \\
\text { observed by the } \\
\text { firm itself, not by } \\
\text { the lenders }\end{array}$ & $\begin{array}{l}\text { The firm choose } \\
\text { a level of } \\
\text { conservatism, c, } \\
\text { upon observing } \\
\text { its risk type }\end{array}$ & $\begin{array}{l}\text { Lenders, upon } \\
\text { observing the } \\
\text { choice of } \\
\text { conservatism, c, } \\
\text { decide a price to } \\
\text { pay for the bond, } \\
\text { P(c) }\end{array}$ & $\begin{array}{l}\text { The game } \\
\text { ends, payoffs } \\
\text { distributed to } \\
\text { the firm and } \\
\text { the lenders. }\end{array}$ \\
\hline
\end{tabular}

investment the firm requires total capital of $A$, where $A$ is the value of total assets to be purchased for the project. Since the firm has no initial assets or liabilities, $A$ will also be the total value of the firm once the investment project is undertaken by the firm. However, $A$ is more than the money that the equity-holder of the firm has, and therefore the firm must finance the capital short-fall by selling corporate bonds to the debt market. The bond that the firm wishes to sell has a fixed maturity value $B$, and must be repaid once the project is completed in a pre-specified time period. The lenders, on the other hand, have plenty of cash so that they can meet the potential financing needs from all firms.

There are two kinds of possible investment projects, and each carries a different level of risk: (1) a risky project, denoted by $R$; and (2) a safe project, denoted by $S$. The risky project is riskier than a safe project in the sense that the risky project's economic 'news' is a mean-preserving-spread of the economic 'news' of the safe project. Obviously, since this new investment project is all that the firms in the debt market have, if a firm takes on a risky project, it becomes a risky firm; and if a firm takes on a safe project, it becomes a safe firm.

The order of this signalling game is follows:

Nature moves first in this game by randomly assigning each firm with either a 
risky investment project $R$ with probability $\rho$, or a safe project $S$ with probability $1-\rho$. The prior distribution of these two types of projects (i.e. the value of $\rho$ ) is common knowledge to both the equity-holders and the lenders in the market. But the true risk level of each firm's investment project can be observed by that firm itself (which include its equity-holder), but not by any of the lenders. Furthermore, the lenders have no other ways of independently knowing the true risk level of any firm in the market except to the extent of the signalling mechanism to be described in this chapter.

Given this information structure, this game is a typical game of asymmetric information. This information structure is also consistent with the economic literature on the information asymmetry in the debt market, such as the model by Stiglitz and Weiss (1981). I sometimes uses the terminology from the game theory, which calls the risk levels ( $r$, and $s$ ) as the type of a firm. Thus, the risky firms may be called the $r$-type, and similarly, the safe ones may be called the $s$-type.

The value of the bond, $D_{\text {type }}(c)$, depends on the risk-type of the firm, as well as the level of the firm's accounting conservatism. Using an option-pricing model, Merton (1974) shows that if a firm's asset volatility is higher, then the value of the firm's debts will be lower, ceteris paribus. At the same time, the value of the firm's equity will be higher. Given such a relationship, risky firms have an incentive to deceive the lenders by telling them that they are safe firms, in the hope of selling their high-risk bonds at a price that is higher than true values. If this lie works, the risky the firm (rather its equity-holder) would have earned an abnormal economic profit by selling its bond at a higher price, in addition to its normal expected returns. But the lenders, on the other hand, would have suffered an abnormal economic loss because they have over-paid for purchase of the bond.

However, rational lenders would not allow such a deceptive scheme to work, 
because they can anticipate the potential lies from risky firms. Since they anticipate the lies, they would not pay such a high price for the bond that is likely to be risky rather than safe. In the most basic case where the lenders cannot distinguish between the risky firms and the safe ones, the lenders will simply pay the average value of the the risky and safe bonds. As there are many competitive lenders in the market, the lenders will actually offer a price that is exactly equal to the expected value of all bonds for sale in the market, $\rho D_{r}(c)+(1-\rho) D_{s}(c)$, conditional on the degree of conservatism $c$. In this very basic case, the lenders will, on average, make neither abnormal gains nor abnormal losses. But the risky firms will make an abnormal gain, while the safe firms will make an abnormal loss. There is, thus, a wealth transfer from the safe firms to the risky ones.

In the second move of this game, after nature assigns the risk types to each firm, each firm will choose its own level of accounting conservatism, $c$, and then will communicate their chosen $c$ to all the lenders in the debt market. Once a firm is committed to a particular level of conservatism, they cannot change it afterwards. High $c$ means a high degree of accounting conservatism. Since $c$ is a trustworthy piece of information sent by the firms to the lenders, $c$ may act as an information signal in the debt market. I denote the zero conservatism level by $c_{0}$, where $c_{0}=0$. In the separating equilibrium analysis later in the chapter, $c_{s}$ denotes the degree of conservatism that a safe-type firm would choose, and $c_{r}$ denotes the degree of conservatism that a risky-type firm would choose.

In the third move of the game, the lenders, upon observing $c$, decides how much to pay for the bond of that particular firm, which is denoted by $P(c)$. The lenders decision about $P(c)$ incorporates the information conveyed by the level of conservatism, $c$, which updates the lenders beliefs about whether a firm is of the $r$-type or the $s$-type. If they believe that the firm is of the $s$-type, then they will be will- 
ing to pay a higher price. But if the lenders believe that the firm is of the $r$-type, then they will only pay a lower price to compensate for the extra risk involved. Again, competitions among the lenders force them to pay exactly the true value of the bond, whether it is risky or safe.

At the end of the game, payoffs are distributed to both parties. This pay-off determination happens as soon as the bonds are sold. The (net) payoff to a lender, denoted by $v_{\text {type }}(c)$, is the value of the bond less the price paid for the bond, contingent on the risk type and the degree of conservatism. This is formally stated as below:

$$
\text { Payoff to lenders: } \begin{cases}v_{s}(c)= & D_{s}(c)-P(c) \\ v_{r}(c)= & D_{r}(c)-P(c)\end{cases}
$$

The (net) payoff to the firm, or more precisely to the equity-holder of the firm, is denoted by $u_{\text {type }}(c)$, and is calculated as the true value of the equity of the firm, $E_{\text {type }}(c)$, less the initial equity investment made by the equity-holder, $E_{0}(c)$. In essence, the net payoff to the firm is the value that the equity-holder gets minus the price paid. More formally, the payoffs to the firm (i.e. its equity-holder) can be written as:

$$
\text { Payoff to the equity-holder/firm: }\left\{\begin{array}{l}
u_{s}(c)=E_{s}(c)-E_{0}(c) \\
u_{r}(c)=E_{r}(c)-E_{0}(c)
\end{array}\right.
$$

The amount of equity investment made by the firm, $E_{0}(c)$, is the difference between the total project value $A$ and the price the bond is sold for $P(c)$. Hence,

$$
E_{0}=A-P(c)
$$


Equation 3.7 summarises the relationship that: if the bond can be sold at a higher price, then the equity-holder can make less equity investment; conversely if the bond can only be sold at a lower price, the equity-holder have to make more equity investment in the firm. Substituting equation 3.7 into Equation 3.6, we get an alternative, but equivalent expression for the firm's payoffs:

Payoff to the equity-holder/firm: $\left\{\begin{array}{l}u_{s}(c)=P(c)-D_{s}(c)=-v_{s}(c) \\ u_{r}(c)=P(c)-D_{r}(c)=-v_{r}(c)\end{array}\right.$

Equation 3.8 shows that the payoff to the firm is the negative of the payoff to the lenders. Therefore, the game is a zero-sum game. It is easy to see why the payoffs add to zero: when the total value of the firm, $A$, is a constant, any abnormal gain (loss) by the lender must result in a corresponding loss (gain) by the equity-holder. The value of debts and the value of equity must add up to $A$.

The payoffs to debt-holders and equity-holders are net abnormal returns rather than gross returns. If there were no information asymmetry in the game, each party in the game would make zero abnormal profit or loss, and therefore all payoffs would be zero. However, when there is information asymmetry in the game, as is assumed in this chapter, the payoffs may not be zero. Furthermore, this signalling game does not impose any restrictions on the risk aversion on both of the lenders and equity-holders. Nevertheless, it does assume that the both types of players can perfectly hedge their income, which means that both types of players are presentvalue-maximizers. 


\subsection{Signalling equilibria}

Now I discuss the characteristics of the equilibria of this signalling game. signalling games can, and often do, have multiple equilibria - some of which are separating, while others are pooling (Fudenberg and Tirole, 1991). Without the help of any signalling or screening mechanisms, the debt market cannot resolve the information asymmetry problem. One possible outcome would be a pooling equilibrium, where the lenders pay the average price to buy every bond, without being able to distinguish between high risk and low risk borrowers. Another possibility would be that the debt market turns into credit rationing Stiglitz and Weiss (1981). In the worst case, the debt market would turn into a market for 'lemons', or junk bonds, where low risk borrowers would exit the debt market leaving the market with only high risk borrowers. Obviously, such a catastrophe does not generally occur in the real debt market, which shows that there must be some sort of signalling or screening mechanisms in place to reduce the information asymmetry in the debt market. In the rest of Chapter 3, I will show that accounting conservatism could be one such signalling mechanism.

\subsubsection{Separating equilibrium}

A separating equilibrium describes a condition where the signals can accurately reveal one player's private information to the other players. In the current signalling game, a separating equilibrium is one in which the risky firm and the safe firm each chooses a different degree of accounting conservatism, and by observing the degrees of conservatism, the lenders can correctly infer the true risky type of the borrower firms.

To derive the separating equilibrium, I first denote the degree of conservatism 
that all risky firms will choose as $c_{r}$, and the degree of conservatism that all safe firms will choose as $c_{s}$. In order for the separating equilibrium to hold, it is necessary that neither types of firms have any incentive to deviate from their equilibrium levels of conservatism. A firm should always be worse off by imitating the choice of conservatism by the other type of firms. In other words, all risky firms are worse off by choosing $c_{s}$, and conversely all safe firms are worse off by choosing $c_{r}$. This is the main separating condition for this signalling game, which is formally stated below:

$$
\left\{\begin{array}{l}
u_{s}\left(c_{r}\right)<u_{s}\left(c_{s}\right) \\
u_{r}\left(c_{s}\right)>u_{r}\left(c_{r}\right)
\end{array}\right.
$$

Furthermore, competitions between lenders will drive the purchase prices of each bond to the exact present value of the bond. This means that the lenders make neither abnormal profits nor abnormal losses in the bonds, ex ante. ${ }^{9}$ Hence, the following conditions must be true at the separating equilibrium:

$$
\left\{\begin{array}{l}
v_{s}\left(c_{s}\right)=0 \\
v_{r}\left(c_{r}\right)=0
\end{array}\right.
$$

which implies that

$$
\left\{\begin{array}{l}
P\left(c_{s}\right)=D_{s}\left(c_{s}\right) \\
P\left(c_{r}\right)=D_{r}\left(c_{r}\right)
\end{array}\right.
$$

Since $v_{\text {type }}(c)=-u_{\text {type }}(c)$, Equation 3.10 also implies that

\footnotetext{
${ }^{9}$ Ex post, or realized, profit or loss from holding the bonds involves random events such as defaults. But the ex ante, or expected, profit or loss should be zero for the lenders.
} 


$$
\left\{\begin{array}{l}
u_{s}\left(c_{s}\right)=0 \\
u_{r}\left(c_{r}\right)=0
\end{array}\right.
$$

Thus, the main separating condition (3.9) becomes

$$
\left\{\begin{array}{l}
u_{s}\left(c_{r}\right)<0 \\
u_{r}\left(c_{s}\right)>0
\end{array}\right.
$$

By substituting the definition of the payoffs of equity-holders, $u_{\text {type }}(c)$, (Equation 3.8) and Equation 3.11 into Inequalities 3.13 above, we have:

$$
\text { Separating condition: }\left\{\begin{array}{l}
D_{r}\left(c_{r}\right)<D_{s}\left(c_{r}\right) \\
D_{r}\left(c_{s}\right)>D_{s}\left(c_{s}\right)
\end{array}\right.
$$

In addition, at the separating equilibrium, the lenders must hold a posterior belief that $\mathbb{P}\left(s \mid c \geq c_{s}\right)=1$ and $\mathbb{P}\left(r \mid c<c_{s}\right)=1$. In other words, if a firm chooses greater or equal to $c_{s}$ degree of conservatism then the lenders will regard that firm as a safe-type; conversely if a firm chooses a less than $c_{s}$ degree of conservatism, the lenders will think of that firm as a risky-type. Does such a separating equilibrium exist? If so, what value (or values) should $c_{s}$ take?

Proposition 3.5. There exists a continuum of Bayesian Nash Separating Equilibria, if the following Single-Crossing Property of Conservatism (i.e., Lemma 3.4) holds:

$$
\frac{\partial D_{r}(c)}{\partial c}>\frac{\partial D_{s}(c)}{\partial c}>0, \forall c
$$

and the $D_{r}(c)$ and $D_{s}(c)$ curves cross each other at $c^{*}$.

If the above condition is satisfied, then $c_{s}>c^{*}$. 
Figure 3.7: Separating Equilibrium

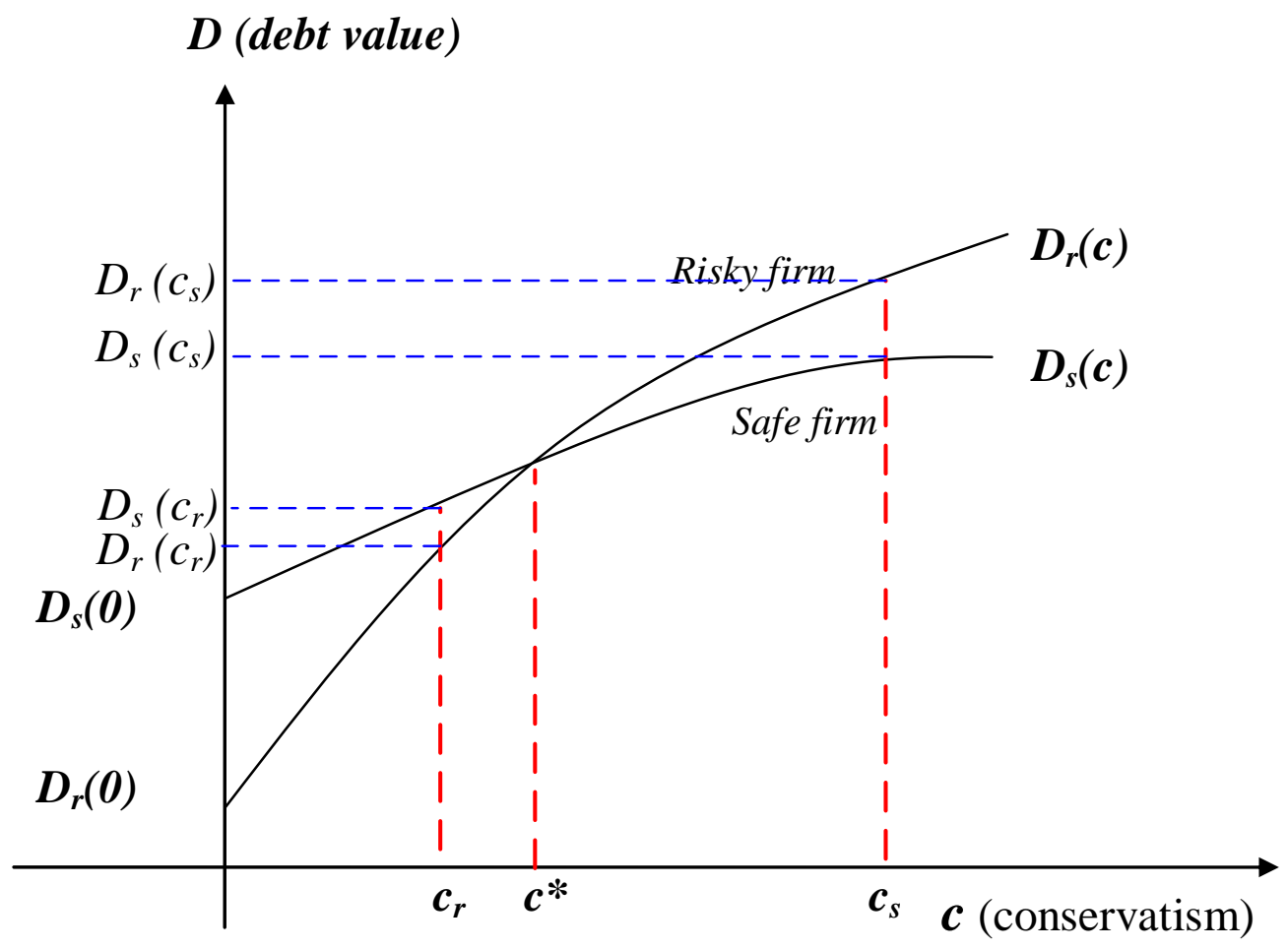


Proof. First, $c^{*}$ is the value of $c$ such that $D_{r}\left(c^{*}\right)=D_{s}\left(c^{*}\right)$, and also let $D^{*} \equiv$ $D_{r}\left(c^{*}\right)=D_{s}\left(c^{*}\right)$. Now, express the values of debt as integrals:

$$
D_{r}\left(c_{s}\right)=D^{*}+\int_{c^{*}}^{c_{s}} \frac{\partial D_{r}(c)}{\partial c} d c
$$

and,

$$
D_{s}\left(c_{s}\right)=D^{*}+\int_{c^{*}}^{c_{s}} \frac{\partial D_{s}(c)}{\partial c} d c
$$

Since,

$$
\frac{\partial D_{r}(c)}{\partial c}>\frac{\partial D_{s}(c)}{\partial c}, \forall c
$$

we have,

$$
\int_{c^{*}}^{c_{s}} \frac{\partial D_{r}(c)}{\partial c} d c>\int_{c^{*}}^{c_{s}} \frac{\partial D_{s}(c)}{\partial c} d c, \forall c_{s}>c^{*}
$$

Therefore,

$$
D^{*}+\int_{c^{*}}^{c_{s}} \frac{\partial D_{r}(c)}{\partial c}>D^{*}+\int_{c^{*}}^{c_{s}} \frac{\partial D_{s}(c)}{\partial c}, \forall c_{s}>c^{*}
$$

which proves the second half of the separating condition (3.14) that,

$$
D_{r}\left(c_{s}\right)>D_{s}\left(c_{s}\right), \forall c_{s}>c^{*}
$$

Similarly, we can also prove the first half of the separating condition 3.14. (Details omitted)

It is helpful to visualize the proof by examining Figure 3.7, which draws the 
value of debt as a function of the the degree of conservatism $c$. Figure 3.7 is simply a graphical presentation of Lemmas 3.3 and 3.4. Because there are two levels of risk - Risky (R) and Safe (S), there are also two curves on the graphs corresponding to each level of risk: the $D_{r}(c)$ curve for the risky firm's debts, and the $D_{s}(c)$ curve for the debts of the safe firm. These two curves cross with each other when $c=c^{*}$.

From Figure 3.7, one can easily observe that if $c_{r}$, the degree of conservatism chosen by risky firms, is less than $c^{*}$, then the first half of the main separating condition ((3.14)) is satisfied, because the $D_{r}(c)$ curve is below the $D_{s}(c)$ curve in this part of the graph. Similarly, if $c_{s}$, the degree of conservatism chosen by safe firms, is greater than $c^{*}$, then the second half of the main separating condition is also satisfied, because the $D_{r}(c)$ curve is now above the $D_{s}(c)$ curve in this part of the graph.

The above analysis shows that at the separating equilibrium, the level of conservatism that the Safe firm can adopt, $c_{s}$, must be greater than $c^{*}$. As a result, there is an entire continuum of Nash Separating Equilibria, as long as $c_{s}>c^{*}$ and $c_{r}<c^{*}$. There is also a Dominant Separating Equilibrium within infinitely many equilibria. And that is $c_{r}=0$ and $c_{s}=c^{*}$ (or more precisely $c_{s}$ approaches $c^{*}$ ). The reason is that 0 and $c^{*}$ are the lowest possible values for each type of firms to choose. Choosing anything higher will only decrease the value of equity in that firm, because higher conservatism will give the debt-holders more protections. ${ }^{10}$

\footnotetext{
${ }^{10}$ Although not the focus of this chapter, a higher degree of conservatism will also likely cause more distortions to the information contents of the firm's financial statements, which may create higher information costs to the equity-holders of the firm. That is a further reason for the firm not to adopt a higher than necessary degree of accounting conservatism.
} 


\subsubsection{Pooling equilibrium \& the "intuitive criterion"}

The conservatism-signalling game also has a pooling equilibrium. In the pooling equilibrium, both the Safe and Risky firms choose the zero level of conservatism, i.e. $c_{\text {pool }}=0$. (Let $c_{\text {pool }}$ denote the level of conservatism in the pooling equilibrium.) In the pooling equilibrium, the lenders hold the posterior belief that: $P(r \mid c=0)=\rho$ and $P(s \mid c=0)=1-\rho$. In other words, the lenders believe both types of firms will select zero degree of conservatism and will not deviate from that plan. Because lenders in the pooling equilibrium are unable to distinguish between high risk and low risk firms, they will simply pay the average price in the pooling situation, i.e. $P_{\text {pool }}=\rho D_{r}(c=0)+(1-\rho) D_{s}(c=0)$, for every bond regardless of its true risk level.

So far the analysis of the conservatism signalling game has produced two possible solution: (1) the separating equilibrium, and (2) the pooling equilibrium. But which equilibrium will the players will choose?

In fact, multiple equilibria are typical of signalling games. To counter that problem, game-theorists have developed a number of equilibrium refinements to limit the number of admissible equilibria in signalling games. The "intuitive criterion" proposed by Cho and Kreps (1987) is a particularly popular refinement of the Nash Equilibrium concept. The intuitive criterion helps researchers to eliminate most of the unstable equilibria from signalling games and keep only the more stable ones. I apply this refinement in this chapter. As a result, the pooling equilibrium is eliminated from the signalling game by the intuitive criterion, because it is not sufficiently stable. That leaves us with the separating equilibrium as the only stable solution to the game.

The intuitive criterion works like this: it rules out the pooling equilibrium in the 
current game, if the risky firms are always worse off by deviating from the pooling equilibrium $c_{p}=0$ (and choosing $c_{r} \geq c^{*}$ instead), regardless of the actual belief held by the lenders. Suppose that this condition is satisfied (which I will prove, later in this chapter, is indeed satisfied), then the rationale is that since the risky firms will never defect from the pooling equilibrium, then the lenders will put a zero posterior probability on the $R$-type choosing $c_{r} \geq c^{*}$, i.e. $P\left(R \mid c \geq c^{*}\right)=0$. In other words, the lender will place zero probability on this particular off-the-path action. On the other hand, the $S$-type firms may find defecting off to $c_{s} \geq c^{*}$ potentially beneficial to them. Therefore, the $S$-type firms can exploit the fact that the $R$-type will never go to $c^{*}$ or higher by adopting precisely $c_{s}=c^{*}$, which signals to the lenders that whoever adopts $c^{*}$ or higher must only be the safe firms. In other words, the lenders will have the posterior that $P\left(S \mid c \geq c^{*}\right)=1$. On this basis, the lenders will be willing to pay a higher price to buy the bond from the firms deviating from the pooling equilibrium and adopt $c \geq c^{*}$. To continue this logic, the safe firms in turn will have rationally anticipated that the lenders will have the posterior belief that:

$$
\left\{\begin{array}{l}
P\left(R \mid c \geq c^{*}\right)=0 \\
P\left(S \mid c \geq c^{*}\right)=1
\end{array}\right.
$$

Having anticipated such posteriors, the safe firms will all move to $c^{*}$ or higher, in order to get sell their bond at higher prices and reduce their abnormal loss to zero. In the next round of anticipation, the lenders, foreseeing that the safe firms have all gone to $c^{*}$ or higher, they will decrease the price paid at the pooling equilibrium $\left(P_{\text {pool }}\right)$ from the average price of both types to the price of the risky bonds only. The consequence of that is that the players quickly move from the pooling equilibrium 
to the separating equilibrium, which shows the pooling equilibrium may not be a stable solution to this particular signalling game.

But is the intuitive criterion actually satisfied in this game? The answer is yes. I formally state the result first, and then prove it.

Proposition 3.6. The pooling equilibrium, where both risky and safe types of firms choose the zero level of accounting conservatism, fails the Intuitive Criterion, if the following Single-Crossing Condition of Conservatism (i.e. Lemma 3.4) holds:

$$
\frac{\partial E_{r}(c)}{\partial c}<\frac{\partial E_{S}(c)}{\partial c}<0, \forall c
$$

To prove this proposition, we must to show that no matter what the lenders believe, moving to $c^{*}$ or higher always makes the risky firms worse off.

First, if the lenders believe any firm choosing $c \geq c^{*}$ is a risky firm, then

$$
u_{r}\left(c \geq c^{*} \mid R\right)=P(c \mid R)-D_{r}(c)=D_{r}(c)-D_{r}(c)=0
$$

Note:

$$
\begin{aligned}
u_{r}\left(c_{\text {pool }}\right) & =P_{\text {pool }}-D_{r}(0) \\
& =\rho D_{r}(0)+(1-\rho) D_{s}(0)-D_{r}(0) \\
& =(1-\rho)\left[D_{s}(0)-D_{r}(0)\right] \\
& >0
\end{aligned}
$$

Hence,

$$
u_{r}\left(c \geq c^{*} \mid R\right)<u_{r}\left(c_{\text {pool }}\right)
$$


Second, if the lenders believe any firm choosing $c \geq c^{*}$ is a safe firm, then

$$
u_{r}\left(c \geq c^{*} \mid S\right)=P(c \mid S)-D_{r}(c)=D_{S}(c)-D_{r}(c)<0
$$

Therefore,

$$
u_{r}\left(c \geq c^{*} \mid S\right)<u_{r}\left(c_{\text {pool }}\right)
$$

The inequalities 3.15 and 3.16 together imply that risky firms are always worse off by defecting from the pooling equilibrium. This completes the proof of Proposition 3.6.

\subsection{Implications}

The signalling theory of accounting conservatism developed in this chapter has the following implications for the accounting literature and accounting standards setters.

First, the signalling theory of accounting conservatism shows that conservatism may help addresses the problem of information asymmetry in the credit market. This theory shows that accounting conservatism is a signalling mechanism which can reduce, or eliminate, the information asymmetry about the borrower firm's riskiness. The model shows that high risk firms tend to adopt a lower degree of conservatism, while low risk firms tend to adopt a higher degree of conservatism. Since the lenders can learn about the true risk levels in the borrower firms through observing the borrower firms' levels of conservatism, credit market rationing problem could be resolved. This underlines the information content contained in a firm's degree of accounting conservatism. 
Second, the signalling theory of conservatism suggests that a higher degree of accounting conservatism is not always good, or 'efficient', if I use the word of Zhang (2008). In contrast, the prior literature tends to hold the view that the higher the degree of accounting conservatism, the more efficient the debt contract is. Such a view is evident in Zhang (2008), who interpret 'efficiency' as both the ex ante saving of interest to the borrower firms and the ex post reduction of managerial opportunism. While this notion of efficiency is intuitive, it may lead to undesirable or even illogical conclusions. If a higher degree of conservatism were always more desirable, then firms in the real world would have all adopted extreme conservatism, which is not supported by the existing empirical evidence. The fact that the existing empirical evidence shows that there is a systematic cross-sectional variation in the degree of conservatism across firms indicates that there must be some costs to adopting higher degrees of accounting conservatism.

In this regard, the signalling model of conservatism explicitly recognizes that one of the costs of accounting conservatism is the decrease in the value of equity, which is the consequence of increasing the value of the debt. Given such cost, firms trade off the benefits and the costs of conservatism and adopt a degree of conservatism that is optimal for themselves. That results in an equilibrium degree of accounting conservatism for each firm. The contribution of this model is that it shows that the equilibrium degree of conservatism may depend on the level of operating risk in the firm.

Third, the results of this chapter differ from the results obtained by Gigler et al. (2009), whose analytical study concludes that accounting conservatism is not ex post efficient, in the sense that conservatism triggers too many 'false alarms', i.e. early violations of debt-covenants. Gigler et al's results indicate that accounting conservatism is not beneficial to debt-contracts, in contrast to the most of the em- 
pirical literature in this area. In contrast, my model concludes that accounting conservatism may indeed be beneficial to debt-contracts, although my model does not argue that conservatism is always beneficial. Whether a higher degree of conservatism benefits a firm depends very much on the firm's level of operating risk

The differences between my conclusions and those of Gigler et al. (2009) are mainly due to the different ways in which each model is constructed. First, Gigler et al's theory is based on a moral hazard model, whereas my theory is based on an adverse-selection/signalling model. Second, Gigler et al.(2009) treat the degree of accounting conservatism as an exogenous variable, whereas I treat it as an endogenous variable. Third, to a lesser extent, the concept of conservatism receives somewhat different statistical characterizations in these two approaches, which partly contributes to the differences in the results obtained. I believe that the statistical characterization of conservatism in this chapter is more intuitive and more consistent with Basu's (1997) operational definition of accounting conservatism.

Fourth, the signalling theory of conservatism proposed in this chapter identifies a potential area for future empirical research. The existing empirical literature on accounting conservatism primarily tends to emphasise the positive effect of conservatism on the value of debt, but ignores the corresponding negative effect on the value of equity. Furthermore, the existing empirical work has predominantly focused on the economic demand for conservatism in a moral hazard framework (for example, Ahmed et al., 2002; Zhang, 2008). According to the best of my knowledge, no studies have yet directly examined the role of accounting conservatism in a signalling framework. It would thus be particularly interesting to empirically test whether firms with low operating risk tend to choose higher degrees of conservatism, and firms with high operating risk tend to choose lower degrees of conservatism. 
Fifth, the signalling theory developed here has a direct implication for accounting standard setters around the world. The signalling theory contends that accounting standards should not be over-restrictive in terms of the degrees of accounting conservatism that firms can adopt. Instead, firms should have some freedom in choosing their own degree of accounting conservatism, within a certain range, of course. If accounting standards forced all firms to adopt the same uniform degree of conservatism regardless of their levels of risk, the signalling power of conservatism, and hence its potential contribution to value, could be lost.

\subsection{Conclusions}

In this chapter, I have proposed a new theory to explain the existence of, and the demand for, accounting conservatism, which is based on a signalling model of conservatism in the debt market. This theory shows that the economic demand for accounting conservatism may not only driven by litigation costs and moral hazard issues, but also driven by the issue of information asymmetry in the debt market. The equilibrium of this chapter's signalling game demonstrates that accounting conservatism, acting as a signalling device, can reduce the information asymmetry between lenders and borrowers. The main findings of this chapter can be divided in two categories, as below.

First, I established four basic properties of accounting conservatism, as stated in the four lemmas. The analytical proofs of these four properties are based on Basu's (1997) definition of conservatism as the asymmetric timeliness of earnings, and re-

quire very few additional assumptions. The definition of risk is based on Rothschild and Stiglitz's (1970) mean-preserving-spread. The four lemmas together examine the joint impact of accounting conservatism and a firm's operating risk on the firm's 
earnings, and the values of debts and equity. These lemmas therefore establish a bridge connecting accounting conservatism on one side and the operating risk on the other.

Second, I investigated the signalling role of accounting conservatism in the debt market. In this chapter, there are two levels of risk: Risky and Safe. The firm itself and its equity-holders know its own level of operating risk, but the lenders in the credit market do not have that information. In the long-run, this information asymmetry problem may lead to adverse-selection in the credit-market, and possibly a credit-rationing problem (Stiglitz and Weiss, 1981). The model shows that accounting conservatism can help resolve this problem, by serving as an information signal about the firm's true level of risk. In particular, this chapter proves that if the Single-Crossing Property of conservatism holds, then there exists a continuum of separating signalling equilibria. In the separating equilibrium, the risky firms choose a low level of conservatism (usually the zero level), while the safe firms choose a high level of conservatism.

In addition, using Cho and Kreps's intuitive criterion, I further ruled out the pooling equilibrium from this signalling game, because the pooling equilibrium is unstable. This implies that the separating equilibrium is the only stable solution to the signalling game.

The proposed theory has a range of potential implications for both accounting researchers and accounting standard setters. In Appendix B to this chapter, I provide a preliminary empirical test of the signalling theory. The results are supportive, but opportunities for more rigorous tests remain for future research. 


\subsection{Appendix A - proofs}

\section{Technical note on the Modified Basu Earnings Function: $M B(I)$}

Recall that the Original Basu Earnings Function, $B(I)$, has a discontinuity at $I=0$. Here, I design a Modified Basu Earnings Function, $M B(I)$, which can preserve the features of the Original Basu Earnings Function as much as possible, but without the discontinuity at $I=0$. To do this, I just need to replace a part of the original Basu function, in an arbitrarily small range around $I=0$, say between $I \in(-k, k)$, $k>0$, such that the new function is continuous everywhere. (See Figure 3.2)

Although there are many choices for the new function between $I \in(-k, k), \mathrm{I}$ confine my attention to a quadratic function. The reason is that every quadratic function has a constant second derivative, which comes conveniently as an alternative (and equivalent, as it turns out) measure of asymmetric timeliness to the standard $c=\beta_{2}-\beta_{1}$. The new function, $f(I)$, must join with the two existing straight-lines at the two end-points: $-k$ and $k$, which means that $f(-k)=-k \beta_{2}$, and $f(k)=k \beta_{1}$. In addition, the joints at these two end-points must be smooth, i.e., $f^{\prime}(-k)=\beta_{2}$, and $f^{\prime}(k)=\beta_{1}$. The derivation is relatively straight-forward, and I leave it for the reader to verify that the following solution satisfies the above requirements:

$$
f(I)=\frac{\beta_{1}-\beta_{2}}{4 k} I^{2}+\frac{\beta_{1}+\beta_{2}}{2} I+\frac{\left(\beta_{1}-\beta_{2}\right) k}{4}
$$

Three interesting points deserve mentioning: (1) since $\beta_{1}<\beta_{2}$ due to asymmetric timeliness, $f^{\prime \prime}(I)$ is a negative quantity $-f^{\prime \prime}(I)=\frac{1}{2 k}\left(\beta_{1}-\beta_{2}\right)<0$, which shows that the function is concave; (2) $f^{\prime \prime}(I)$ is (negatively) proportional to the standard measure of asymmetric timeliness, $c=\beta_{2}-\beta_{1}$. Hence, the higher the $c$, the lower the $f^{\prime \prime}(I)$. In fact, as long as I choose the same $k$ every time, $f^{\prime \prime}(I)$ as a measure of 
conservatism is equivalent to $c$. (3) The quadratic function, $f(I)$, always exists for any values of $\beta_{1}$ and $\beta_{2}$, which guarantees that I can always find the modified Basu function, $M B(I)$.

Finally, please note that within the range $I \in[-k, k]$, the second derivative of $M B(I)$ is the same as the second derivative of $f(I)$; but outside this range, the second derivative of $M B(I)$ is zero because of the linearity. In other words,

$$
\begin{cases}M B^{\prime \prime}(I)=f^{\prime \prime}(I)=\frac{1}{2 k}\left(\beta_{1}-\beta_{2}\right) & \text { if } I \in[-k, k] \\ M B^{\prime \prime}(I)=0 & \text { if } I \notin[-k, k]\end{cases}
$$

\section{Proof of Lemma 3.1:}

By Rothschild-Stiglitz Theorem (1970), the following two statements are equivalent:

(a) $\mathbb{E}\left[M B\left(\tilde{I}_{s}\right)\right] \geq \mathbb{E}\left[M B\left(\tilde{I}_{r}\right)\right]$, provided that $M B(\tilde{I})$ is a concave and everywhere twice-differentiable function of the news-signal, $I$;

(b) $\tilde{I}_{r}$ is a mean-preserving-spread of $\tilde{I}_{S}$.

Because statement (b) is true, statement (a) must also be true, since $M B(\tilde{I})$ is a concave function of $I$ per Basu's definition of accounting conservatism. Since $x_{r}=\mathbb{E}\left[M B\left(\tilde{I}_{r}\right)\right]$ and $x_{s}=\mathbb{E}\left[M B\left(\tilde{I}_{s}\right)\right]$ by definition, statement (a) implies $x_{s} \geq x_{r}$.

\section{Proof of Lemma 3.2:}

Lemma 3.2 states that certain certain conditions, the earnings of the riskier firm have more marginal decrease by increasing the degree of conservatism, than do the earnings of the safe firm.

Based on the approach taken in Rothschild and Stiglitz (1970), integrating by parts twice yields 


$$
\mathbb{E}[M B(\tilde{I})]=M B(0)+M B^{\prime}(\infty) \bar{I}-\int_{0}^{\infty} M B^{\prime \prime}(I) F^{2}(I) d I
$$

where

$$
F^{2}(I)=\int_{0}^{I}(1-F(\mu) d \mu,
$$

$\bar{I}$ is the expected value of $\tilde{I}$, and $F($.$) is the cumulative density function of 'news',$ I. Then, it follows that

$$
x_{s}-x_{r}=\mathbb{E}\left[M B\left(\tilde{I}_{s}\right)\right]-\mathbb{E}\left[M B\left(\tilde{I}_{r}\right)\right]=\int_{0}^{\infty} M B^{\prime \prime}(I)\left[F_{r}^{2}(I)-F_{s}^{2}(I)\right] d I
$$

And Rothschild and Stiglitz shows that the condition that $I_{r}$ is a MPS of $I_{s}$ implies that $F_{r}^{2}(I)-F_{s}^{2}(I) \leq 0$. Therefore,

$$
\begin{aligned}
\frac{\partial x_{s}}{\partial M B^{\prime \prime}\left(I_{s}\right)}-\frac{\partial x_{r}}{\partial M B^{\prime \prime}\left(I_{r}\right)} & =\frac{\partial}{\partial M B^{\prime \prime}(I)} \int_{0}^{\infty} M B^{\prime \prime}(I)\left[F_{r}^{2}(I)-F_{s}^{2}(I)\right] d I(3.17) \\
& =\int_{0}^{\infty}\left[F_{r}^{2}(I)-F_{s}^{2}(I)\right] d I \leq 0
\end{aligned}
$$

Thus,

$$
\frac{\partial x_{s}}{\partial M B^{\prime \prime}(I)} \leq \frac{\partial x_{r}}{\partial M B^{\prime \prime}(I)}
$$

which shows that as the degree of asymmetric timeliness $M B^{\prime \prime}$ increases, the risky firm's earnings decrease faster than the safe firm's earnings. Because the previous technical note explained that that $M B^{\prime \prime}(I)$ is negatively proportional to $c$, Inequality 3.18 means that:

$$
\frac{\partial x_{r}}{\partial c} \leq \frac{\partial x_{s}}{\partial c}
$$


Furthermore, using Pratt's (1964) famous Risk Aversion Theorem, it is straightforward to prove that the two derivatives above are less than zero, because increasing the degree of conservatism induces a higher curvature to the modified Basu earnings function, $M B(I)$, which is equivalent to a higher risk aversion in the expected utility theory (details available from the author). Therefore,

$$
\frac{\partial x_{r}}{\partial c} \leq \frac{\partial x_{s}}{\partial c}<0
$$

This completes the proof of Lemma 3.2.

\section{Proof of Lemma 3.4:}

From Lemma 3.3, we know

$$
\frac{\partial x_{r}(c)}{\partial c}<\frac{\partial x_{s}(c)}{\partial c}<0
$$

To derive the next inequality, we use two assumptions here: condition 2 of Lemma 3.4 requires $D$ being a linear or convex and decreasing function of $x$; (ii) given the level of conservatism is constant, the earnings of the risky firm are lower than the earnings of the safe firm, i.e., $x_{r}(c)<x_{s}(c)$. Combining these two relations, we have

$$
\frac{\partial D_{r}(c)}{\partial x_{r}(c)} \leq \frac{\partial D_{s}(c)}{\partial x_{s}(c)}<0
$$

Now multiplying 3.19 with 3.20 , we get:

$$
\frac{\partial D_{r}(c)}{\partial x_{r}} \frac{\partial x_{r}(c)}{\partial c}>\frac{\partial D_{s}(c)}{\partial x_{s}} \frac{\partial x_{s}(c)}{\partial c}>0
$$

Notice that these two terms are the results of the chain rule of calculus below: 


$$
\frac{\partial D_{r}(c)}{\partial c}=\frac{\partial D_{r}(c)}{\partial x_{r}} \frac{\partial x_{r}(c)}{\partial c} \text { and } \frac{\partial D_{s}(c)}{\partial c}=\frac{\partial D_{s}(c)}{\partial x_{s}} \frac{\partial x_{s}(c)}{\partial c}
$$

Combining the chain rule and Inequality 3.21 , it follows that

$$
\frac{\partial D_{r}(c)}{\partial c}>\frac{\partial D_{s}(c)}{\partial c}>0
$$




\subsection{Appendix B - an empirical test of the signalling theory}

In this Appendix, I report a very simple empirical test of the signalling theory of accounting conservatism. The purpose of this test is to provide initial evidence regarding on the risk-signalling theory as a potentially valid explanation of accounting conservatism. I first describe the overall empirical design of this test, as well as the data and proxies used. I then report the results of the test, followed by a brief conclusion.

\section{B.1 Test design, data and proxies}

The aim of this test is to examine whether the risk-signalling theory of accounting conservatism has validity in the real world. The theory predicts that firms of higher operating risk tend to adopt a lower degree of accounting conservatism, and conversely firms of lower operating risk tend to adopt a higher degree of accounting conservatism. Firms make such choices regarding their degrees of conservatism in order to signal to the lenders on their true risk levels. In Chapter 3, "operating risk" is defined as the volatility of the economic value of the total assets of the firm. Therefore, if the signalling theory of conservatism is descriptive of how real firms behave in the debt market, then we should be able to observe that firms' degree of accounting conservatism is negatively correlated with their asset volatility $(V O L)$.

This simple test employs the augmented regressions approach for testing the correlation between the degree of conservatism and the level of asset volatility. In particular, three cross-sectional measures of accounting conservatism are used: (1) Basu's (1997) AT measure, (2) Ball and Shivakumar's (2005) AACF measure, and 
(3) the Default-Adjusted-Basu measure proposed in Chapter 2 of this thesis. I select these measures of conservatism because all three measures are based on Basu's (1997) asymmetric timeliness of earnings definition of accounting conservatism, which is the definition of conservatism adopted in the signalling theory.

The augmented regression for these measures of conservatism are stated below:

(1) Basu (1997) AT regression augmented by asset volatility:

$$
\begin{aligned}
\frac{E P S_{i t}}{P_{i t}}= & \alpha_{0}+\alpha_{1} D R_{i t}+\beta_{0} R_{i t}+\beta_{1} R_{i t} D R_{i t}+ \\
& \beta_{2} V O L_{i t}+\beta_{3} R_{i t} V O L_{i t}+\beta_{4} R_{i t} D R_{i t} V O L_{i t}+\varepsilon_{i t}
\end{aligned}
$$

where:

- $E P S_{i t}$ : Earnings per share for firm i year $\mathrm{t}$

- $P_{i t}$ : Opening stock market price for firm i year $\mathrm{t}$

- $R_{i t}$ : Stock markets return for firm i year $\mathrm{t}$

- $D R_{i t}$ : Dummy variable that is equal to 1 if the stock market return for firm i in year $\mathrm{t}$ is negative, and equal to 0 if the stock market return for firm $\mathrm{i}$ in year $\mathrm{t}$ is non- negative.

- $V A_{i t}$ : Volatility of Assets for firm i year $\mathrm{t}$, estimated by the iterative method of Vassalou and Xing (2004)

(2) Ball and Shivakumar's (2005) AACF regression augmented by asset volatility:

$$
\begin{aligned}
A C C_{i t}= & \alpha_{0}+\alpha_{1} D_{C F O_{i t}+\beta_{0} C F O_{i t}+\beta_{1} D C F O_{i t} C F O_{i t}+} \\
& \beta_{2} V_{O L}+\beta_{3} C F O_{i t} V O L_{i t}+\beta_{4} D C F O_{i t} C F O_{i t} V O L_{i t}+\varepsilon_{i t}
\end{aligned}
$$


where

- $A C C_{i t}$ : Accruals measured as: $\Delta$ Inventory $+\Delta$ Debtors $+\Delta$ Other current assets - $\Delta$ Creditors - $\Delta$ Other current liabilities - Depreciation.

- $D C F O_{i t}$ : Dummy variable that is set to 0 if $C F O_{i t} \geq 0$, and is set to 1 if $C F O_{i t}<0$.

- $C F O_{i t}$ : Cash-flow for period t.

- $V A_{i t}$ : Volatility of Assets for firm i year $\mathrm{t}$, estimated by the iterative method of Vassalou and Xing (2004)

(3) The DAB measure is selected for testing the signalling theory, because in Chapter 2, I argued that it is less biased than the standard Basu (1997) measure in respect of the default risk. The DAB measure is augmented by asset volatility (VOL) as in the following regression:

$$
\begin{aligned}
\frac{N I B I_{i t}}{V_{i t-1}}= & \alpha_{0}+\alpha_{1} D T R_{i t}+\beta_{0} T R_{i t}+\beta_{1} D T R_{i t} T R_{i t}+ \\
& \beta_{2} V O L_{i t}+\beta_{3} T R_{i t} V O L_{i t}+\beta_{4} D T R_{i t} T R_{i t} V O L_{i t}+\varepsilon_{i t}
\end{aligned}
$$

where

- $N I B I_{i t}$ : Net Income before Interest Expense

- $V_{i t-1}$ : The total opening value of the firm, as defined earlier when introducing the Merton (1974) model. It is the sum of the market values of equity and debt of the firm.

- $T R_{i t}$ : The rate of return of the total value of the firm, $V$, calculated as: $T R_{i t}=$ $\left(V_{i t}-V_{i t-1}-C F F_{i t}\right) / V_{i t-1} . C F F_{i t}$ is the net cashflow from financing activities for firm $i$ in year $t$. 
- $D T R_{i t}$ : A dummy variable that is set to 1 , if $T R_{i t}<0$; and is set to 0 , if $T R_{i t} \geq 0$

The relationship between asset volatility $(V O L)$ and conservatism can be tested through the coefficient of the interaction term, $\beta_{4}$, between asset volatility and the respective asymmetric timeliness coefficients in the three regressions above (3.22, 3.23 and 3.24). The signalling theory predicts that all three $\beta_{4}$ 's in these regressions are negative.

However, asset volatility $(V O L)$ is not directly observable. So I estimate it using Vassalou and Xing's (2004) iterative method. This method has already been introduced and applied in Chapter 2 - section 2.4, and is therefore not repeated here.

This test uses the same data sample as that used in Chapter 2. The net sample consists of 12,531 firm-year observations after deleting all missing values and trimming $1 \%$ from the top and bottom of the key variables. The descriptive statistics and correlation tables for this sample have already been reported in Chapter 2 section 2.4 , and therefore are not repeated here.

\section{B.2 Empirical results}

Table 3.2 shows the results of fitting the augmented Basu and AACF regressions (3.22 and 3.23) to the sample data. Panel A of Table 3.2 reports the result of the augmented Basu regression (3.22). Panel A of Table 3.2 shows that the $\beta_{4}$ coefficient on interaction term, $D R * R * V A$, is -0.101 , and is statistically significant at $1 \%$ level. This negative interaction effect indicates that when a firm's asset volatility increases, its degree of conservatism decreases. This result is consistent with the theoretical prediction of the signalling model. 
The result of the augmented AACF regression is shown in Panel B of Table 3.2. The result is very similar to that of Panel A: The $\beta_{4}$ coefficient on the interaction term, $D C F O * C F O * V A$, is -0.189 , and is statistically significant at $1 \%$ level. Thus, when $V O L$ increases in a firm, i.e. when the firm's operating risk increases, its degree of conservatism tend to decreases, as predicted by the signalling theory. The other regression coefficients in Table 3.2 - Panel B are generally consistent with the prior literature (Ball and Shivakumar, 2005). The good news timeliness, which is proxied by the regression coefficient of $C F O$, is -0.149 and is significant at $1 \%$ level. The asymmetric timeliness coefficient $(D C F O * C F O)$ is 0.260 and also significant at $1 \%$ level.

Table 3.3 reports the results of the augmented DAB regression (Equation 3.24). The value of $\beta_{4}$, which is the coefficient on the interaction variable $T R * D T R * V O L$, is -0.118 , and significant at $1 \%$ level. This result is also consistent with the previous two regressions in that the degree of conservatism is decreasing in the volatility of assets.

To summarise this simple test of the signalling theory, the evidence obtained from this test is strongly consistently with the signalling theory of accounting conservatism. The higher the degree of risk in a firm, the lower the degree of conservatism is in that firm. Three measures of accounting conservatism - the AT measure, the AACF measure and the DAB measure - all yield similar results. This further increases the robustness of the results. However, the test reported here is currently the only empirical test examining the relationship between the degree of accounting conservatism and the volatility of assets. 
Table 3.2: Basu AT \& AACF regressions augmented by Asset Volatility (VOL)

Panel A: Basu AT measure and Asset Volatility (VOL)

\begin{tabular}{lccc}
\hline & Estimate & t value & p value \\
\hline (Intercept) & 0.073 & 18.14 & $<2.2 \mathrm{e}-16 * * *$ \\
$\boldsymbol{D} \boldsymbol{R}$ & -0.001 & -0.22 & 0.827 \\
$\boldsymbol{R}$ & 0.021 & 2.42 & $0.016 * *$ \\
$\boldsymbol{V O L}$ & -0.153 & -14.20 & $<2.2 \mathrm{e}-16 * * *$ \\
$\boldsymbol{D} \boldsymbol{R}^{*} \boldsymbol{R}$ & 0.155 & 7.92 & $0.000 * * *$ \\
$\boldsymbol{D} \boldsymbol{R}^{*} \boldsymbol{V O L}$ & -0.005 & -0.28 & 0.778 \\
$\boldsymbol{R}^{*} \boldsymbol{V O L}$ & -0.028 & -2.11 & $0.035 * *$ \\
$\boldsymbol{D R}^{*} \boldsymbol{R} * \boldsymbol{V O L}$ & -0.102 & -3.20 & $0.001 * * *$ \\
\hline Significh
\end{tabular}

Significance levels: $* 10 \%, * * 5 \%, * * * 1 \%$.

Residuals standard error: 0.1222 on 12523 degrees of freedom

Multiple R-Squared:0.202; Adjusted R-Squared:0.2015

F-statistics: 452.7534 on 7 and 12523 DF. P-value:0.

Panel B: AACF measure and Asset Volatility (VOL)

\begin{tabular}{|c|c|c|c|}
\hline & Estimate & t value & $\operatorname{Pr}(>|\mathbf{t}|)$ \\
\hline (Intercept) & 0.023 & 11.72 & $<2.2 \mathrm{e}-16 * * *$ \\
\hline DCFO & 0.031 & 6.75 & $0.000 * * *$ \\
\hline CFO & -0.149 & -9.18 & $<2.2 \mathrm{e}-16 * * *$ \\
\hline VOL & -0.011 & -2.19 & $0.029 * *$ \\
\hline$D C F O * C F O$ & 0.260 & 11.46 & $<2.2 \mathrm{e}-16 * * *$ \\
\hline$D C F O * V O L$ & -0.024 & -3.23 & $0.001 * * *$ \\
\hline$C F O * V O L$ & 0.100 & 2.62 & $0.009 * * *$ \\
\hline$D C F O * C F O * V O L$ & -0.189 & -4.57 & $0.000 * * *$ \\
\hline
\end{tabular}

Significance levels: *10\%, **5\%, ***1\%.

Residuals standard error: 0.0685 on 12523 degrees of freedom

Multiple R-Squared:0.0309; Adjusted R-Squared:0.0304

F-statistics: 57.0936 on 7 and 12523 DF. P-value:0.

Note: All t-statistics are White-adjusted. 
Table 3.3: Default-Adjusted-Basu measure and Asset Volatility (VOL)

\begin{tabular}{|c|c|c|c|}
\hline & Estimate & t value & $\operatorname{Pr}(>|\mathbf{t}|)$ \\
\hline (Intercept) & 0.057 & 38.97 & $<2 \mathrm{e}-16 * * *$ \\
\hline$T R$ & 0.000 & -0.02 & 0.988 \\
\hline DTR & -0.005 & -1.92 & $0.055 *$ \\
\hline VOL & -0.076 & -18.29 & $<2 \mathrm{e}-16 * * *$ \\
\hline$T R^{*} D T R$ & 0.140 & 15.69 & $<2 \mathrm{e}-16 * * *$ \\
\hline$T R^{*} V O L$ & 0.002 & 0.40 & 0.690 \\
\hline$D T R^{*} V O L$ & -0.003 & -0.39 & 0.693 \\
\hline$T R * D T R * V O L$ & -0.118 & -9.45 & $<2 \mathrm{e}-16 * * *$ \\
\hline
\end{tabular}

Significance levels: *10\%, $* * 5 \%, * * * 1 \%$.

Residual standard error: 0.05565 on 12523 degrees of freedom

Multiple R-squared: 0.2218; Adjusted R-squared: 0.2213

F-statistic: 509.8 on 7 and 12523 DF, p-value: < 2.2e-16 


\section{Conclusions and Implications for}

\section{Future Research}

In this thesis, I have studied accounting conservatism from three perspectives. In Chapter 1, the existing measures of accounting conservatism were surveyed from a construct validity perspective, and it was argued that the construct validity of the existing measures is not robust. In Chapter 2, the impact of default risk on the Basu (1997) measure of accounting conservatism was examined. Chapter 2 not only concluded that the Basu measure is potentially biased by the existence of default risk of a firm, it also proposed a Default-Adjusted-Basu (DAB) measure that is free from this bias. Chapter 2 proposed a signalling theory of accounting conservatism in the debt market characterized by asymmetric information. This signalling theory suggests that conservatism can be used by borrower firms to signal their risk levels to the lenders, and provides a new perspective for understanding the economic demand for accounting conservatism. Since a more detailed summary of these chapters has already been given at the General Introduction to this thesis, the concluding section will instead discuss some possible areas for future research.

The first area for future research is to more systematically study the construct validity of the existing and new measures of conservatism. In particular, the differences between the two major groups of measures need to be reconciled. In fact, 
the reconciliation task has already begun with Roychowdhury and Watts (2007). But Roychowdhury and Watts's study only focus on two measures of conservatism, AT and MTB, and there is still a lot more work to be done to reconcile the other measures of accounting conservatism.

The second area is to re-examine the existing empirical studies that apply the Basu (1997) measure of conservatism in light of the bias identified in this thesis. Because the default-risk induced bias was previously unrecognized in the literature, it is possible that some studies using the Basu measure have been affected by this bias. For example, many empirical studies have relied on the Basu AT measure to prove that leverage is a determinant of conservatism (e.g. Lara et al., 2009b). But given the bias analysed in Chapter 2, that conclusion is likely to be incorrect, because leverage should be highly positively correlated with the Basu measure of conservatism simply because leverage is highly correlated with the default risk of a firm. Thus, it would be useful to re-examine the existing empirical evidence and question whether leverage is really an economic determinant of the degree of accounting conservatism in firms. In this regard, the Default-Adjusted-Basu measure proposed in this thesis might be a useful aid to empirical researchers, because this measure is free from the default-risk bias.

The third area is to build more rigorous analytical models to study the role of conservatism in the debt-contracting process. The existing debt contracting theory of conservatism proposed by Watts (2003a), and widely accepted by empirical researchers, is intuitive but often fails to pass rigorous examination. For instance, Guay and Verrecchia (2006) have criticised the view held by Watts (2003a), Bushman and Piotroski (2006) and others that conservatism improves debt contracting efficiency by reducing the debt covenant slacks.

The work in Chapter 3 agrees with Guay and Verrecchia (2006) in principle. 
The first reason is that debt-holders can always price protect themselves, no matter what the degree of conservatism is in the borrower firm are. Hence, a more conservative firm can sell their bonds at a higher price, but that does not mean its debt contract is more efficient. Efficiency and bond price are two different things. Gigler et al. (2009) in fact argue that the debt-contracting efficiency is decreased by conservatism. The second reason is that it is hard to accept the argument that if a firm nearly defaults on its debts, its managers would voluntarily increase the firm's degree of conservatism, given that a higher degree of conservatism can erode the equity value of the firm. Is it not irrational for a shareholder to voluntarily decrease the value of their own shares? The existing debt-contracting theory of conservatism fails to provide a satisfactory answer to the above problem. Clearly, more rigorous analytical research, such as that by Gigler et al. (2009), is needed to fully understand the debt-contracting role of accounting conservatism.

A fourth area for future research is to examine the information content of accounting earnings under conservatism. While conservatism can reduce the information asymmetry in the debt market as shown in Chapter 3, it arguably also creates more information asymmetry in the equity market, because conservatism 'biases' accounting numbers. The loss of information content is often used as an argument against conservatism by accounting standard setters (e.g. IASB, 2006; FASB, 2006). However, this argument, to date, has not been substantiated by any empirical or analytical evidence. On the contrary, LaFond and Watts (2008) find some empirical evidence that accounting conservatism may actually lead to a lower information asymmetry in the equity-market, which implies that earnings under a conservative accounting system contain more useful information than do the earnings under a less conservative or neutral accounting system. Thus, it would be worthwhile for accounting researchers to further investigate the role of accounting conservatism in 
the equity-market, and in particular, the impact of conservatism on the quality of earnings for the purpose of equity-valuation.

A fifth area would be to examine the relative importance of public and private debt in determining a firm's choice of its reporting conservatism. The signalling model in Chapter 3 has explicitly assumed that all lenders in the market do not have any private information about the risk characteristics of the borrower firms. That assumption resembles more of the information characteristics of the public debt market, where the lenders do not personally know, and have never met with, the borrowers. However, private lenders, such as commercial banks, would normally have much closer relationships with the borrowers, which allows them to gain more private information about the borrowers. In that case, information asymmetry is not as great as that in the public debt market, which indicates that perhaps the signalling power of conservatism in the private market is not as strong as that in the public debt market. This is another interesting topic for empirical researchers to investigate.

A sixth area for future research is to empirically investigate the association between firms' operating risk and the degree of accounting conservatism. The signalling model outlined in Chapter 3 suggests that there may be a negative correlation between operating risk and accounting conservatism, but empirical testing of this model (such as the tests reported in Chapter 3) is still at an early stage. Thus, in future research, it would be very useful to conduct more detailed and more powerful empirical tests on the association between operating risk and accounting conservatism. 


\section{Bibliography}

Adcock, R. (2002). Measurement validity: A shared standard for qualitative and quantitative research. American Political Science Review 95(03), 529-546.

Ahmed, A. S., K. B. Bruce, R. M. Morton, and M. Stanford-Harris (2002). The role of accounting conservatism in mitigating bondholder-shareholder conflicts over dividendspolicy and in reducing debt costs. The Accounting Review 77(4), 867-890.

Ahmed, A. S. and S. Duellman (2007). Accounting conservatism and board of director characteristics: An empirical analysis. Journal of Accounting and Economics 43(2-3), 411-437.

Ahmed, A. S., R. M. Morton, and T. F. Schaefer (2000). Accounting conservatism and the valuation of accounting numbers: Evidence of the Feltham-Ohlson (1996) model. Journal of Accounting, Auditing \& Finance 15(3), 271.

Akerlof, G. A. (1970). The market for 'lemons': Quality uncertainty and the market mechanism. The Quarterly Journal of Economics 84(3), 488-500.

Altman, E. I. (1968). The prediction of corporate bankruptcy: A discriminant analysis. Journal of Finance 23(1), 193-194. 
Association., A. E. R., A. P. Association., N. C. on Measurement in Education., and A. P. Association. (1985). Washington, DC: American Psychological Association.

Bagnoli, M. and S. G. Watts (2005). Conservative accounting choices. Management Science 51(5), 786-801.

Ball, R., S. P. Kothari, and A. Robin (2000). The effect of international institutional factors on properties of accounting earnings. Journal of Accounting and Economics 29(1), 1-51.

Ball, R., A. Robin, and G. Sadka (2008). Is financial reporting shaped by equity markets or by debt markets? An international study of timelines and conservatism. Review of Accounting Studies 13(2-3).

Ball, R., A. Robin, and J. S. Wu (2003). Incentives versus standards: Properties of accounting income in four East Asian countries. Journal of Accounting and Economics 36(1-3), 235-270.

Ball, R. and L. Shivakumar (2005). Earnings quality in UK private firms: Comparative loss recognition timeliness. Journal of Accounting and Economics 39(1), $83-128$.

Ball, R. and L. Shivakumar (2006). The role of accruals in asymmetrically timely gain and loss recognition. Journal of Accounting Research 44, 207-242.

Barth, M. E., W. H. Beaver, and W. R. Landsman (2001). The relevance of the value relevance literature for financial accounting standard setting: Another view. Journal of Accounting and Economics 31(1-3), 77-104. 
Basu, S. (1997). The conservatism principle and the asymmetric timeliness of earnings. Journal of Accounting and Economics 24(1), 3-37.

Bauman, M. P. (1999). An empirical investigation of conservatism in book value measurement. Managerial Finance 25(12), 42.

Beatty, A. (2007). Discussion of "asymmetric timeliness of earnings, market-tobook and conservatism in financial reporting". Journal of Accounting and Economics 44(1-2), 32-35.

Beatty, A., J. Weber, and J. J. Yu (2008). Conservatism and debt. Journal of Accounting and Economics 45(2-3), 154-174.

Beaver, W., W. Landsman, and E. Owen (2008). Asymmetry in earnings timeliness and persisitence: A simultaneous equations approach. Working Paper, Stanford University.

Beaver, W. H. and S. G. Ryan (2000). Biases and lags in book value and their effects on the ability of the book-to-market ratio to predict book return on equity. Journal of Accounting Research 38(1), 127-148.

Beaver, W. H. and S. G. Ryan (2005). Conditional and unconditional conservatism: Concepts and modeling. Review of Accounting Studies 10(2-3), 269.

Beekes, W., F. P. Peter, and S. Young (2004). The link between earnings timeliness, earnings conservatism and board composition: Evidence from the UK. Corporate Governance: An International Review 12(1), 47-59.

Bester, H. (1985). The level of investment in credit markets with imperfect information. 
Black, F. and M. Scholes (1973). The pricing of options and corporate liabilities. Journal of Political Economy 81, 637-654.

Brown, W. D., H. He, and K. Teitel (2006). Conditional conservatism and the value relevance of accounting earnings: An international study. European Accounting Review 15(4), $605-626$.

Bushman, R. M. and J. D. Piotroski (2006). Financial reporting incentives for conservative accounting: The influence of legal and political institutions. Journal of Accounting and Economics 42(1-2), 107-148.

Bushman, R. M. and C. D. Williams (2009). Bank transparency, loan loss provisioning behavior, and risk-shifting. University of North Carolina Working Paper.

Callen, J. L., O.-H. Hope, and D. Segal (2009). The pricing of conservative accounting and the measurement of conservatism at the firm-year level. Review of Accounting Studies Forthcoming.

Campbell, D. T. and D. W. Fiske (1959). Convergent and discriminant validation by the multirait-multimethod matrix. Psychological Bulletin 56(2), 81-105.

Campbell, D. T. and E. S. Overman (1988). Methodology and epistemology for social science: selected papers. Chicago: University of Chicago Press.

Chatfield, M. (1996). The History of Accounting: An International Encyclopedia (1st ed.)., Chapter Conservatism, pp. 160-166. New York: Garland Science.

Chen, Q., T. Hemmer, and Y. Zhang (2007). On the relation between conservatism in accounting standards and incentives for earnings management. Journal of Accounting Research 0(0). 
Cheng, Q. (2005). What determines residual income? The Accounting Review 80(1), 85-101.

Cho, I.-K. and D. M. Kreps (1987). Signaling games and stable equilibria. Quarterly Journal of Economics 102(2), 179-221.

Choi, W. (2007). Bank relationships and the value relevance of the income statement: Evidence from income-statement conservatism. Journal of Business Finance \& Accounting 34(7-8), 1051-1072.

Choi, Y.-S., J. F. O’Hanlon, and P. F. Pope (2006). Conservative accounting and linear information valuation models. Contemporary Accounting Research 23(1), 73-101.

Cook, T. D. and D. T. Campbell (1979). Quasi-Experimentation: Design \& Analysis Issues for Field Settings. Boston: Houghton Mifflin Company.

Cotter, D. and J. Donnelly (2006). Research report no. 91: Conservative accounting, the book-to-market ratio and stock returns. Technical report, The Association of Chartered Certified Accountants.

Cronbach, L. J. and P. E. Meehl (1955). Construct validity in psychological tests. Psychological Bulletin 42(4), 281-302.

Crosbie, P. and J. Bohn (2003). Modeling Default Risk (KMV LLC). Moody's KMV.

Dhaliwal, D. S., K. J. Lee, and N. L. Fargher (1991). The association between unexpected earnings and abnormal security returns in the presence of financial leverage. Contemporary Accounting Research 8(1), 20-41.

Dietrich, J. R., K. A. Muller, and E. J. Riedl (2007). Asymmetric timeliness tests of accounting conservatism. Review of Accounting Studies 12(1), 95-142. 
Dimson, E., P. Marsh, and M. Staunton (2009). Credit Suisse Global Investment Returns Yearbook 2009. Credit Suisse Research Institute.

Fama, E. and K. French (1995). Size and book-to-market factors in earnings and returns. Journal of Finance 50(1), 131-155.

Fama, E. F. and K. R. French (1993). Common risk factors in the returns on stocks and bonds. Journal of Financial Economics 33(1), 3-56.

FASB (1980). Statement of Financial Accounting Concepts No. 2: Qualitative Charateristics of Accounting Information. Norwalk, Connecticut: Financial Accounting Standards Board.

FASB (2006). PRELIMINARY VIEWS: Conceptual Framework for Financial Reporting: Objective of Financial Reporting and Qualitative Characteristics of Decision-Useful Financial Reporting Information. Financial Accounting Standards Board.

FASB (2009). Acccounting Standards Codifcation 230-10-45: Statement of Cash Flows.

Feltham, G. A. and J. A. Ohlson (1995). Valuation and clean surplus accounting for operating and financial activities. Contemporary Accounting Research 11(2), $689-731$.

Fox, J. (1997). Applied Regression Analysis, Linear Models, and Related Methods. SAGE Publications.

Francis, J., R. LaFond, P. M. Olsson, and K. Schipper (2004). Costs of equity and earnings attributes. The Accounting Review 79(4), 967-1010. 
Fudenberg, D. and J. Tirole (1991). Game Theory. Cambridge, Massachusetts: The MIT Press.

Gassen, J., uuml, R. U. lbier, and T. Sellhorn (2006). International differences in conditional conservatism: The role of unconditional conservatism and income smoothing. European Accounting Review 15(4), 527 - 564.

Gigler, F., C. Kanodia, and R. Venugopalan (2009). Accounting conservatism and the efficiency of debt contracts. Journal of Accounting Research 47(3)(0), 767797.

Gigler, F. B. and T. Hemmer (2001). Conservatism, optimal disclosure policy, and the timeliness of financial reports. The Accounting Review 76(4), 471.

Giner, B. and W. Rees (2001). On the asymmetric recognition of good and bad news in France, Germany and the United Kingdom. Journal of Business Finance \& Accounting 28(9/10), 1285-1332.

Givoly, D. and C. Hayn (2000). The changing time-series properties of earnings, cash flows and accruals: Has financial reporting become more conservative? Journal of Accounting \& Economics 29(3), 287-320.

Givoly, D., C. K. Hayn, and A. Natarajan (2007). Measuring reporting conservatism. Accounting Review 82(1), 65-106.

Grambovas, C. A., B. Giner, and D. Christodoulou (2006). Earnings conservatism: panel data evidence from the european union and the united states. Abacus $42(3 / 4), 354$.

Grinblatt, M. and C. Y. Hwang (1989). Signalling and the pricing of new issues. The Journal of Finance 44(2), 393-420. 
Guay, W. and R. Verrecchia (2006). Discussion of an economic framework for conservative accounting and Bushman and Piotroski (2006). Journal of Accounting and Economics 42(1-2), 149-165.

Hamada, R. S. (1972). The effect of the firm's capital structure on the systematic risk of common stocks. The Journal of Finance 27(2), 435-452.

Hatfield, H. R. (1927). Accounting, its principles and problems. D. Appleton and company, New York.

Hayn, C. (1995). The information content of losses. Journal of Accounting \& Economics 20(2), 125-153.

Holthausen, R. W. and R. L. Watts (2001). The relevance of the value-relevance literature for financial accounting standard setting. Journal of Accounting and Economics 31(1-3), 3-75.

Huijgen, C. A. and M. J. Lubberink (2005). Earnings conservatism, litigation and contracting: The case of cross-listed firms. Journal of Business Finance \& Accounting 32(7-8), 1275-1309.

IASB (1989). Framework for the Preparation and Presentation of Financial Statements. International Accounting Standards Board.

IASB (2006). Preliminary Views on an improved Conceptual Framework for Financial Reporting: The Objective of Financial Reporting and Qualitative Characteristics of Decision-useful Financial Reporting Information. International Accounting Standards Board.

Khan, M. and R. L. Watts (2009). Estimation and empirical properties of a firm- 
year measure of accounting conservatism. Journal of Accounting and Economics 48(2-3), 132-150.

Klein, A. and C. A. Marquardt (2006). Fundamentals of accounting losses. The Accounting Review 81(1), 179.

Kothari, S., K. Ramanna, and D. J. Skinner (2009). What should GAAP look like? a survey and economic analysis. SSRN Working Paper.

Krishnan, G. V. (2005a). The association between big 6 auditor industry expertise and the asymmetric timeliness of earnings. Journal of Accounting, Auditing \& Finance 20(3), 209-228.

Krishnan, G. V. (2005b). Did houston clients of Arthur Andersen recognize publicly available bad news in a timely fashion? Contemporary Accounting Research 22(1), 165-193.

Krishnan, G. V. (2007). Did earnings conservatism increase for former Andersen clients? Journal of Accounting, Auditing \& Finance 22(2), 141-163.

Kwok, W. C. and D. J. Sharp (1998). A review of construct measurement issues in behavioral accounting research. Journal of Accounting Literature 17, 137-174.

Kwon, Y., D. P. Newman, and Y. S. Suh (2001). The demand for accounting conservatism for management control. Review of Accounting Studies (6), 29-51.

LaFond, R. and S. Roychowdhury (2008). Managerial ownership and accounting conservatism. Journal of Accounting Research 46(1), 101-135.

LaFond, R. and R. Watts (2008). The information role of conservatism. The Accounting Review 83(2), 447-478. 
Lara, J. M. G. and A. Mora (2004). Balance sheet versus earnings conservatism in Europe. European Accounting Review 13(2), 261-292.

Lara, J. M. G., B. G. Osma, and A. Mora (2005). The effect of earnings management on the asymmetric timeliness of earnings. Journal of Business Finance \& Accounting 32(3-4), 691-726.

Lara, J. M. G., B. G. Osma, and F. Penalva (2009a). Accounting conservatism and corporate governance. Review of Accounting Studies 14(1), 161-201.

Lara, J. M. G., B. G. Osma, and F. Penalva (2009b). The economic determinants of conditional conservatism. Journal of Business Finance and Accounting 36(3-4), $336-327$.

Lev, B., B. Sarath, and T. Sougiannis (2005). R\&d reporting biases and their consequences. Contemporary Accounting Research 22(4), 977-1026.

Littleton, A. C. (1941). A genealogy for "cost or market". The Accounting Review 16(2), 161-167.

Lobo, G. J. and J. Zhou (2006). Did conservatism in financial reporting increase after the Sarbanes-Oxley act: Initial evidence. Accounting Horizons 20(1), 57.

Mason, L. (2004). The impact of accounting conservatism on the magnitude of the differential information content of cash flows and accruals. Journal of Accounting, Auditing \& Finance 19(3), 249-282.

Mensah, Y. M., X. Song, and S. Ho (2004). The effects of conservatism on analysts' annual earnings forecast accuracy and dispersion. Journal of Accounting, Auditing \& Finance 19(2), 159-183. 
Merton, R. C. (1974). On the pricing of corporate debt: The risk structure of interest rates. Journal of Finance 29(2), 449-470.

Messick, M. (1989). In Educational measurement, Volume 3rd, pp. 3-103. New York London: American Council on Education : Macmillan Pub. Co. ; Collier Macmillan Publishers.

Milde, H. and J. G. Riley (1988). Signaling in credit markets. The Quarterly Journal of Economics 103(1), 101-129.

Modigliani, F. and M. H. Miller (1958). The cost of capital, corporation finance and the theory of investment. The American Economic Review 48(3), 261-297.

Monahan, S. (2005). Conservatism, growth and the role of accounting numbers in the fundamental analysis process. Review of Accounting Studies 10, 227-260.

Narayanamoorthy, G. (2006). Conservatism and cross-sectional variation in the post-earnings announcement drift. Journal of Accounting Research 44(4), 763789.

Pae, J. (2007). Unexpected accruals and conditional accounting conservatism. Journal of Business Finance \& Accounting 34(5-6), 681-704.

Pae, J., D. B. Thornton, and M. Welker (2005). The link between earnings conservatism and the price-to-book ratio. Contemporary Accounting Research 22(3), $693-717$.

Parker, R. H. (1969). Readings in the Concept o\& Measurement of Income, Chapter 17: Lower of cost and market in Britain and the United States: an historical survey, pp. 239-258. Cambridge University Press. 
Paton, W. A. and R. A. Stevenson (1916). Principles of Accounting. University of Chicago Press.

Penman, S. H. and X.-J. Zhang (2002). Accounting conservatism, the quality of earnings, and stock returns. The Accounting Review 77(2), 237-264.

Pope, P. F. and M. Walker (1999). International differences in the timeliness, conservatism, and classification of earnings. Journal of Accounting Research 37, 53.

Pope, P. F. and M. Walker (2003). Ex-ante and ex-post accounting conservatism, asset recognition, and asymmetric earnings timeliness. Working Paper, Lancaster University.

Pratt, J. (1964). Risk aversion in the small and in the large. Econometrica 32, p.122-36.

Qiang, X. (2007). The effects of contracting, litigation, regulation, and tax costs on conditional and unconditional conservatism: Cross-sectional evidence at the firm level. The Accounting Review 82(3), 759-796.

Rajan, M. V., S. Reichelstein, and M. T. Soliman (2007). Conservatism, growth, and return on investment. Review of Accounting Studies 12, 325-370.

Ronn, E. I. and A. K. Verma (1986). Pricing risk-adjusted deposit insurance: An option-based model. The Journal of Finance 41(4), 871-895.

Rothschild, M. and J. E. Stiglitz (1970). Increasing risk: I. A definition. Journal of Economic Theory 2(3), 225-243. 
Roychowdhury, S. and R. L. Watts (2007). Asymmetric timeliness of earnings, market-to-book and conservatism in financial reporting. Journal of Accounting and Economics 44(1-2), 2-31.

Ruddock, C., S. J. Taylor, and S. L. Taylor (2006). Nonaudit services and earnings conservatism: Is auditor independence impaired? Contemporary Accounting Research 23(3), 701-746.

Ryan, S. G. (2006). Identifying conditional conservatism. European Accounting Review 15(4), 511-525.

Shepard, L. A. (1993). Evaluating test validity. Review of Research in Education 19, $405-450$.

Shreve, S. E. (2004). Stochastic Calculus for Finance II: Continuous-time Models. Springer-Verlag, New York.

Sivakumar, K. and G. Waymire (2003). Enforceable accounting rules and income measurement by early 20th century railroads. Journal of Accounting $R e$ search 41(2), 397-432.

Sterling, R. R. (1967). Conservatism: The fundamental principle of valuation in traditional accounting. Abacus 3(2), 109-122.

Stiglitz, J. E. and A. Weiss (1981). Credit rationing in markets with imperfect information. The American Economic Review 71(3), 393-410.

Stiglitz, J. E. and A. Weiss (1987). Macro-economic equilibrium and credit rationing. NBER Working paper 2164.

Vassalou, M. and Y. Xing (2004). Default risk in equity returns. Journal of Finance 59(2), 831-868. 
Venkatraman, N. and J. Grant (1986). Construct measurement in organizational strategy research: A critique and proposal. The Academy of Management Review 11(1), 71-87.

Watts, R. L. (2003a). Conservatism in accounting part i: Explanations and implications. Accounting Horizons 17(3), 207-221.

Watts, R. L. (2003b). Conservatism in accounting part ii: Evidence and research opportunities. Accounting Horizons 17(4), 287-301.

Watts, R. L. (2006). What has the invisible hand achieved? Accounting and Business Research Speical Issue: International Accounting Policy Forum, 51-61.

Zhang, J. (2008). The contracting benefits of accounting conservatism to lenders and borrowers. Journal of Accounting and Economics 45(1), 27-54.

Zhang, X.-J. (2000). Conservative accounting and equity valuation. Journal of Accounting \& Economics 29(1), 125-149.

Zhang, X.-J. (2005). Discussion of "conservatism, growth and the role of accounting numbers in fundamental analysis process". Review of Accounting Studies 10(2-3), 261. 